\title{
CHARLES TEMPLETON AND THE PERFORMANCES OF UNBELIEF
}

by

DAVID VANCE, B.A.

\author{
A thesis submitted to \\ the Faculty of Graduate Studies and Research \\ in partial fulfilment of \\ the requirements for the degree of
}

Master of Arts

Department of History

\author{
Carleton University \\ Ottawa, Ontario \\ August 12, 2008 \\ (C) Copyright \\ 2008, David Vance
}




$\begin{array}{ll}\begin{array}{l}\text { Library and } \\ \text { Archives Canada }\end{array} & \begin{array}{l}\text { Bibliothèque et } \\ \text { Archives Canada }\end{array} \\ \begin{array}{l}\text { Published Heritage } \\ \text { Branch }\end{array} & \begin{array}{l}\text { Direction du } \\ \text { Patrimoine de l'édition }\end{array} \\ \begin{array}{l}\text { 395 Wellington Street } \\ \text { Ottawa ON K1A 0N4 } \\ \text { Canada }\end{array} & \begin{array}{l}\text { 395, rue Wellington } \\ \text { Ottawa ON K1A 0N4 } \\ \text { Canada }\end{array}\end{array}$

Your file Votre référence ISBN: 978-0-494-43500-7

Our file Notre référence

ISBN: 978-0-494-43500-7

NOTICE:

The author has granted a nonexclusive license allowing Library and Archives Canada to reproduce, publish, archive, preserve, conserve, communicate to the public by telecommunication or on the Internet, loan, distribute and sell theses worldwide, for commercial or noncommercial purposes, in microform, paper, electronic and/or any other formats.

The author retains copyright ownership and moral rights in this thesis. Neither the thesis nor substantial extracts from it may be printed or otherwise reproduced without the author's permission.
AVIS:

L'auteur a accordé une licence non exclusive permettant à la Bibliothèque et Archives Canada de reproduire, publier, archiver, sauvegarder, conserver, transmettre au public par télécommunication ou par l'Internet, prêter, distribuer et vendre des thèses partout dans le monde, à des fins commerciales ou autres, sur support microforme, papier, électronique et/ou autres formats.

L'auteur conserve la propriété du droit d'auteur et des droits moraux qui protège cette thèse. $\mathrm{Ni}$ la thèse ni des extraits substantiels de celle-ci ne doivent être imprimés ou autrement reproduits sans son autorisation.
In compliance with the Canadian Privacy Act some supporting forms may have been removed from this thesis.

While these forms may be included in the document page count, their removal does not represent any loss of content from the thesis.
Conformément à la loi canadienne sur la protection de la vie privée, quelques formulaires secondaires ont été enlevés de cette thèse.

Bien que ces formulaires aient inclus dans la pagination, il n'y aura aucun contenu manquant.

\section{Canada}




\begin{abstract}
To date, the life of Charles Templeton has been examined only with regard to the manner in which he "commodified" Christianity, thus ensuring its continued vitality and relevance in twentieth-century Canada. This thesis demonstrates that Templeton's life can also be used to investigate the ways in which he publically presented "unbelief" according to the assumptions and expectations of the culture in which he operated. Through his work in four different media - religious literature, television, novels and autobiography - Templeton's various expressions of unbelief demonstrated an ongoing transition away from Christianity and towards an alternate interpretive framework. Moreover, his consistent framing of these expressions within the cultural context of each medium reflected four distinct "performances": inadvertent "echoes" of unbelief in his religious literature, an "investigative" unbelief in his television interviews, a "dramatic" unbelief in his novels, and a "noble" unbelief in his autobiography.
\end{abstract}




\section{Acknowledgements}

It is impossible to know where to begin my thanks, for so many people have been helpful and supportive throughout the construction of this project. At Atlantic Baptist University, Dr. Dan Goodwin introduced me to the idea of studying Charles Templeton, and Dr. Dennis Bustin was a source of encouragement as well. These two professors were exceptional in their active involvement in their students' lives, and I benefitted personally, rather than just academically, from their efforts. At Carleton University, Dr. Joanna Dean challenged me to re-examine many of my preconceptions regarding the history and expression of Christianity, and she did so in a way that allowed me to draw my own conclusions. She has been an excellent supervisor, the best example of her dedication being found in her editing of my chapters while on vacation in Norway, using a computer in the lobby of the hotel. Dr. James Opp, my second supervisor, has also been influential in my developing approach to religious history. He has been patient and supportive, even while pushing me to perform beyond what I believed possible. His help during the rather late nights of the revising process was especially appreciated.

Thanks to Richard Gilbert, Ernie Campbell and Ted Smith for taking time to speak to me about their experiences with Templeton. While the scope of the thesis did not allow much discussion of Templeton's Christianity outside of his religious writings, it is my hope that others will be able to benefit from the information you provided.

To the members of the Metropolitan Bible Church where I fellowshipped and worked, thanks for your flexibility with me as I continually tried to balance my employment and school work. Thanks also for your patience during the various times in 
which I absentmindedly left potent critiques of Christianity in the church lobby. To Pastor Rick Reed, who consistently showed interest in the project, thanks for your encouragement.

To the staff of the Starbucks on Carling and Woodroffe, thanks for providing a welcoming atmosphere day after day (after day after day).

I cannot begin to express thanks to my friends and family. Many of these people kept in touch with me closely during the writing process to ensure that I was still alive, and to invite me out for ice cream or coffee when they thought I needed a break. Others gave me space when they knew I needed it, respecting my need to finish this thesis. To all of these wonderful people, I am deeply appreciative.

To my wife, Chrissy - what can I say? You have been to me the very image of grace and kindness as this project weighed so heavily, at times, on our first year of marriage. You are a gift to me. Thanks for everything.

It has been strange, as a relatively conservative Christian, to write about expressions of secularism and religious decline. Nevertheless, I have made it through the maze, and I seem to be alright. Thanks to God for guiding me through. 


\section{Table of Contents}

Abstract

Acknowledgements

iii

Table of Contents

v

Introduction

1

Chapter 1

Inside Christian Literature

19

Chapter 2

Inside Television

42

Chapter 3

Inside Novels

73

Chapter 4

Inside Autobiography

113

Conclusion

152

Bibliography

159 


\section{Introduction}

The world's a scene of changes, and to be Constant, in nature were inconstancy. ${ }^{l}$

In an obituary for his friend, Charles Templeton, Pierre Berton summarized Templeton's life with the simple phrase, "A remarkable Canadian." ${ }^{2}$ This was certainly an apt way of describing Templeton, a man whose life entertained, challenged, and confused millions throughout the nation as he pursued a plethora of different career paths, rose to the top of each, and did all of this while remaining firmly planted within the public eye. Commonly called "the Dwight L. Moody of our day" in the years between the 1936 and 1957, Templeton rose from humble roots in Toronto, Ontario, to become - at least in terms of sheer numbers - Canada's greatest evangelist. ${ }^{3}$ During this time, he served as the president of Youth for Christ in Canada and led rallies of up to sixteen thousand people at the Maple Leafs Gardens. ${ }^{4}$ He then became the shared "official evangelist" of the American National Council of Churches and the United Church of Canada, drawing record-breaking crowds in major cities throughout Canada and preaching to an average of $1,500,000$ people per year - "converting," in the process, an average of 150 people each night of his campaigns. ${ }^{5}$

\footnotetext{
${ }^{1}$ Quote by Abraham Cowley. Templeton inserted this quote before the preface of his memoir. Charles Templeton, Charles Templeton: An Anecdotal Memoir (Toronto: McClelland and Steward Limited, 1983).

${ }^{2}$ Pierre Berton, "Lives Lived: Charles Bradley Templeton" in the Globe and Mail (September 6, 2001).

${ }^{3}$ Collin Hansen, “Billy Graham's Bible Dilemma” Christian History \& Biography 83 (Summer, 2004).

4 "16000 Worshippers Flock to Youth Rally" in the Globe and Mail (June 17, 1946).

${ }^{5}$ Templeton, Charles Templeton, 64; Edward Boyd, "Religion's Super Salesman," in American Magazine (August, 1953).
} 
In 1957, Templeton shocked and devastated the Christian communities in North America by renouncing his faith and ministry. Rather than fading into memory, however, he moved even further into the limelight by establishing himself as a public personality in various media industries. For example, immediately after he left the faith in 1957, he became quite involved with the television industry, functioning as an interviewer for the popular CBC affairs show, Close- $U p$, and winning two awards as "Best Newcomer to Canadian Television" for his interviewing skills. ${ }^{6}$ In 1966, he took on the directorship of CTV's fledgling News and Public Affairs department and helped shape the development of the television industry. In addition to television, he participated heavily in the print industry, serving in 1959 as the executive managing editor of Canada's biggest newspaper at the time, the Toronto Star. Ten years later, he accepted the position of editor-in-chief of Maclean's magazine. He was conspicuous as well in the radio industry, having run, with Pierre Berton, a program called Dialogue, in which the two well-known characters daily "discuss[ed] the news in an opinionated way," as Templeton described it. ${ }^{7}$ This program ran for almost eighteen years, produced nearly four thousand broadcasts, and in 1978 won an award for "Best Radio Program." During the period between the mid 1940s and the mid 1980s, Charles Templeton was a recognizable figure to anybody who regularly watched television, read the paper, or listened to the radio.

Given this exceptional amount of public exposure and influence, the degree to which Templeton has been ignored by Canadian historians is fascinating. Certainly, he has been mentioned in works on a variety of topics, most notably works on Canadian and

\footnotetext{
${ }^{6}$ Templeton, Charles Templeton, 123.

${ }^{7}$ Ibid., 288.

${ }^{8}$ Ibid., 289.
} 
American Protestantism and the development of various media in Canada. ${ }^{9}$ However, these references have often been off-handed, as if simultaneously to recognize his presence in these various areas, while admitting uncertainty regarding the nature of his influence and role. After much consideration, it seems likely that the lack of scholarly attention afforded to Templeton lies less in doubts regarding his importance within Canadian culture, and more from a sense of ambivalence regarding how to approach him. Was he a quintessential example of twentieth-century Protestant religion in Canada? If so, how does one treat his strong ties with American religion? Is he an important pioneer in the growing Canadian television industry? If so, then how does one treat his eventual abandonment of the industry for various other media, and his assertions that for him, television was merely "work, an opportunity and a stepping stone?"10 These questions are further complicated by the sheer breadth and diversity of scope in Templeton's life. As one journalist noted in 1977 ,

He has been, in reasonable order: sports cartoonist, evangelist, church executive, songwriter, TV playwright, movie script-writer, television host, actor, executive managing editor of the Toronto Star, politician, candidate for provincial party leader, advertising executive, director of news and public affairs for the CTV network, editor of Maclean's magazine, full-time inventor, entrepreneur, radio commentator, newscaster and author. ${ }^{11}$

What is an historian to make of Charles Templeton?

Thus far, Kevin Kee has been the only scholar to try to answer this question. In Revivalists: Marketing the Gospel in English-speaking Canada, 1884-1957, he devotes a chapter to Templeton, focusing on his years of Christianity and treating Templeton as an

\footnotetext{
${ }^{9}$ Notable examples include Joel Carpenter's Revive Us Again: The Reawakening of American Fundamentalism (New York: Oxford University Press, 1997); various works on evangelicalism by Mark Noll, and Paul Rutherford's work on the television medium in Prime Time Canada (Toronto: University of Toronto Press, 1990).

${ }^{10}$ Templeton, Charles Templeton, 155.

${ }^{11}$ Roy MacGregor, “Templeton's Progress," in the Canadian (July 16, 1977): 2.
} 
example of how Protestant Christianity was "commodified" in Canada in the midtwentieth century in order to grapple with the ongoing social challenges posed by modernity. ${ }^{12}$ Kee's work combines insights from performance and commodification theory with a cultural approach to religion, effectively making sense of how Templeton (and several other evangelists) took advantage of society's gender assumptions, notions of excitement and respectability, and varying attitudes towards religion and revivalism in order to ensure Christianity's vitality throughout the twentieth century. However, while Kee has admirably created a paradigm through which to approach Templeton's life, certain aspects of his history rest uneasily within Kee's framework - most notably, his ultimate rejection of Christianity in 1957. Templeton's narrative of doubt and faith struggle as presented in his Anecdotal Memoir seems to stand in tension with Kee's assertion that his evangelism represented a performance of the continuing vitality of Christianity. How do these two impulses fit together? It seems that while Kee has succeeded in opening the life of Charles Templeton to historical analysis, more of the story remains to be told.

This thesis is an attempt to contribute to what Kee started - the opening of the life of Charles Templeton to further historical analysis and the creating of additional frameworks through which to approach his complex experiences. It recognizes the value of how Kee used Templeton's life to effectively explore the ways in which Christian belief was expressed according to cultural expectations in the mid-twentieth century, yet it suggests that Templeton's life can also be used as a vehicle to explore the opposite side of the story - the various ways in which unbelief can be expressed in accordance with

\footnotetext{
${ }^{12}$ Kevin Kee, Revivalists: Marketing the Gospel in English-speaking Canada, 1884-1957 (Kingston and Montreal: McGill-Queen's University Press, 2006), 166.
} 
cultural assumptions and expectations. More specifically, just as Kee examined the way in which Templeton framed his expressions of belief according to the cultural demands of the time in his Christian years, so does this thesis examine how Templeton expressed "unbelief" according to the inherent cultural expectations and demands of four distinct media: Christian literature, television interviews, novels, and autobiography. The consistent questions posed during this investigation are: What can the life and public performances of Charles Templeton reveal about the nature of unbelief, and its presentation? Is unbelief confined to the purely intellectual realm, revolving around a simple inability or unwillingness to accept a specifically "Christian" set of beliefs? Is its form and presentation - as Kee and others have shown of belief and faith - influenced by the specific cultural assumptions and expectations of the society in which it exists?

This thesis argues that the life and public presentations of Charles Templeton demonstrate two significant things about how Templeton experienced unbelief. First, they show that his unbelief was a continuous process. It was not a sudden intellectual "enlightenment" or a simple one-time rejection of certain essential beliefs; rather, it was an ongoing transition from one belief system to another, a continual reframing of reality in such a way that constituted a consistent rejection, or resistance, against a previous system of thought, even as it embodied a gradual - tenuous, at times - embracing of a new system of meaning, significance, and values. In this way, this thesis places Templeton's loss-of-faith experience and rejection of Christianity near the beginning of the story instead of at the end (or as the very ending itself) as so many histories of religious decline tend to do. As it will be demonstrated through this thesis, for Templeton, his conscious decision to reject Christianity was only one small part of the 
entire unbelief experience; the process through which he reframed his perception of reality accordingly had begun earlier and continued throughout the rest of his life. Within the specific context of Templeton's life, this new interpretive system that marked the gradual replacement of Christianity was that of agnosticism, which, as Templeton eventually defined it, was marked by the firm assertion that "I cannot know" whether or not there is a God. "There may have been a First Cause to which one might apply the name God," Templeton expressed with finality in his last work, Farewell to God: My Reasons for Rejecting the Christian Faith (1996), "there might even be a Supreme Being from which all existence proceeds, but on the basis of the available evidence the question is beyond resolution." ${ }^{\text {13 }}$ While Templeton's final "arrival" at the mature expression of agnosticism is beyond the scope of this thesis - that will need to be saved for a larger project - this investigation will explore much of the early and intermediate stages of this transition, as Templeton increasingly presented specific elements of this belief system most notably, emphasizing a staunch rationalism, and a sense of morality and purpose found apart from God.

The second thing Templeton's public presentations demonstrate is that just as the staging of belief is rooted in an understanding of, and in accordance to, specific cultural demands and values of society, so is the expression of unbelief influenced by the same. In the four media examined, Templeton demonstrates radically different forms of unbelief according to the specific cultural requirements and expectations of the various media he uses. This tailoring of the presentation of unbelief according to cultural expectations, it will be argued, constitutes "performance" - four different performances of unbelief for

\footnotetext{
${ }^{13}$ Charles Templeton, Farewell to God: My Reasons for Rejecting the Christian Faith (Toronto: McClelland \& Stewart Inc., 1996), 18.
} 
the four different media - effectively showing that while unbelief may indeed be, at core, a matter of intellectual dissent, the ways in which this intellectual dissent is cloaked, shaped and framed is profoundly influenced by the attitudes, values, and assumptions of the culture in which it is situated.

Before explaining how this argument will be demonstrated, it seems necessary to define and contextualize some of the foundational terms that will be used throughout this thesis. First, the term "unbelief" is the basis for this whole investigation, and it is deliberately chosen, in an effort to avoid falling into the rather stagnant language of what has become known as "the secularization debate" in Canada. Many terms have been used to describe the phenomenon of religious decline, the most notable and resilient of which has been "secularization." While there is some variety, within Canadian historiography secularization has most often referred to the decline of the influence of religion within an entire society, which posits that the society in question - in this case, Canada - somehow became less "religious" than it once was. The difficulties in adequately describing and explaining such a process are obvious - what does it mean to be "religious?" Is there some sort of essentially "religious" quality that must be lost in order for a society to become "secular?" An entire "secularization debate" has been framed around this very question, with certain historians such as Richard Allen, Ramsay Cook and David Marshall effectively suggesting that yes, secularization consists of the loss of some sort of essential "sacred" quality that was lost to the "secular" influences of modernization. ${ }^{14}$

\footnotetext{
${ }^{14}$ See Richard Allen, The Social Passion: Religion and Social Reform in Canada, 1914-1918 (Toronto: University of Toronto Press, 1971); Ramsay Cook,The Regenerators: Social Criticism in Late Victorian English Canada (Toronto: University of Toronto Press, 1985); and David Marshall, Secularizing the Faith: Canadian Protestant Clergy and the Crisis of Belief, 1850-1940 (Toronto: University of Toronto Press, 1992). A. B. McKillop also contributed to the groundwork for the secularization thesis in the last chapter of his A Disciplined Intelligence: Critical Inquiry and Canadian Thought in the Victorian Era (Montreal \&
} 
These claims, however, have been consistently countered by other historians, such as Marguerite Van Die, Phyllis Airhart, Michael Gauvreau and Nancy Christie - to name only a few - who argue that the divisions between the categories of "sacred" and "secular" were artificial at best. Moreover, they assert, the very evidence that the "secularization" historians had treated as signs of decline were in fact indicators of vitality and strength, as the churches and religious leaders restructured their religion in order to "serve the present age," effectively ensuring their continued relevance and plausibility. ${ }^{15}$ Ultimately, this debate failed to reach any sort of consensus, chiefly because, as historian George Emery has noted, "the debate turns on definition." ${ }^{16}$ Both groups are working from different notions of what constituted "religion" and "religious decline," as indicated most clearly by a brief interaction between David Marshall in Phyllis Airhart. After Marshall criticized Airhart for holding an "all-encompassing" definition of religion which led to the conclusion that "only change, never decline, is possible," Airhart immediately retaliated by asserting that Marshall's own (considerably more conservative) definition was "surprisingly static" and allowed "little in the way of change that does not lead to decline."17

Kingston: McGill-Queen's University Press, 1979). However, any location of his work among the proponents of the secularization theory must be measured carefully. In the first place, his work only suggested the presence and shape of secularization in the implications of his greater argument regarding the "moral imperative" that informed the Canadian interaction between piety and intellect (ix, xx). Secondly, in updated preface to the 2001 edition of the work, he discussed the limitations of using "secularization" as a conceptual tool, suggesting that "it might, indeed, be highly problematic" (xxiv).

${ }^{15}$ Phyllis Airhart, Serving the Present Age: Revivalism, Progressivism, and the Methodist Tradition in Canada (Montreal \& Kingston: McGill-Queen's University Press, 1992), 10. See also Marguerite Van Die, An Evangelical Mind: Nathanael Burwash and the Methodist Tradition in Canada, 1839-1918 (Montreal \& Kingston: McGill-Queen's University Press, 1989); and Michael Gauvreau, The Evangelical Century: College and Creed in English Canada from the Great Revival to the Great Depression (Montreal \& Kingston: McGill-Queen's University Press, 1991).

${ }^{16}$ George Emery, The Methodist Church on the Prairies, 1896-1914 (Montreal \& Kingston: McGillQueen's University Press, 2001), xviii.

${ }^{17}$ Emery refers to this interaction in his introduction. See Emery, xviii. 
The use of the term "unbelief" in this thesis represents an attempt to join a growing number of historians who are moving beyond the stagnant language of the secularization debate in their attempts to discuss religious decline. It sees validity in the argument that the categories of "sacred" and "secular" exist only within the realm of the ideal and theoretical, and as such, are not terribly useful for understanding religious change. As Colleen McDannell persuasively argued in her work, Material Christianity: Religion and Popular Culture in America, "If we look at what Christians do rather than what they think, we cannot help but notice the continual scrambling of the sacred and the profane." ${ }^{, 18}$ Furthermore, it acknowledges the truth in the arguments posed by historians like Lawrence Moore, and more relevantly, Kevin Kee, in their assertions that by "commodifying" religion, popular and official religious leaders effectively allowed religion to retain a sense of vibrancy and relevance during tumultuous times. However, it also recognizes the validity of the proponents of the secularization thesis in their arguments that somehow, religious decline did indeed occur - that somewhere in the midst of ensuring a relevant and vibrant faith, something happened which acted contrary to intentions and effectively made it possible - even likely - for people to say, "I do not believe in God."

Indeed, the statement "I do not believe in God," is the basis of the term "unbelief" as used throughout this thesis. It is a loose reference to James Turner's influential work, Without God, Without Creed: The Origins of Unbelief in America, which defined unbelief

\footnotetext{
${ }^{18}$ Colleen McDannell, Material Christianity: Religion and Culture in Popular America (New Haven \& London: Yale University Press, 1995), 4.
} 
as "the continuing absence of a conviction that any... superhuman power exists." ${ }^{19} \mathrm{He}$ was especially concerned with the notion of the "possibility of unbelief," and stated that the purpose of his work was to find out "how it became possible for many people to say, 'I do not believe in God." ${ }^{20}$ Within the context of this thesis, unbelief is treated similarly - as Templeton's simple, yet prevalent, inability or unwillingness to believe in God. Likewise, just as Turner was interested in the "process" of unbelief in America - the manner in which unbelief developed and became possible, this thesis is inherently interested in the process of unbelief in Templeton's life - the manner in which it became possible for Templeton to say, "I do not believe in God," and the various ways in which he continued to manifest this lack of belief throughout the various stages and venues in his life. To summarize, then - within the context of this thesis, "unbelief" is the inability or unwillingness of an individual or society to believe in God, and it is treated within the context of a process - it is a movement from belief in God to an inability or unwillingness to believe in God. Thus, unbelief is ultimately relative. For example, atheism may constitute unbelief in one individual and not another, depending on whether or not this atheism was a part of a transition away from belief. A lack of belief in God is not "unbelief" unless there was belief in the first place, which was then somehow rejected.

This treatment of unbelief is very much influenced by other, newer approaches to religious decline. Most obvious, perhaps, is the influence of British historian Callum Brown, who, in his excellent work, The Death of Christian Britain: Understanding Secularization, 1800-2000 (2001), presented a new framework for understanding

\footnotetext{
${ }^{19}$ James Turner, Without God, Without Creed: The Origins of Unbelief in America (Baltimore and London: The John Hopkins University Press, 1985), xv.

${ }^{20}$ Turner, xiv.
} 
religious decline. He posits this process as a matter of identity and self-conceptualization rather than the loss of any sort of "sacred" element. "What emerges," he states, "is a story not merely of church decline, but of the end of Christianity as a means by which men and women, as individuals, construct their identities and their sense of 'self'."21

Secularization occurred in the 1960s, he asserts, as men and, in particular, women restructured the discursive frameworks through which they interpreted reality, a process which radically affected the role in which Christianity played in their lives. To put it simply, "Religion mattered and mattered deeply in British society as a whole in the 1950s. But it started to stop mattering in the 1960 s. ${ }^{.22}$ Christianity had simply stopped functioning as the dominant context through which people understood themselves and the world around them. This approach influences the treatment of "unbelief" in this thesis in several ways. Rather than attempting to impose any sort of system of "essential" religious decline upon Templeton's life, Brown's framework allows the historian liberty to let Templeton establish the definition of unbelief according to his own terms. Regardless of how he defined his faith, Templeton's very rejection of his particular version of Christianity effectively provides the historian with a tailored definition of unbelief - as the inability or unwillingness to believe what he used to. The focus is not on any particular "sacred" element that is lost, but rather on the explicit rejection of the subject of his or her previous beliefs, whatever they might have been. Thus, unbelief is defined by the subject, not the historian.

\footnotetext{
${ }^{21}$ Callum Brown, The Death of Christian Britain: Understanding Secularisation, 1800-2000 (London and New York: Routledge, 2006), 2.

${ }^{22}$ Brown, 7.
} 
Brown's framework also extends the definition of unbelief used in this thesis by asserting that it is essentially related to one's perception of self, and the context through which one interprets the world. That is, if the measure of Christian vitality is related to the degree to which it informs one's perceptions of identity and interpretation of the world, then any system of meaning, value, purpose or significance that competes with, or replaces, that of Christianity must ultimately be regarded as an agent of unbelief - a contribution to one's overall rejection of Christianity. After Templeton officially abandoned Christianity in 1957, he quickly presented several things that functioned as sites of purpose and meaning for him, such as a firm sense of morality, a persistent pursuit of truth, and, eventually, a life calling. As he had consciously left behind his Christian system for interpreting meaning and identity, these various sites of meaning effectively constituted replacement sites for the framework of values Christianity had once provided, and Templeton's presentation of these sites constituted presentations of unbelief - again, a continuing rejection of Christianity as a means for explaining his identity and his perception of the world.

This treatment of unbelief is further influenced by the work of Tina Block. In her outstanding doctoral dissertation, Block was the first Canadian historian to apply a "lived religion" approach to secularization, specifically exploring the particularly "nonreligious" character of the Pacific Northwest. ${ }^{23}$ Her research is comprehensive, and combines an impressive array of primary documents, oral interviews and quantitative

\footnotetext{
${ }^{23}$ The "lived religion" approach mentioned here is that introduced by such scholars as David Hall and Robert Orsi, who argue that religion did not merely take place in the minds and abstract philosophies of religious people, but in their daily lives. See David D. Hall (ed.), Lived Religion in America: Toward a History of Practice (Princeton, New Jersey: Princeton University Press, 1997); and Robert Orsi, "Everyday Miracles: The Study of Lived Religion," in Lived Religion in America: Toward a History of Practice, edited by David D. Hall (New Jersey: Princeton University Press, 1997).
} 
analysis. This wide spectrum of sources allowed Block to approach secularization from ground level, examining how "irreligion" was widespread in the lives of Northwesterners as they effectively "lived" it through various forms of resistance to established religious institutions, attitudes and assumptions. Block's thesis was particularly influential in the particular way in which she presented secularization as a phenomenon that occurred within the "everyday" lives of common people, and was thus inextricably tied to the cultural context in which they lived. "Viewed in the realm of the everyday," Block states, "secularism, like religion, appears as a complex cultural phenomenon with its own set of choices, priorities, and practices. Northwesterners were secular in multiple, creative ways in response to a range of influences, including social mores, family pressures, material circumstances, and personal impulses. ${ }^{.24}$

Although a general lack of primary sources renders a "lived religion" approach to Templeton's life impossible, much has been learned from the way in which Block managed to locate unbelief within a cultural context. Indeed, just as Block presented "irreligion" largely as a matter of resistance to and contestations of various subtle religious cultural influences - such as notions of family, wealth and prosperity, and social regulations - Templeton's presentation of "unbelief" through his various media performances was similarly composed of resistances to specific religious narratives and assumptions - usually concerning the treatment of Jesus, the process of evangelism, the presentation of religious experiences, and proper means through which to approach truth and knowledge. Moreover, he expressed these resistances through the adoption of various Canadian cultural narratives and assumptions, such as conservative religious assumptions

\footnotetext{
${ }^{24}$ Tina Block, "Everyday Infidels: A Social History of Secularism in the Postwar Pacific Northwest," (Ph.D. dissertation, University of Victoria, 2006), 2.
} 
regarding gender and doubt from the 1940s and 50s, the prevalent idea of the "trustworthy journalist" of the 1950s and 60s, the various ingredients of drama and controversy in the 1960s and 70s, and various notions and manifestations of respectability in the 1970s and 1980s. By situating secularization within a specific cultural context, Block effectively contributes a local layer to Brown's treatment of secularization, suggesting that if unbelief involves a reconceptualization of one's identity and interpretation of the world, it may well do so in congruence with the cultural assumptions and narratives of the particular social context in which it is situated.

The other important term that needs to be defined is "performance." The usage of this term throughout this investigation will not be nearly so onerous a task as was defining "unbelief," chiefly because performance has been employed as a concept for several years within many different areas of history, as well as other schools of study. In a general sense, performance refers to "cultural living," to use the phrase of historian Greg Dening. In his own work, Performances, Dening expands on this notion, treating performance as the ways in which people "talk" to each other using culturally-grounded symbols:

Cultural living in its bare bones is talk, talk translated into all sorts of symbols. That's its realism. We make all our relationships by talk. All our institutions, all our roles. The theatre of everyday life is talk, and we are experts in reading the immediate meaning of our words, but more importantly what those words really mean. This talk is not just babble, not just the stream of consciousness, though there is plenty of both. The talk is shaped in some way, given beginnings and endings, given dramatic form. The talk is not just talk. It is presentation. Timing makes it so; punchlines, too; ambience; gestures; silences; presence; rhythm; fast flows and discontinuities; engagement with an audience; rhetorical forms, sometimes as old as culture itself, sometimes raw and new. ${ }^{25}$

\footnotetext{
${ }^{25}$ Greg Dening, Performances (Chicago: The University of Chicago Press, 1996), 34.
} 
In this cryptic, yet profound, paragraph, Dening embodies the very notion of performance he discusses. Performance, as he describes it, is the manner in which the "symbolic" talk through which we communicate with each other is given "dramatic form," and shaped according to recognizable cultural frameworks. Through this process, the "talk" gains power and effectiveness as it assumes a shape more akin - more relatable - to the life we all experience.

In the particular context of this thesis, performance relates to the conscious or unconscious framing of an idea, event or identity in conformity to a specific set of cultural expectations, assumptions or narratives. This should be distinguished from the mere presentation of identity. For example, Templeton, as a self-proclaimed agnostic, expressed his identity as an unbeliever in several ways, both consciously, such as when he explicitly told the story of his faith struggle and the intellectual problems he had with Christianity, and unconsciously, such as when he off-handedly or implicitly dismissed faith as a source of knowledge, or when he highlighted sites of meaning that effectively indicated the increasing coherence of a replacement framework of meaning to that which had been provided by Christianity. However, while these examples constitute presentations, expressions and even manifestations of unbelief, they do not, in and of themselves, constitute "performances" of unbelief. It is in the shaping of these expressions in accordance with some sort of cultural framework - composed of recognized expectations, social mores and recognizable narratives - that the element of "performance" is introduced.

In Templeton's case, he consistently framed his expressions of unbelief in accordance with the specific cultural expectations and requirements associated with the 
various media in which he was involved. For example, in his television interviews, he seemed to (consciously or unconsciously) tap into the cultural attitude regarding the inherent trustworthiness of journalists as he expressed his doubts regarding Christianity, thereby performing what might be called an "investigative unbelief." His evocation of an established cultural paradigm allowed him to implicitly situate himself on the side of truth as he pursued doubts about Christianity on behalf, it seemed, of the public. More deliberately, in his novels he seemed to consciously harness the tensions of unbelief by framing its presentation within the context of the cultural requirements of the novel form - the inherent sense of immediate and recognizable controversy, drama and excitement that allows the author to retain narrative power over his or her audience.

To summarize, then, Templeton's performances of unbelief consisted of the various ways in which he presented his continuing rejection of Christianity - and his gradual embracing of other frameworks of meaning - in accordance with the specific cultural expectations and requirements of each of the media he employed. This is demonstrated throughout this thesis by examinations of four media - one per chapter and the particular way in which Templeton performed his unbelief in each. The narrative begins with Templeton's religious writings, in order to demonstrate how unbelief can be presented even in the midst of a performance of a strong, vibrant belief system. To be specific, he believed the cultural role of his literature was to present a positive, confident, clear and useful Christianity, and as such, his presentations of unbelief took the form of unwritten "echoes" - possibilities of unbelief that were made plausible by his very attempts to present a strong, effective Christianity. 
Chapter two is concerned with Templeton's television interviews with CBC immediately after he left Christianity in 1957 and with CTV ten years later. Accordingly, the unbelief Templeton presents is that of a very tenuous, undeveloped sort, framed in accordance with the cultural expectations of the television medium - specifically, the dominant notion of the "trustworthy journalist," which posited journalists as the defenders of truth on behalf of the public. Within this context, Templeton performed an "investigative unbelief" as he searched for truth regarding questions of life, truth and God.

Three of Templeton's novels are the objects of analysis in the third chapter, The Kidnapping of the President (1974), Act of God (1977), and The Third Temptation (1980). Again, Templeton exhibits unbelief in several ways throughout this chapter, and consistently framed these presentations in accordance with various cultural sites of controversy of the $1960 \mathrm{~s}$ and $70 \mathrm{~s}$. Moreover, this evocation of various controversies was itself an act of conforming to the specific cultural requirements of the novel medium the need for enough recognizable and relatable drama to keep the audience within the "narrating power" of the author. As such, the performance demonstrated within this medium was that of a distinctly "dramatic unbelief."

Finally, the fourth chapter examines Templeton's autobiography and the ways in which he established unbelief once more in congruence with the requirements of the cultural form, specifically according to the narratives in which Templeton framed his presentation of self. A narrative of "nobility" was the predominant way in which Templeton constructed his life, and as such, he performed a "noble," or respectable, unbelief. Seemingly addressing concerns regarding notions of responsibility and 
respectability - especially regarding attitudes towards careers, employment, intellectual honesty and his experience with, and abandonment of, Christianity - Templeton tapped into prevalent cultural attitudes as he presented an unbelief rooted in honesty, decency and intellectual integrity.

It should be noted that this thesis only brushes the surface of what this investigation could potentially examine. For example, Templeton conducted thousands of radio broadcasts with Pierre Berton under the auspices of a program called Dialogue. A cursory examination of a few episodes reveals another whole division and performance of unbelief, although the exact nature of this performance would require much time and research. Nevertheless, it seems that these broadcasts (especially those in the early 1970s) reveal another intermediate stage of Templeton's unbelief process - one in which he simultaneously sharply criticizes Christianity, even while he expresses hope that it will adopt a more useful social role. Moreover, other non-fiction books Templeton wrote after his rejection of Christianity promise to yield exceptional insights into the performance of unbelief, most notably Succeeding (1989), and Templeton's last work, Farewell to God: My Reasons for Rejecting the Christian Faith (1996). The latter, in which Templeton presents a mature expression of agnosticism, will be alluded to briefly in the conclusion, but it warrants a much greater examination than can be provided within the scope of this thesis. It is the hope of this author that others will eventually find Charles Templeton to be as fascinating a subject, and that his life and works will be further explored within the historical community. 


\section{Chapter 1: Inside Christian Literature}

"Let the grace of our God be heralded with no uncertain sound, and let us look with confidence to God to revive his church in the midst of these years!",l

It might seem strange to begin a thesis on Charles Templeton's performances of unbelief with an examination of the literature he wrote during his Christian years, for in these works he did not consciously present any manifestations of unbelief at all. Indeed, each of his three works of religious literature examined in this chapter - "The Church and Its Evangelistic Task" (1952), Life Looks Up (1955) and Evangelism for Tomorrow (1957) represented an effort to express Christianity in particularly vibrant and powerful terms. ${ }^{2}$ However, this chapter argues that in Templeton's most impassioned cries for Christian renewal, he was nevertheless inadvertently expressing an early, foundational form of unbelief. These unconscious presentations were not characterized by "rejections" of Christian beliefs, as were dominant in his later, more developed portrayals of unbelief. Rather, these inadvertent expressions functioned more like his later presentations of various sites of meaning and purpose, which, in turn, served as indicators of a movement from Christianity to a replacement system of interpreting the world (which he later identified as "agnosticism").

\footnotetext{
${ }^{1}$ Charles Templeton, "The Church and Its Evangelistic Task," in Religion in Life 21:3 (Summer, 1952): 333.

${ }^{2}$ Templeton, "The Church and Its Evangelistic Task,"; Charles Templeton, Life Looks Up (New York: Harper \& Brothers Publishers, 1955); Charles Templeton, Evangelism for Tomorrow: A Vigorous Reappraisal of the Mission of the Church to Win the Commitment of Modern Man (New York: Harper \& Brothers Publishers, 1957).
} 
Specifically, it will be argued that in his religious literature Templeton contributed to the beginning of the unbelief process by unintentionally enabling the terms by which Christianity could be rejected as a system of beliefs, values and significance and replaced by an alternate system - in effect, by establishing three distinct "possibilities" of unbelief. The first of these possibilities involves the narrow way in which Templeton defined his Christianity, thereby preserving and enabling the specific elements of his faith that he eventually rejected. The second concerns his commodification of Christianity, and the manner in which he transformed his faith into something that was useful, but not essential, for meaning and purpose in life. The third possibility of unbelief is seen in Templeton's rendering of weakness and doubt as aberrations of the Christian life, thereby condemning his own experiences and forcing himself to a watershed decision.

It is significant to note that in his unwitting establishment of these various "possibilities" of belief, Templeton did not "present" or "perform" unbelief in the same sense as he did in his use of the television, novel, and autobiographical media. Indeed, as mentioned earlier, his only intention in his Christian literature was to present Christianity in a manner that conformed to his cultural expectations of the genre - he had no intention of addressing unbelief at all. Yet this is exactly how Templeton's unbelief performance should be interpreted within these religious writings - as an "echo," or a series of "echoes" - located in the unwritten implications and the subtle overtones of his greater performance of a strong, confident and useful Christianity. In this light, it may be useful to explore the nature of Templeton's performance of belief before attempting to examine the resulting "echoes" of unbelief. 
Templeton wrote three works of Christian literature. One of these, Life Looks Up (1955) was a collection of fourteen of his most effective sermons, which he delivered regularly during the various evangelistic "preaching missions" he conducted as the official evangelist of the American National Council of Churches and the United Church of Canada during the 1950s. The other two - a brief but poignant essay entitled "The Church and Its Evangelistic Task" (1952) and a published series of lectures (which had first been delivered as "The Stone Lectures" at Richmond Theological Seminary), Evangelism for Tomorrow (1957) were instructional works designed to advise Christian leaders on the purpose and methods of effective evangelism. While the three books had differing purposes and audiences, they shared some things in common: they all endeavoured to portray a specific image of Christianity, and in this, they all conformed to specific cultural expectations and assumptions Templeton held regarding the manner in which Christianity should be presented. These cultural ideals, in turn, influenced the manner in which he performed a vibrant Christianity, and subsequently provided the framework through which his unbelief expressions were restrained to the form of "echoes" behind his valiant calls for renewal.

To put it simply, Templeton was working within a set of cultural assumptions specifically, a combination of notions from his fundamentalist and liberal Protestant backgrounds regarding of gender, usefulness, and the role of the Christian communicator - that led him to present his Christianity in powerful, clear, and useful terms, thus constituting a performance of a "strong," vibrant Christianity. It is against this backdrop that the unwritten "echoes" of unbelief are made visible. In particular, three distinct ways in which he communicates Christianity in clear, powerful terms also constitute three 
unintentional possibilities of unbelief. The first of these "echoes" of unbelief is found in the implications of Templeton's efforts to define the parameters of Christianity in clear, unmistakable terms. This allowed for him to valiantly call for people to adhere to a defined set of Christian ideals and boundaries, but it also inadvertently enabled and preserved the very terms by which he would ultimately and continually reject Christianity.

In 1948, four years before he wrote "The Church and Its Evangelistic Task," Templeton had abandoned his work with Youth for Christ and his own Nazarene church in Toronto in search of a more intellectually-grounded faith at Princeton University, which was considered by many at the time to be a mainstay of the liberal Protestant tradition. ${ }^{3}$ This transition, as Kevin Kee points out, constituted a transition in Templeton's Christianity from fundamentalism to liberal Protestantism, especially with regard to his rejection of Biblical infallibility, the distinctly social element he added to his evangelism, and a heavier reliance on modern sciences and philosophies in his messages. ${ }^{4}$ However, despite the overtly "liberal" character of Templeton's presented faith in the 1950s, he showed evidence of his conservative roots in one significant way - he continued to define the parameters of Christianity in narrow, conservative terms, insisting on certain essential elements of Christian faith, especially the divinity of Jesus. In fact, the manner in which Templeton expressed the nature of Christianity was so narrow that it

\footnotetext{
${ }^{3}$ Richard Gilbert, personal email to David Vance, March 3, 2006.

${ }^{4}$ See Templeton, quoted in Kevin Kee, Revivalists: Marketing the Gospel in English-speaking Canada, 1884-1957 (Kingston and Montreal: McGill-Queen's University Press, 2006), 166; Templeton, Evangelism for Tomorrow, 22, 66, for evidence of these liberal "thrusts" in Templeton's Christian writings.
} 
effectively embodied the very sort of didactic systems that liberal Christians resisted as a central element of their very identity. ${ }^{5}$

This distinction is significant because Templeton's insistence on adhering to this conservative thread enabled him to create a binary of belief/unbelief conditions that would not be possible, or at least as feasible, if he had truly adopted liberal Christianity. Simply put, Templeton's relatively narrow, conservative conditions for Christianity, as presented in his religious works, contained within themselves the distinct possibility of rejection - and hence, unbelief - even as they provided him with a clear set of ideals to use in his calls for proper Christian living and devotion. Templeton consistently presented his Christianity in terms of oppositions, either explicitly or implicitly stated. For example, in discussing the presence and danger of sin in the world, he exclaims, "There is a war on... a bitter, desperate, long-lived, relentless war! A war between right and wrong, between good and evil, between God and anti-God. Where do you stand?"6 To be a Christian is to be on God's side; to reject God's side is to reject Christianity. The possibility for rejecting "God's side" is explicit. Other oppositions are more implicit in their potential for rejection: "How then do you live the good life, the life pleasing to God? The answer is a simple one, a deceptively simple one: by living your life as it was intended to be lived, in a daily relationship with God." ${ }^{, 7}$ The unspoken alternative is that if you do not want to live "the good life," then do not live in daily relationship with God.

\footnotetext{
${ }^{5}$ See William R. Hutchison, The Modernist Impulse in American Protestantism (New York: Oxford University Press, 1976), 8-9, for a description of how a defining characteristic - one of the only defining characteristics - of American liberal Protestantism was the attempt to escape various sorts of "antinomies" that distinguished between the realms of the "sacred" and the "secular."

${ }^{6}$ Templeton, Life Looks Up, 20.

${ }^{7}$ Ibid., 61.
} 
While less obvious than the first statement, this too contains the possibility for rejection, and thus perpetuates the binary.

Templeton's binary between belief and unbelief becomes quite striking when he begins to describe what he presents as the essential elements of Christianity. Without exception, they revolve around Jesus. "Life is to be lived a certain way," he states, "and 'The Way' is revealed to us in history and, perfectly, in Jesus Christ." ${ }^{\text {" }}$ Elsewhere, he states, "Christianity is not ten rules for living; it is Christ. He is our example, he is our

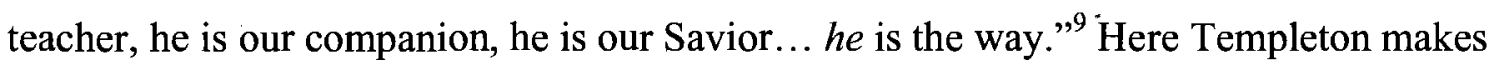
clear that to accept Jesus is to accept the Christian "way"; to reject Jesus is to reject Christianity. He has created a condition for belief in Christianity, and an opposing condition for unbelief. However, he proceeds to take it even further than this: he insists on the acceptance of Jesus' divinity as a condition for belief in Christianity. In Life Looks $U p$, Templeton states, "There are some who contend it does not matter whether [the resurrection] is a fact or not, but it would seem absolutely central to Christian faith. The Apostle Paul states it succinctly: 'If Christ be not risen, then is our preaching vain, and your faith is also vain." ${ }^{10}$ In Evangelism for Tomorrow he is even more direct: "The Christian Church exists and evangelizes only as it lives in its faith in Christ's saviorhood. If he is not deity then the Church is a mere ethical society with nothing unique to say. If the supernatural is dropped from the gospel it ceases to be the gospel. If Jesus is merely a man (albeit incomparable, transcendent, Godlike) then there is no gospel."

\footnotetext{
${ }^{8}$ Ibid.

${ }^{9}$ Ibid., 117.

${ }^{10}$ Ibid., 187.

${ }^{11}$ Ibid., 124.
} 
Templeton's presentation of Christianity in such narrow, conservative terms contained within itself an "echo" of unbelief, an unacknowledged but significant possibility of the rejection of Christianity. This did not signal any sort of inevitable decline of Templeton's belief at the time - on the contrary, it contributed to his presentations of a strong Christianity - but his clear definition ultimately enabled and preserved the very terms by which he eventually rejected the faith. In 1957, the same year that Evangelism for Tomorrow was published, Templeton admitted that he could no longer accept the notion of Jesus' divinity and as a result, he could no longer call himself a Christian. Furthermore, as will be demonstrated in each of the succeeding chapters, in every successive medium through which he communicated, Templeton continued to identify the divinity of Christ as the chief intellectual obstacle to his acceptance of Christianity. Thus, his conservative definition of Christianity formed the foundation for his continuing rejection of the religion throughout the rest of his life.

Templeton's inadvertent preservation of the conditions by which he would eventually reject Christianity was not the only way in which he made unbelief possible through his performance of a strong and effective Christianity in his religious writings. Another "echo" of unbelief may be found in Templeton's practice of "commodifying" Christianity - the framing of faith as a commodity that would ultimately improve life, in order to present a Christianity that was strong, effective and useful in the twentieth century. ${ }^{12}$ While it is tempting to interpret these processes of accommodation and

\footnotetext{
${ }^{12}$ Laurence Moore's Selling God is the foundational work for understanding how religion has been commodified in order to ensure Christian's vitality in a "marketplace of culture," while Kevin Kee has applied this theoretical framework to Templeton's life, demonstrating how Templeton commodified Christianity in order to maintain its relevance during the mid-twentieth century. Robert Laurence Moore, Selling God: American Religion in the Marketplace of Culture (New York: Oxford University Press, 1995).
} 
commodification as manifestations of secularization within an increasingly liberal Protestantism (as the proponents of the secularization thesis have done in the past), ${ }^{13}$ it must be remembered that these accommodations did not represent a rejection of core evangelical beliefs. Rather, Templeton presented them as the natural expressions and consequences of the traditional gospel message. However, while his accommodation and commodification cannot be merely dismissed as the fruits of an increasingly "secular" liberal theology, they nevertheless contributed to the possibility of unbelief in his narrative of Christianity by inadvertently presenting Christianity's role as a means instead of an end, something useful, but not necessarily vital. Thus, even while Templeton's commodification embodied an effective and relevant Christianity, it also effectively established the foundations for unbelief by transforming Christianity into a disposable option, preparing the way for its rejection in favour of a more effective means for achieving a "happy" and fulfilled life.

Templeton was acutely aware of the anxious undertone of the 1950s, particularly as the Cold War increasingly threatened North American security and values. In Life Looks Up, he wrote, "At the heart of the growing tension, twentieth-century man lives out his uncertain days with growing apprehensiveness and profound uncertainty."14 Templeton believed that the problems of the modern social situation had specific implications for Christianity - the Church needed to adapt its message so as to be

\footnotetext{
${ }^{13}$ See especially David Marshall, Secularizing the Faith: Canadian Protestant Clergy and the Crisis of Belief, 1850-1940 (Toronto: University of Toronto Press, 1992).

${ }^{14}$ Templeton, Life Looks Up, 31.
} 
relevant and understandable to the people to whom it ministered. ${ }^{15}$ As he stated in "The Church and Its Evangelistic Task,"

Tomorrow's evangelism must study its generation and speak in understandable terms to its unique needs... The effective evangelist must not only know theology, he must know people. Manufacturers and publishers, for purely commercial reasons, pay large sums for surveys which purport to reveal the likes and dislikes, the concerns and antipathies, the drives and fears of the American people. Surely "the children of the world are wiser than the children of light."16

Templeton was quick to add a qualifier: "Not to suggest that the church should ever pander to the desires of men," he stated, "but surely the Church must be wise in its understanding of the man today, and, in understanding, speak to him with penetration and genuine helpfulness."17

Although this accommodation was presented as a strategy for more effectively relating the traditional gospel to the present age, the produced effect was the inadvertent transformation of Christianity into "a commodity as necessary to life as salt," as remarked by one journalist who was "sold" by Templeton's performance of Christianity. ${ }^{18}$ In his religious writings, Christ was frequently presented as the means through which to secure a more worthwhile life, rather than the target and source of life itself. For example, Templeton constantly referred to the "abundant, adventurous, vital, unselfish living" that could be found in following Jesus. ${ }^{19}$ In discussing the early Christians, Templeton wrote: "They had something that was changing the world. They

\footnotetext{
${ }^{15}$ Templeton, "The Church and Its Evangelistic Task," 332-333.

${ }^{16}$ Ibid., 332.

${ }^{17}$ Ibid.

${ }^{18}$ Edward Boyd, "Religion's Super Salesman," in American Magazine (August, 1953) [Viewed at "Charles Templeton: Religion's Super Salesman" http:/www.templetons.com/charles/supersales.html (Accessed February 24, 2006)].

${ }^{19}$ Templeton, "The Church and Its Evangelistic Task," 330.
} 
had a cause that was supreme. They followed behind the most heroic Leader in history. They marched under the noblest banner of all time. And it is to this the Church calls us today!" ${ }^{20}$ This must have been an inspiring message to a generation locked in the confused and deceptive tensions of the Cold War. In a situation where the enemy was invisible, the fighting intangible and responsibility of the individual unclear, here was an opportunity to live a purposeful life, to change the world in a tangible way, and to follow "the most heroic Leader in history!" All that was necessary to achieve this purposeful life was to follow Jesus.

Templeton took this commodification process even further in his discussions on how to obtain happiness. Jesus was presented as the ultimate example of the happy life: "Whenever men look about for the perfect life, the radiant, joyful life, the truly happy life, they turn to Jesus."21 As such, Christianity quickly became a tool for achieving happiness. In Life Looks Up, Templeton stated, "Life is not what you find, it is what you create. We are born with two things, existence and opportunity, and these are the raw materials out of which, under God, we can make a worth-while life. You never find happiness, just as you never find steel; you fashion it out of rough ore... You do not find happiness, you create it." ${ }^{, 22}$ Here, Christianity is clearly presented as a tool for fashioning happiness out of the raw materials provided by God, and life is presented as a process of refining happiness out of life circumstances.

In another chapter entitled "Life Can Be Beautiful - If," Templeton more fully explores the pursuit of happiness. "How do you get the most out of life?" he asks. "How

\footnotetext{
${ }^{20}$ Templeton, Life Looks Up, 20.

${ }^{21}$ Ibid., 103.

22 Ibid., 142.
} 
do you find happiness? You turn to Jesus for light and you get a strange answer. He says, in effect, that you never find happiness by looking for it. Happiness isn't a goal, it isn't an end to itself. Happiness is a by-product of a life lived for God and others. Happiness is found, not in saving your life for yourself, but in giving it away!"23 While Templeton states here that "happiness isn't a goal, it isn't an end to itself," his protest seems weak, as his entire chapter is essentially dedicated to the question, "How do you find happiness?" He concludes his chapter with the following statement: "How may we find the best that life can give? We return to the words of Jesus, 'Whoever loses his life for my sake and the gospel's will save it.' Then give your life away to God and find it, full-orbed and abundant." ${ }^{, 24}$ Despite Templeton's statements to the contrary, this chapter's consistent focus on happiness and its positive conclusion still effectively treat happiness as an end to be achieved through the Christian tradition of "giving away one's life."

Another way by which Templeton inadvertently presented Christianity as the means instead of the end was in his presentation of Christianity as a "world changer" and Jesus as its chief "revolutionary." This revolutionary rhetoric was a direct extension of Templeton's efforts to address the particular demands of the current world situation. In a sermon entitled "Revolution! - Christian Style," he noted that "the world is sick, seriously, critically sick, and all kinds of radical remedies have been proposed." 25 In this context, he presented his own remedy - "a revolution - Christian style!" 26 "We need a revolution in the Church," he explained; "a revolution from the grass-roots to the highest echelons, from the humblest member to the most dignified ecclesiastic, a revolution that

\footnotetext{
${ }^{23}$ Ibid., 99.

${ }^{24}$ Templeton, Life Looks Up, 103.

${ }^{25}$ Ibid, 28.

${ }^{26} \mathrm{Ibid}$.
} 
will rouse us from our torpor and call us to the heroic dedication of mind and heart our age demands. ${ }^{, 27}$ This was a revolution that would wake a sleeping Church and empower it to address the world's problems.

At the heart of this call for revolution was Templeton's conviction that it was the responsibility of the Church to apply God's love to the problems and situations of the world. "We must come awake to the realization that the problems of the world are our problems," he exclaimed, "and we must bring Christian compassion and Christian helpfulness to them. Christianity is not the mere salvation of the individual soul, it is the demonstration of God's love in human life. ${ }^{, 28}$ Here Templeton clearly presents Christianity as a means of improving the world. "Christianity is not a matter of mere church membership," he argues, "or sitting in a pew singing some pleasant little hymns, or remembering to say one's prayers. Christianity is a great compulsion that thrusts you to the heart of the world's problems and empowers you to do something to solve them."29 Elsewhere he put it more succinctly: "Christianity does not remove you from the world and its problems; it makes you fit to live in it, triumphantly and usefully. ${ }^{, 30}$ As usual, Jesus was Templeton's model for this social approach. Described as "the most dynamic and revolutionary figure the world has ever seen," Jesus clearly saw the problems of the world and did something about them - he laid down his life for the world. "31 "He took the cross and, using it as a pry and Calvary as a fulcrum, turned the world upside down!"32

\footnotetext{
${ }^{27}$ Ibid., 30.

${ }^{28}$ Ibid., 32.

${ }^{29}$ Ibid., 34.

${ }^{30}$ Ibid., 155.

${ }^{31}$ Ibid., 29.

${ }^{32}$ Ibid.
} 
It is clear that by commodifying Christianity, Templeton was able to present it as a powerful and effective force desperately needed during the tumultuous years of the 1950s. However, even while presenting his faith in such forceful, dynamic terms, he was also unintentionally transforming it into a means for improving life (respectively speaking, for living a purposeful life, for achieving happiness, and for solving the world's problems) rather than the fulfilment and foundation of life itself. This reflects a possibility of unbelief because through this repositioning, Christianity became $u s e f u l$ as a tool for achieving happiness, instead of essential as the end, source and foundation of life. As Christianity became a mere means for achieving purpose and happiness, it effectively became disposable and replaceable by another ideology or practice that contributed to the same end. As the following chapters will demonstrate, Templeton eventually replaced Christianity, as the primary means through which he pursued purpose and happiness in life, with a moral system located outside of a supernatural context, based on an amalgamation of the philosophies of Jesus, Gandhi and Albert Schweitzer. ${ }^{33}$

Finally, the last "echo of unbelief" in Templeton's writings to be discussed lay within his tendency to present Christianity in such strong, forceful terms that he actually turned weakness and doubt into aberrations, instead of natural experiences in the Christian life. This condemnation of weakness led Templeton to equate spiritual success with spiritual strength and certainty - to fail to be strong in one's faith was to fail as a Christian in general. In this way, he unintentionally placed Christianity upon precipitous terms - there was no real room in his faith for weakness or doubt; and since both of these were a very real part of his life (as in human life in general), unbelief became a viable

\footnotetext{
${ }^{33}$ Templeton, Charles Templeton, 337; Sylvia Fraser, "The Real Charles Templeton," in Chatelaine (February, 1975): 77.
} 
alternative. The only way to give expression to his doubts and experiences was either to alter his Christianity or abandon it altogether. Ultimately, Templeton chose the latter option.

As mentioned earlier, Templeton's presentation of Christianity in strong, powerful terms was at least partially rooted in his religious assumptions regarding the inherently sacred nature of the act of communicating the gospel. This marked the first appearance of one particularly resilient trend which will be demonstrated in each of the successive chapters - Templeton's insistence that effective and compelling communication techniques were vitally important in order to reinforce the power of a worthy idea. In the context of his Christian writings, this impulse expressed itself in conjunction with his existing beliefs and assumptions, particularly in the context of his largely conservative evangelical concern regarding the need for conversion and the transformative work of the Holy Spirit in the lives of those who heard the Christian message.$^{34}$ For Templeton, then, preaching - and the communication of Christianity in general - was understood as a profoundly important, spiritual affair. Preaching was not just a matter of talking about spiritual things in front of an audience, it was "the proclamation of the gospel," a "word from the Lord," the direct "communicat[ion] of "the eternal word of God to the very heart of contemporary man." 35

In this way, preaching - and communicating the gospel in general - had to be forceful and convincing in order to do justice to the nature of the medium. "The man who would preach for a verdict," Templeton admonished, "must not only believe that God can

\footnotetext{
${ }^{34}$ Joel Carpenter, Revive Us Again: The Awakening of American Fundamentalism (New York: Oxford University Press, 1997), 6.

${ }^{35}$ Templeton, Evangelism for Tomorrow, 137; "The Church and Its Evangelistic Task," 333.
} 
transform human personality, he must expect to see it as a result of the proclamation of the gospel." ${ }^{36}$ It had to be entertaining: for him, the "cardinal sin" of evangelism was not misrepresentation of the Gospel, it was "dullness." "Dullness in the preacher is a greater sin than unspirituality, bad exegesis, or shoddy homiletics, for the preacher's first responsibility is to get the attention of his audience. ${ }^{.37}$ Most importantly, it had to be attractive and positive. As previously quoted, Templeton emphasized that Christian evangelism "is a call to abundant, adventurous, vital, unselfish living, and the dominant note of true New Testament evangelism must make this abundantly clear." ${ }^{38}$ Templeton did not dwell on the hardships and doubts faced by Christians, for this would not produce a convincing and attractive message. Of utmost importance was the proclamation of the gospel in a confident, exciting, vibrant way - this was the evangelism that would change the world! In emphasizing the importance of a persuasive, forceful preaching style, Templeton's particular philosophy of evangelism left little room for doubt or uncertainty. Consider the following paragraph from "The Church and Its Evangelistic Task":

Protestantism must rediscover the effectiveness of the communication of the gospel through public preaching. It must be preaching that is authoritative but not dogmatic - a word from the Lord. It must inform but it must also inspire. It must be Biblical and historical, speaking the ancient wisdom of the church, but it must also be relevant and practical in application. It must be interesting but never a mere collection of quotes and quips and epigrams that sounds as though it was written with Bartlett's Quotations open at one elbow and Time Magazine at the other. It is not necessarily great preaching because it is profound in content or persuasive

\footnotetext{
${ }^{36}$ Templeton, Evangelism for Tomorrow, 137.

${ }^{37}$ Ibid., 99.

${ }^{38}$ Templeton, "The Church and Its Evangelistic Task," 330.
} 
in delivery; it must communicate the eternal word of God to the very heart of contemporary man with power and helpfulness and illumination. ${ }^{39}$

This is a powerful passage, and it provides insight on why strong, authoritative communication was so important to Templeton. Templeton presented public preaching as "a word from the Lord." In this light, what made preaching significant was not its innate potential to persuade people to accept Christianity, it was its unique nature as a communication of "the eternal word of God," "a Word from the Lord." In this light, preaching takes on a revered, almost sacred quality - the preacher did not represent himself, a fallible, sinful human, but rather a messenger of the Almighty God, who was the very source of all certainty and truth. As such, weakness and doubt had no part to play; in order to be faithful to the nature of the message, the minister had to exhibit certainty and strength, speaking with the confidence and power of one delivering "a word from the Lord." Templeton's resounding command at the close of the essay is a typical demonstration of this style of preaching: "To this hungry, confused and wandering generation... the church comes with the 'good news' of God. Let it be a church renewed in commitment to Christ and to his gospel! Let it be a church afire with the evangel and moving out to do its leavening and redemptive task! Let the grace of our God be heralded with no uncertain sound, and let us look with confidence to God to revive his church in the midst of these years! ${ }^{, 40}$

Another factor that contributed to Templeton's presentation of Christianity in strong, confident terms was his subscription to a particularly masculine brand of Christianity. This was likely a lingering remnant of his previous and deep involvement in

\footnotetext{
${ }^{39}$ Ibid., 333.

${ }^{40}$ Ibid., 333.
} 
fundamentalist Christianity, a movement which, according to Betty Deberg, had long been preoccupied with upholding traditional Victorian gender roles, emphasizing that men should be masculine, and women should be feminine. ${ }^{41}$ Fundamentalists argued that Christianity was a strong religion; it represented strength and courage. As such, Christian men - and especially Christian leaders - were expected to be "manly" about their faith. As Deberg states, fundamentalists "associated the ability to live untroubled by doubt with true manliness and true faith. ${ }^{, 42}$ Billy Sunday, the famous fundamentalist baseball playerturned-preacher of the early twentieth century, is the classic example of the meld of masculine ideals and Christianity, and his exhortation is typical of this mixing: "Strong men resist, weaklings compromise... Lord save us from off-handed, flabby-cheeked, brittle-boned, weak-kneed, thin-skinned, pliable, plastic, spineless, effeminate, sissified, three-caret Christianity." ${ }^{43}$ Templeton's presentation of Christianity, while not so inflammatory, shared many characteristics with this line of thinking. Templeton consistently presented Christianty in what he doubtlessly considered masculine terms, celebrating strength and confidence and disapproving of weakness and doubt.

Templeton's book of sermons, Life Looks Up, is full of examples of this strong, confident presentation of Christianity. For instance, he devoted an entire chapter to the pursuit of spiritual certainty. Discussing the apostles' strength of faith, he asked, "How may we know such certainty? ${ }^{, 44} \mathrm{He}$ then proceeded to argue that spiritual certainty is possible (although somewhat intangible): "We begin our quest for certainty by ridding

\footnotetext{
${ }^{41}$ Betty DeBerg, Ungodly Women: Gender and the First Wave of American Fundamentalism (Minneapolis: Fortress Press, 1990), viii.

${ }^{42}$ Ibid., 91 .

${ }^{43}$ Billy Sunday, quoted in DeBerg, 89.

${ }^{44}$ Templeton, Life Looks Up, 172.
} 
our mind of the idea that God will be apprehended through any or all of the five senses." ${ }^{, 45}$ He continued, "the real things in the world are the invisible spiritual realities. Is it so difficult, then, to believe in God? We may not apprehend Him with our finite perceptions but this does not mean He does not exist. It simply means He exists beyond our ken." ${ }^{, 46}$ Templeton's devotion of an entire sermon to the subject of spiritual certainty is significant - it reflects his own preoccupation with confidence and strength and demonstrates a certain averseness to - or even a desire to combat - uncertainty and doubt. $^{47}$

Occasionally Templeton did mention doubt and failure in Christian life: "Who has not known moments of hotheaded impetuosity? Who has never vacillated in his devotion to his ideals? Who has never doubted the Divine purpose and has never denied his Lord by thought or word or action?"48 However, this apparent sympathizing with spiritual weakness was actually a discussion on how to avoid the spectacular spiritual failures of Samson and Peter, respectively. "Let these giants speak to you who are strong and let their counsel be, 'Let him that thinketh he standeth take heed lest he fall!" discussion regarding Christ's resurrection, Templeton presents a more characteristic treatment of doubt and weakness: "Why should we doubt him then? In the resurrected Christ we see one who has come back from the ultimate grapple of life and his first word is 'Peace.' Why should we despair then? Why should we draw back and be afraid? Why

\footnotetext{
${ }^{45}$ Ibid.

${ }^{46}$ Ibid., 174.

${ }^{47}$ Templeton's presentation of Christianity provides many other subtle examples of his appreciation of confidence and strength and, inversely, his disapproval of weakness. He often made comments such as, "Ours is a day that demands greatness and heroic resolve, and yet we sleep!" (Templeton, Life Looks Up, 48).

${ }^{48}$ Ibid., 43.

${ }^{49}$ Ibid., 50.
} 
should there be a tempest in our souls? The victorious, risen Christ returns to say, 'Peace. ${ }^{, 50}$ In these subtle ways, Templeton presented strength and confidence as the normative characteristics of the Christian experience, implicitly suggesting that weakness and doubt were exceptional and problematic - experiences that had no part to play in the Christian life.

Perhaps the clearest example of Templeton's celebration of strength and disapproval of weakness can be found in his discussion of various Biblical figures. His description of Samson is revealing:

There he goes, walking with the imperious assurance of the man who knows he has no peer: unshorn hair, bulging biceps, bronzed and radiantly healthy, knowing the favour of both God and man. There he stands, admired for his disposition (Samson means 'Sunny'), worshiped for his courage, honoured for the position he held as 'Judge' in Israel and followed with undeviating devotion because of his superb military leadership. ${ }^{51}$

Masculinity and strength are celebrated here in no uncertain terms. However, Templeton's treatment of the disciple John is perhaps even more useful for illuminating his attitudes towards strength and weakness. "Let no turn aside from this tremendous figure of a man because he has sometimes been portrayed as effeminate and weak," Templeton admonishes. "He is no weakling, no sissy. You may be absolutely certain about that. ${ }^{, 52}$ Throughout his presentation of John, Templeton seems almost offended at the thought of weakness in the man, and he strives to correct the misrepresentation. "As you can see, this man is no sentimental dreamer, no aesthetic, soft-eyed sissy. John is a

\footnotetext{
${ }^{50}$ Ibid., 192.

${ }^{51}$ Ibid., 42.

${ }^{52}$ Ibid., 149.
} 
strong-willed, hot-tempered positive personality." ${ }^{, 53}$ Furthermore, Templeton goes so far as to establish John as a sort of ideal of masculinity and strength: "a relatively successful businessman with calloused hands who moved among people of importance. A dominant, affectionate, aggressive man, but with something of the mystic about him. Moreover... he is a man of great courage and loyalty. Quite a man! Little wonder millions have been intrigued by him across the centuries." 54

Most telling, however, is the way in which Templeton then drew links between John's spiritual strength and God's love. "Why was John especially beloved by Jesus?" Templeton asked. Was it not, first of all, because of his faith? ...From the day he heard John the Baptist cry 'behold the Lamb of God,' he began to follow Jesus as Lord and, so far as we know, he never doubted or forgot." ${ }^{, 55}$ Here the connection between Templeton's view of Christianity and spiritual strength is quite clear: good Christianity requires spiritual strength and the resolution to resist weakness and doubt! "Was it easy for John to believe?" he continued. "It was more difficult than it is for you or me. But he did believe, and his faith never appeared to falter. ${ }^{, 56}$ Templeton concluded his discussion on John with the words, "It takes the finest kind of manhood and womanhood truly to follow Christ... It takes courage; the highest kind of courage. But God loves the courageous, the Church needs the courageous, and the world is changed by the courageous!" 57 It seems clear that Templeton's adherence to specific religious assumptions regarding masculinity and gender, as well as the inherently sacred nature of the

\footnotetext{
${ }^{53}$ Ibid., 150.

${ }^{54}$ Ibid., 151 .

${ }^{55}$ Ibid., 152.

${ }^{56} \mathrm{Ibid}$.

${ }^{57}$ Ibid., 154.
} 
communication of Christianity, powerfully influenced his presentation of a strong, forceful and confident Christianity. Herein lay the third, unwritten "echo" of unbelief - in the very strength and confidence with which Templeton presented his Christianity, he also unwittingly transformed his own weakness and doubt into spiritual aberrations. This posed a significant dilemma for Templeton - it permitted no room in his Christianity for his very real experiences with intellectual doubt. As a result, he was forced to hide and repress his struggles. His later writings reveal that he repressed his doubts for several years - a process that eventually lead to physical problems, such as pains in his chest, shortness of breath, and "a numbness radiating to my forearms and hands." ${ }^{58}$ These symptoms, he later explained, "were exacerbated by difficulties I was having with my faith. The old doubts were resurfacing. I would cover them over with prayer and activity but soon there would be a wisp of smoke and a flicker of flame and then a firestorm of doubt. I would banish them again only to have them return." ${ }^{59}$ In all of this, Templeton was too ashamed of his doubts to confide in others. "Part of the problem," he stated in his Anecdotal Memoir, "was that there was no one to talk to: how does a man who, each night, tells five to ten thousand people how to find faith confess that he is struggling with his own?" ${ }^{60}$ Ultimately, his rendering of weakness and doubt as aberrations made unbelief a viable option. It presented him with a watershed decision: he could continue to live a "hypocritical" life with a Christianity that left no room for his doubts, or he could leave Christianity altogether and live a life free of the tension that had plagued him for years. He summed up his decision in his memoir, "I could stay in the ministry, paper over

\footnotetext{
${ }^{58}$ Templeton, Charles Templeton, 84.

${ }^{59}$ Ibid., 85.

${ }^{60}$ Ibid.
} 
my doubts and daily live a lie, or I could make the break. I packed my few possessions in a rented trailer and started on the road back to Toronto." 61

In conclusion, this chapter has demonstrated how Templeton performed unbelief in a very distinct manner in his three works of Christian literature. Since he was not in any way attempting to express unbelief (quite the opposite), his "performance" of unbelief took the form of "echoes" that appeared only in the unwritten implications of Templeton's presentation of a strong, confident and useful Christianity. Although these echoes were unconsciously performed, they nevertheless reflected the early stages of a developing unbelief, as Templeton inadvertently established the very terms by which he would eventually find it possible to reject Christianity and embrace an alternate interpretive system. He did this in three ways. First, in his efforts to define Christianity in clear, unmistakable terms, he effectively established the specific elements of Christianity that he eventually and continually rejected - specifically, concerning the divinity of Jesus. Second, in his efforts to ensure Christianity's continued relevance through commodification, he unintentionally transformed it into a disposable means for improving life, which could be easily jettisoned in favour of an alternative ideological system that served the same goal. Finally, in presenting such a strong, forceful Christianity, he unwittingly condemned his own life experiences, ultimately forcing himself to a watershed decision between his faith and what he perceived as a more honest approach to his life. These "echoes," then, constitute Templeton's performance of unbelief in his Christian literature. In the next chapter, his performance of unbelief will be explored during the time period immediately following his abandonment of

\footnotetext{
${ }^{61}$ Ibid., 90.
} 
Christianity in 1957 , as he demonstrated an attempt to regain a sense of identity and purpose through his various television presentations on CBC's Close-Up and CTV's W5. 


\section{Chapter 2: Inside Television}

"Let's go back to first things. God. Now I find it impossible to believe that there is such a thing as what you could best describe as a personal God. I find it impossible because I look at the world around about me, and I just don't find it credible. I used to; I don't any longer. Do you have any trouble believing in God?",

In chapter one, Templeton's performances of unbelief were discussed as presented through his three works of religious literature. Without exception, these were unconscious, inadvertent performances, found only within the unwritten implications of his performance of a strong, vibrant Christianity, and thus they were described as "echoes of unbelief." His performance of unbelief on television was quite different. Although his presentations of unbelief were still largely implicit - he rarely discussed his rejection of Christianity directly - he advanced a steady, developing unbelief, and this time it was not confined to implications and undertones. This chapter will examine the manner in which Templeton performed unbelief through two television programs, Close- $U p$ and $W 5$. Through these shows Templeton exhibited an early form of unbelief, one that represented a continuing rejection of the Christian system for interpreting meaning and reality, and early attempts to replace it with some other framework of meaning. He did this in three ways: first, in his efforts to find meaning and purpose in life outside the context of Christianity; second, in his increasing antagonism toward Christianity; and third, in his explicit statements regarding his rejection of a narrowly-defined Christianity.

Furthermore, this chapter argues that these presentations were framed in congruence with a variety of cultural expectations and assumptions inherent to the television medium. In

\footnotetext{
${ }^{1}$ Charles Templeton, television interview with Sir George F. MacLeod on Close-Up (Toronto: CBC, December 2, 1962), 01:11.
} 
particular, he tapped into the celebrated notion of the newsman as the "trustworthy journalist," the public defender of truth. As such, most of these presentations of a developing unbelief assumed the form of questions, interrogations, and investigations into the truth of the nature of man and the universe. In this light, Templeton performed a distinctly questioning, "investigative" unbelief in his television shows, locating the presentation of unbelief firmly within the cultural context of the broader society.

The year 1957 was climatic for Templeton, marking not only his conscious abandonment of Christianity and his career in the ministry, but also the beginning of his divorce with his wife, the death of his mother, and his move from New York back to his home city of Toronto. He later described the following years as a period of profound confusion as he attempted to reorient himself. "I didn't know who I was," he stated in his Anecdotal Memoir. "I had lost an identity and had not yet found a new one... It was as though I had been returned to my teens. I was in a twilight world, a creature of neither the sun nor the night. It was almost two years before I walked with any assurance." ${ }^{2}$ While he attempted to recapture his sense of identity, he decided to write screen plays, which he sold to the Canadian Broadcasting Corporation (CBC). ${ }^{3}$ It was this collaboration with the $\mathrm{CBC}$ that eventually led to his dynamic career in the television industry. Exiting the CBC building one day, Templeton was intercepted by Ross McLean, a revolutionary producer largely responsible for shaping the Canada's blossoming news and public affairs genre of television. ${ }^{4} \mathrm{He}$ asked Templeton to be a guest in his popular affairs show, Tabloid.

\footnotetext{
${ }^{2}$ Charles Templeton, Charles Templeton: An Anecdotal Memoir (Toronto: McClelland and Stewart Limited, 1983), 107-108.

${ }^{3}$ Ibid., 103-104.

${ }^{4}$ See Paul Rutherford, When Television was Young: Primetime Canada 1952-1967 (Toronto: University of Toronto Press, 1990), 93-94, and the chapter "Information for Everyone."
} 
Following Templeton's successful performance, McLean hired him, along with Pierre Berton, as an interviewer for his upcoming news show, Close-Up. ${ }^{5}$ Television was not an entirely new thing to Templeton - in the early and mid fifties he had hosted a religious television show called Look $U p$ and Live, in which he interviewed popular guests and delivered short, snappy talks on a variety of spiritual topics - however, he was unprepared for "the sweat-box of fearsome tension" that was the developing world of public-affairs television. ${ }^{6}$ In his memoir, Templeton later recalled the tenuous nature and raw quality of this early work. "The medium was new in Canada," he stated, "and the people in charge, despite a brave air of savoir faire, were pioneering. There were few precedents and no rules. Except for some brief filmed segments, programs such as Close$U p$ were assembled as they were broadcast, interviews were done 'live to air' and mistakes were irrevocable."7

Templeton worked with Close-Up until 1959, winning, in the process, two awards as the "Best Newcomer to Canadian Television." ${ }^{8}$ In 1959, he left the television industry to pursue a variety of other interests, including working as the managing editor for the Toronto Star, contending for the leadership of the Liberal Party of Ontario, and serving as the president of a small advertising company called Technamation Canada. ${ }^{9}$ In 1966, however, Templeton was called back to the television industry when the vice-president and general manager of Canadian Television Network, Murray Chercover, asked if he

\footnotetext{
${ }^{5}$ Templeton, Charles Templeton, 106.

${ }^{6} \mathrm{Ibid} ., 97 ; 107$. Unfortunately, I have been unable to find footage of Templeton on this television series.

${ }^{7}$ Ibid., 107.

${ }^{8}$ Ibid., 123. According to his Anecdotal Memoir, Templeton considered the Liberty award to be "late" so he sent it back.

${ }^{9}$ Ibid., 125-126.
} 
would be willing to work for CTV as Director of News and Public Affairs. ${ }^{10}$ This role entailed a dramatic change of pace from Templeton's earlier work with CBC's Close- $U p$. Although his work as an interviewer had been more frantic and raw in 1957, when the genre and technology was still relatively new, he had been relatively excluded from the behind-the-scenes planning that now characterized his work. ${ }^{11}$ Furthermore, his interviewing skills were still put to the test in his flagship public affairs show, $W 5$, in which he acted as producer, supervisor, and reporter. ${ }^{12}$ Templeton continued to work with CTV until 1969, when he was hired as the editor of Maclean's magazine.

According to historian Paul Rutherford, Close- $U p$ was a type of television experiment - a way of moving beyond mere public affairs to delivering a meaningful and informative news program. Rutherford classified it as a "news magazine," offering several segments in each half-hour show, "using interviews to explore issues of life as well as affairs." ${ }^{\prime 13}$ The show was often filmed live (host Frank Willis often opened the show with the slogan, "We know it's live; we hope it's lively"), but was occasionally edited as technology and skill improved. ${ }^{14} \mathrm{~W} 5$, which was created shortly before Templeton took over in 1967 , had a similar focus, dedicating itself to answering the questions "Who?" "What?" "When?" "Where?" and "Why?" on a number of topics each show. This show, airing almost ten years after Close-Up had begun, was more polished in its presentation, and more heavily produced. Interviews were closely edited, sets were

\footnotetext{
${ }^{10}$ Ibid., $125-126$.

${ }^{11}$ Ibid., 127.

${ }^{12}$ Ibid.

${ }^{13}$ Rutherford, 177.

${ }^{14}$ Frank Willis, introduction to television show Close-Up (Toronto: CBC, March 9, 1957), 00:01.
} 
constructed deliberately and provocatively,${ }^{15}$ and it lacked the general "raw" quality of the often-live Close-Up performances. In addition, while Close-Up was consistently black and white, $W 5$ introduced color to its broadcasts in the late $60 \mathrm{~s}$, often using bright (or alternatively, dark) colors as backdrops, which subtly influenced the tone of the interviews. As mentioned previously, Templeton's involvement was far greater in $W 5$ than in Close-Up; whereas in Close-Up he simply interviewed previously determined guests at previously determined locations, on $W 5$ he had control over almost every element of the broadcast. ${ }^{16}$

The nature of these two programs, and the nature of television itself during this period, is quite significant for understanding Templeton's expressions of unbelief in this medium, for it provided the cultural context through which he performed his "investigative" unbelief. According to Rutherford, by 1960 "primetime viewing had become the single most common cultural experience of Canadians." ${ }^{, 17}$ Television had become a powerful phenomenon, and the people involved in the industry found themselves in positions of great cultural authority. The newsman (or newswoman), in particular, became the focus of what has been referred to as the "cult of the journalist," which "portrayed the newsman as the public's watchdog." ${ }^{18}$ Having been frustrated by the hypocrisies and incongruencies he detected within the Church, and having found himself unconvinced by the central tenets of the Christian faith, Templeton had effectively left the ministry and become a journalist. He saw his abandonment of

\footnotetext{
${ }^{15}$ For example, the introduction of three coffins to the set representing the deaths of God, Jesus Christ, and the Christian church.

${ }^{16}$ See Templeton, Charles Templeton, 127-129.

${ }^{17}$ Rutherford, 8.

${ }^{18}$ Ibid., 178.
} 
Christianity largely in terms of a movement from intellectual dishonesty to a more noble, honest, pursuit of truth. As he had stated in his memoir, "there was no real choice. I could stay in the ministry, paper over my doubts and daily live a lie, or I could make the break." ${ }^{19}$ For a man so concerned with intellectual integrity, the celebrated role of "newsman," as a public hero of truth, must have seemed quite attractive to Templeton. Indeed, as will be discussed later in the chapter, Templeton seemed fond of playing this role, often calling on scientists to "validate" the supernatural claims of religious people, attempting to represent the interests of the "common man," and later, purposefully arranging his sets in such a way that suggested almost clinical detachedness. ${ }^{20}$

Related to this cultural notion of the newsman as a trustworthy figure was television's inherent ability to produce a very intimate atmosphere. ${ }^{21}$ Television journalism had a quality of trustworthiness. Despite the fact that the newscaster was speaking to thousands or millions of people, the individual at home saw only one man or woman looking directly into their eyes and speaking in conversational tones. Templeton himself made frequent use of this concept. An interview in 1997 with historian Kevin Kee regarding Templeton's former religious program, Look Up and Live, demonstrates this point well. Kee asked Templeton, "Now you're there in the early days of television. Did you find... that the way that you preached changed because you were on television?" After a moment of conversation, Templeton stated:

It really was a matter of style more than content. I was saying the same things. But I was saying them as I would speak to you as an individual

\footnotetext{
${ }^{19}$ Templeton, Chares Templeton, 90.

${ }^{20}$ For instance, when discussing issues on $W 5$ he often eschewed all furniture, fireplaces, and other distractions, using merely two chairs and a pure white backdrop as if to suggest a total absence of all influences and manipulations, and hence, a completely objective interview.

${ }^{21}$ Rutherford, 178.
} 
because the great mistake most television preachers make is that they talk as though they're talking to a lot of people. And of course they're only talking to one person sitting by a television set. And that was the first lesson I had to learn. That was, you're talking to somebody personally. Don't preach. Talk. ${ }^{22}$

Templeton's interviews on Close- $U p$ and $W 5$ clearly reflect this philosophy, with a slight twist. Rather than speaking directly to the audience, he was now speaking candidly with special guests. Great pains were taken to produce the illusion of intimacy - Templeton would joke around with the guests as they sat in arm chairs by the fire or reclined beside the French Riviera. The overall impression is of two ordinary people having a meaningful discussion, of which the viewer is invited to be a part.

The cultural characteristics, assumptions and expectations of the television medium shaped the way in which Templeton presented his unbelief. Specifically, the innate sense of trustworthiness of the medium (provided by its ability to produce a sense of intimacy and its positioning of the newsman as a public hero of truth) created a context in which the various expressions of his developing unbelief were framed in the form of a genuine and objective search for truth - an investigation for answers regarding the ultimate nature of reality. This context of an "honest investigation" was further enhanced by the specific nature of Templeton's role on both television shows: while he played some part in the construction and production of $W 5$, he was more consistently and prominently an "interviewer" in the two programs. As such, nearly all of Templeton's expressions of unbelief in this medium assumed the form of questions as he interviewed and sometimes interrogated - his guests. "What is happiness?" he asked one. "What is the difference between Jesus and Gandhi?" he demanded of another. In all of these ways,

\footnotetext{
${ }^{22}$ Unpublished interview between Kevin Kee and Charles Templeton, August 27, 1997.
} 
Templeton's framing of his presentations of unbelief in accordance to the cultural expectations, assumptions and requirements of the television medium constituted a performance of a distinctly "investigative" unbelief - an effectual grounding of his developing unbelief in an honest pursuit of truth on behalf of the public.

In the previous chapter, much attention was given to his tendency to treat Christianity as a means for attaining happiness rather than as an end in itself. In his television performances, Templeton continued to explore the themes of the ends and means of life, albeit in a different tone. That is, rather than positively presenting Christianity as a tool for attaining a meaningful life (as was the case in his religious literature), his television performances were notably devoid of his previous Christian certainty and instead implicitly posed the question: "What is the meaning of life?" Viewed within the context of Templeton's life, this represented an ongoing rejection of the Christian system of meaning and significance, and an effort to find a replacement framework through which to interpret reality.

One way in which he demonstrated this investigative attempt to locate meaning apart from God was in his constant exploration of the notions of happiness and success. Perhaps the most striking example of this is found in a Close-Up interview with the renowned Christian minister, Norman Vincent Peale, regarding his best-selling book, The Power of Positive Thinking (1952). This was a conversation that seemed to fascinate Templeton, not least, one assumes, because the two men shared so much in common. As with Templeton, Peale had been heavily involved in the newspaper industry before he joined the ministry, had quickly risen to success as a preacher, and had become quite interested in combining his Christianity with the best of science, psychology and 
philosophy. ${ }^{23}$ What interested Templeton the most, however, were Peale's insights into the nature of happiness. After a brief conversation regarding the success of his book and his views on various religious contemporaries, Templeton changed the direction of the interview. "Dr. Peale," he asked, "do you believe that happiness is a byproduct of the Christian message?" Peale responded in the affirmative, stating that yes, he did believe so. "Well then," Templeton continued, "let me ask you a tough question to answer very briefly, but that is: What is happiness?" 24 As Peale responded by discussing the notion of personal wholeness and fulfillment, Templeton continued to probe the issue with questions such as "Now you've told us what it is; how do you get it?" and "Are you, Dr. Norman Vincent Peale, happy?" - nodding attentively each time to the answers Peale provided. $^{25}$

These questions, especially Templeton's philosophical inquiry into the nature of happiness, are very significant. First, they represented a movement away from the religious answers that had once satisfied him. His very act of questioning "What is happiness?" implied a continuing rejection of the interpretive system that had once addressed this question and an attempt to locate an answer outside the context of Christianity. ${ }^{26}$ Second, they represented a shaping of this developing unbelief in accordance with the requirements of the cultural medium; Templeton's search for meaning outside Christianity was posed in the form of an investigation of truth, in which

\footnotetext{
${ }^{23}$ Charles Templeton, television interview with Dr. Norman Vincent Peale on Close- Up, (Toronto: CBC, December 27, 1957), 01:20.

${ }^{24}$ Ibid.

${ }^{25} \mathrm{Ibid}$

${ }^{26}$ In Life Looks Up, Templeton had confidently declared that happiness consisted of living in good relationship with God and others. Charles Templeton, Life Looks Up (New York: Harper \& Brothers Publishers, 1955), 99.
} 
he - in his references to "us" as the recipient of Peale's knowledge - was acting as the trustworthy representative of the public.

This investigative demonstration of unbelief was continued in Templeton's exploration of the relationship between success and happiness. In an interview with Edgar and Jean Riley, a married couple of mixed religious beliefs (Edgar was Catholic and Jean was Protestant), his questions implied concern with whether or not they were able to have a successful marriage despite the religious obstacles, and if they considered themselves "happily married." ${ }^{27}$ An interview with a female doctor, Eleanor Black, found Templeton smiling broadly as he questioned her on the nature of her success, and on the satisfaction she derived from her work. ${ }^{28}$ He seemed especially impressed with the success of Norman Vincent Peale, presenting figures regarding his total book sales and the sizes of his preaching audiences, extrapolating on the amount of people Peale had influenced both within the United States and internationally, and praising Peale was his status as an "outstanding contemporary" of both Billy Graham and Fulton J. Sheen. The overall impression provided by Templeton portrayed Peale as a shining example of a successful and, due partially to the nature of his work, happy life. ${ }^{29}$ These examples are significant because they represent a subtle argument that something outside of the specific realm of religion had real meaning and value; in this case, "success" was presented as meaningful because it was related to happiness and fulfillment, which were, in turn, presented as being intrinsically valuable and desirable in their own right.

\footnotetext{
${ }^{27}$ Television interview between Charles Templeton and Edgar and Jean Riley on Close-Up (Toronto: CBC, December 15, 1957), 00:37.

${ }^{28}$ Television interview between Charles Templeton and Dr. Elinor Black on Close-Up (Toronto: CBC, November 3, 1957), 01:21.

${ }^{29}$ Templeton interview with Peale, 01:20.
} 
Another example of Templeton's investigative efforts to find meaning outside the realm of religion is found within his presentation of honesty and personal integrity as sites of meaning apart from God - a trend that plays an increasingly important role in each of the successive chapters. Through the particular manner in which he posed his questions, Templeton presented these traits as being meaningful in that they enabled one to better one's self or society, implicitly arguing that these were worthy goals indeed. One of Templeton's most dynamic and forceful interviews demonstrates this point. In June of 1957, he joined British Columbian actor and media figure Bernie Braden at Braden's residence overlooking the French Riviera. After a brief conversation, Templeton seemed to be concerned with Braden's hesitancy to face life head on and admit he was not reaching his potential as an individual by committing himself to one task or career.

Templeton: Now Bernie, are you saying that you're aware that you're sort of running away from the fear of failure? In other words, if you committed yourself utterly to some facet of your talents, and then you failed, you wouldn't have an out. Is this what's bothering you? A fear of failure?

Braden responded that his experiences in his career had brought him up to be a versatile media man: "Versatility was the thing if you want to make money."

Templeton: You said in an interview which was done of you in England that you can't go on blaming the age you live in forever for your own personal predicament.

Braden: $\quad$ That was kind of a pompous thing to say, wasn't it?

Templeton: Not at all. 
Braden conceded that although the statement sounded pompous, he still believed it to be true - people are able to make excuses for everything.

Braden: And I don't think you can go on doing that; I think I've got to face it one of these days and have a bash at something real, you know.

Templeton: I notice also you're critical of yourself. I think this is a very good thing, but it's also, isn't it, a device sometimes, Bernie, by which we beat the other guy to the criticism. And this takes the edge off it.

Braden: $\quad$ You're doing a really provocative interview, here, aren't you?

Templeton: No, I don't think so. I'm just trying to talk to Bernie Braden.

Braden: Well if you think I'm going to deny that you're wrong. I think it's probably true.

Templeton: Do you think that you ever will give yourself to any one thing, Bernie, in terms of doing the absolute, ultimate best that lies within you?

"I can't say," responded Braden, who then admitted that he had never been able to find that one thing, and that he had never accomplished anything that had truly satisfied him. ${ }^{30}$

In this forceful interrogation, Templeton essentially forced Braden to be truthful with himself and to confront the reality he had been avoiding. His statements, usually formed as questions, continually and subtly undermined Braden's efforts to let himself off the hook, and ultimately forced him to directly and publicly address his problems. This notion of being honest with one's self was likely a sensitive issue for Templeton, who had struggled inwardly for several years over the predicament of whether he should continue in the ministry and ignore his spiritual struggles, or face his doubts head on, no matter the consequences. Perhaps Templeton's interaction with Braden represented a

\footnotetext{
${ }^{30}$ Television interview between Charles Templeton and Bernie Braden on Close-Up (Toronto: CBC, June $22,1957), 00: 32$.
} 
reliving of that internal conflict. In any case, the relentlessness with which Templeton demanded honesty from Braden presented the concepts of honesty and personal integrity as meaningful and important, and the notions of "doing one's best" and "reaching one's potential" were implicitly portrayed as a worthy of pursuit. In this way, he was again presenting a developing unbelief by expressing a rejection of easy Christian answers to the questions of life, and an inclination to find meaning and purpose apart from religion, specifically in notions of success and personal integrity. Whereas during his years of Christianity the value of ideas such as "success" and "honesty" would have been interpreted through the framework of a dynamic relationship with God, now Templeton seems to have presented them as meaningful in their own right. Furthermore, he was presenting this transition in accordance with the cultural expectations and requirements of the medium through which he was communicating - in this case, by framing his unbelief assertions in a particularly intense, yet deliberately intimate, search for truth as he probed the deep recesses of Braden's life.

Another way in which Templeton presented unbelief through his television shows was in the increasing antagonism he presented towards Christianity in the shaping of his questions and the tone of his investigations. Here, his developing unbelief was expressed in a more straightforward manner and developed in a chronological fashion. In 1957, the year in which he officially left Christianity and joined secular television, his treatment of religion was almost gentle as he explored its value in a somewhat detached sense. As time went on, however, his attitude and questions became more and more antagonistic towards organized religion and Christian faith, culminating in his eventual declaration of the death of Christianity in 1967. 
In 1957, Templeton seemed largely interested in exploring the social value of religion. His interview with Norman Vincent Peale was characteristic of this trend. Although he himself had been most interested in Peale's discussion on the nature of happiness, the interview was based upon Peale's assertions that this true happiness was rooted in Christianity - that, in Templeton's words, "happiness is the byproduct of the Christian message."31 Templeton himself seemed dispassionate about this notion, but not unsympathetic - he nodded encouragingly to Peale throughout his responses. Indeed, in 1957 Templeton seemed generally wearied by religion, but not antagonistic. His interviewing style reflected the role of mediator during this time, negotiating between the views of various religious and scientific figures. For example, in a discussion on suicide, he mediated between a religious figure, Dean Charles Fielding of Trinity College University, and a psychiatrist, Dr. Herbert C. Modlin, directing questions to both and attempting to synthesize their responses. ${ }^{32}$ Here, he seemed to be exploring what insight religious answers could provide to a widespread social problem. On another occasion, he mediated a conversation on faith healing involving two religious figures - healing advocate and minister Rev. Alpheus Noseworthy, and Dr. E. Crosley Hunter of the more liberal United Church - and a scientific one, psychiatrist and General Director of the Canadian Mental Health Association, Dr. John Griffin. Templeton remained relatively neutral as he questioned them each in turn, but expressed reservations regarding the benefits of such an investigation, commenting, "it may be pointless," before asking his

\footnotetext{
${ }^{31}$ Templeton interview with Peale, 01:20.

${ }^{32}$ Television interview between Charles Templeton, Dean Charles Fielding and Dr. Herbert C. Modlin on Close-Up (Toronto: CBC, October 27, 1957), 00:55.
} 
first question. ${ }^{33} \mathrm{He}$ concluded the discussion in a relatively benign manner, in this case stating, "A diversity of opinion, all agreeing as to the possibility, difference of opinion as to the results." 34

While this year marked, for Templeton, a relatively gentle approach to religion, it was also the year in which several increasingly antagonistic tendencies appeared in his treatment of the subject. While these tendencies were rather innocuous at this stage, as time progressed they became more and more aggressive, forming the foundations of many of his later arguments against Christianity. For example, while in his Christian years he had attempted to combine faith and science, in his television performances he constantly presented a division between the two realms, implicitly emphasizing science as a more valid form of knowledge than faith. The interviews on suicide and faith healing demonstrate this trend well. In the discussion on suicide, Templeton effectively compartmentalized the interview by directing all questions of scientific content towards the representative of science and all questions of morality and philosophy towards the representative of religion, and allowing for no interaction between the two realms. Furthermore, he established the psychiatrist, Dr. Modlin, as the obvious expert on the matter, beginning the interview with him and directing most of the questions his way. The religious figure, Dean Fielding, seemed present merely to add additional philosophic insight to facts already established. ${ }^{35}$

Within the faith healing discussion, the opposite case was true. Rather than compartmentalizing religion and science he placed them in opposition, positioning

\footnotetext{
${ }^{33}$ Charles Templeton, television interview with Rev. Alpheus Noseworthy, Dr. E. Crosley Hunter and Dr. John Griffin on Close-Up (Toronto: CBC, October 13, 1957), 01:44.

${ }^{34}$ Ibid.

${ }^{35}$ Templeton interview with Modlin and Fielding, 00:55.
} 
science as the higher form of knowledge. Rev. Noseworthy was implicitly presented as the fundamentalist religious figure who believed that faith healings were from God, while Dr. Griffin was the established scientific figure who admitted that healings happened, but doubted they were of divine nature. (Dr. Hunter, who seemed to represent the middle ground between the two views, was relatively silent during the interview, speaking briefly only twice.) In contrast to the discussion on suicide, here Templeton asked questions to which both sides could respond, such as whether or not faith healings were really of God, and whether these were a healthy practice to pursue. The responses were predictably conflicting. Significant, though, was Templeton's response to Noseworthy's arguments. When Noseworthy asserted that he personally knew people who had been supernaturally healed, Templeton questioned, "Let me ask you this, if I may: have you ever troubled to have any of these cures authenticated by disinterested medical doctors?"36 The implications to his question are clear - things of faith, before they can be accepted as truth, should be validated by science. Templeton was clearly, if implicitly, arguing that religion was a less reliable and trustworthy source of knowledge than science. In essence, these questions presented a disconnection between religion and science in which religion could, at best, inform science, and at worst, be invalidated by it.

The year 1957 also marked the beginning of Templeton's tendency to use his interviews to highlight apparent hypocrisies and inconsistencies within Christianity. This began gently at first. He seemed to genuinely like Dr. Peale, but he questioned the popular nature of his persona: "How do you account," he asked, "for the popularity - the

\footnotetext{
${ }^{36}$ Templeton interview with Noseworthy, Hunter and Griffin, 01:44. James Opp's book, The Lord for the $B o d y$, is an excellent source for further exploring epistemological assumptions regarding faith healing and medical science. James Opp, The Lord for the Body (Montreal \& Kingston: McGill-Queen's University Press, 2005).
} 
enormous popularity - of a Billy Graham, of yourself, who are exponents of the Christian faith, whereas most of the great Christians across the centuries beginning with Jesus himself was martyred for his faith [sic]?"37 Templeton seemed slightly suspicious of popular modern religious figures because they did not seem to reflect the lives of Jesus and his disciples. In his conversation with Rev. Noseworthy and Dr. Modlin regarding faith healing, he again raised this concern. "There's a question which occurs to me," he stated, "and that is, Jesus, when he healed people in Biblical times almost invariably sent them away quietly, told them to tell no one, whereas many a modern faith healer advertises it in the paper that healings have been effected. ${ }^{38}$ These concerns with the incongruencies between modern religion and original Christianity, along with Templeton's tendency to marginalize religion in comparison to science, eventually became mainstays in his presentations of more developed forms of unbelief, as will be explored in chapters three and four.

Templeton's treatment of organized religion, in particular, became increasingly antagonistic as time progressed. Although these criticisms of the institutional forms of Christianity did not necessarily represent antagonism against Christianity in and of themselves, when examined in context with the rest of Templeton's negative comments towards faith they contribute to a larger picture of general antipathy towards Christianity, and religion in general. A Close-Up interview in 1962 with Sir George MacLeod illustrates this growing sentiment. ${ }^{39}$ As he sat with MacLeod, a liberal Protestant and

\footnotetext{
${ }^{37}$ Templeton interview with Peale, 01:20.

${ }^{38}$ Templeton interview with Noseworthy, Hunter, and Griffin, 01:44.

${ }^{39}$ Since Templeton left Close- $U p$ in 1959, it must be assumed that he was functioning as a guest interviewer in this episode, as he often made guest appearances during this time on such programs as Tabloid and Court of Opinion.
} 
former Moderator of the Church of Scotland, in armchairs beside a cozy-looking

fireplace, he divulged that he thought the Church was in trouble because it was failing in

several key areas. Here, unusually, Templeton presented his thoughts explicitly, noting that one thing which particularly bothered him about the Church was that it simply did

not seem relevant to the lives of ordinary people:

The one thing that I notice - I was in the Church for many years as you know - in the Church I never realized how little impact the Church had upon the basic lives, the everyday lives, of people. Now that I'm no longer in the Church, what astonishes me is the gulf between the Church as an institution - the gospel in these [that?] talks to peoples' lives- and the way people feel about it [sic]. The general reaction I get is that people couldn't care less. $^{40}$

MacLeod responded at length, asserting that he agreed:

Yes. Well, I think we've got - two things occur to me about that. I'm more conscious of that than I was, I mean I've become increasingly conscious of what you've said. No doubt if I came out into a secular job I would have exactly the same experience as you have, and I find far more ministers in the church, both in this country and at home indistinguishable the atmosphere in both places I think - are aware of this increasing gulf. ${ }^{41}$

Significantly, Templeton used MacLeod's remark to illustrate his point, stressing a

breakdown of communication between the Church and the people:

I wonder now, can the church say, in terms without equivocation, certain things are true as far as your eternal destiny is concerned, or... isn't this the problem. That, even as I ask you that question - and your answer, while pertinent, was rather difficult to follow, if I may presume to say sothe guy in shirt sleeves drinking a bottle of beer by his television set watching "I Love Lucy", does he understand what you're saying, does he understand - not so much you, because you're pretty direct - but does he understand what the church is really trying to say? Can he cotton on to it, can he grasp it, can he respond? ${ }^{42}$

\footnotetext{
${ }^{40}$ Templeton interview with MacLeod, 01:11

${ }^{41}$ Ibid.

${ }^{42}$ Ibid.
} 
This dynamic conversation between Templeton and MacLeod demonstrates Templeton's increasing tendencies to vocalize criticisms of the Church - a practice which eventually became a defining characteristic of his public persona. This tendency manifested itself here as a complaint that the common people could not understand the message of the Church, or its application to their lives. Speaking for the "common man" was a lifelong practice for Templeton, dating back to his Christian years when he wrote and spoke "in layman's language" - in "language that is deliberately simple and nontheological" - to a "cross section of society. ${ }^{43} \mathrm{He}$ had always been sensitive about the importance of communicating messages in terms that the simplest of people could understand. In his religious literature, this meant writing clearly and imaginatively. With television, it manifested itself in his attempts to appear approachable (sitting intimately in front of the fire with MacLeod, like two ordinary men) and presenting himself as a sort of voice for the common man - the kind who liked to drink beer and watch "I Love Lucy," for instance. In this way, even though Templeton was using positive statements here rather than questions, his concerns regarding the church were still shaped in accordance with the cultural assumptions and expectations of the television medium, especially those concerning the intimacy of television, and the role of the newsman as the public's investigator of truth.

Templeton returned to the theme of the incomprehensible church message later in the interview:

I find it hard to know precisely what a person should do who isn't interested in becoming a Christian. Let me use a bad parallel. If a

\footnotetext{
${ }^{43}$ Charles Templeton, Evangelism for Tomorrow: A Vigorous Reappraisal of the Mission of the Church to Win the Commitment of Modern Man (New York: Harper \& Brothers Publishes, 1957), vii; Templeton, Life Looks $U p, 10$.
} 
relatively simple person wanted to find out what he needed to do to find faith, I think you could argue that Billy Graham - with whom I profoundly disagree - that Billy Graham would give an answer which is much more useful than would the thoughtful church of which you're a representative. Now, is it possible to communicate what you've been saying to me here, is it possible to communicate this and make it live? I don't think it is, and I think this is one of the reasons why the church isn't making an impact. ${ }^{44}$

Templeton's statements here are significant both for their content (his argument that the "thoughtful" Church was not resonating with the common man and that, in fact, it might be impossible for it to do so) and the context in which they were presented (his use of explicit statements rather than questions suggests a stronger, more confident approach to the subject). Here, Templeton exhibited a firm criticism against the Christian church, which, although not constituting a criticism of the religion as a whole, contributed to the larger picture of his antagonism against Christianity.

He voiced another such criticism in the same interview. Templeton and, he suggested, the population in general, were disturbed by the rampant divisions apparent throughout Christianity.

Templeton: There's one other thing which is troublesome, I think, to the average person, and I find it troublesome too. And that is that the church is saying, 'Come to us and we will do you good.' But the immediate question is "What church? Which church?" One says, "We are right;" all others are, "Come to us, come to us." People don't know who's right. The question is, who is right?

MacLeod responded by suggesting that the range of denominations was not necessarily a bad thing, that some denominations suited some people's unique preferences better than others.

\footnotetext{
${ }^{44}$ Templeton interview with MacLeod, 01:11.
} 
Templeton: But hasn't a person got a right to say, "If you can't agree among yourselves, why should I come along?"

MacLeod: You could say that if you like -

Templeton: - It is said, Dr. MacLeod -

MacLeod: Yes, yes... you've been the negative all through this talk and I've been the positive. You can put it that way, ok. I put it in another way. I will say, well, isn't it wonderful. ${ }^{45}$

Here both the content and the context of his criticism are significant, as he framed his presentations of unbelief in accordance with the cultural assumptions of the medium. With regard to content, he condemned the Church for its disunity, arguing that its conflicting perceptions of truth made it unattractive to people as a source of truth. He suggested that both he and the common people were troubled by this, effectively presenting another gulf between the Church and society. With regard to context, Templeton again used explicit statements, going so far as to forcefully interrupt his guest in mid-sentence to assert in no uncertain terms that this was a problem that could not be easily dismissed. Furthermore, he again positions himself as the representative of the public. In both of these ways he takes on the role of the "public hero of truth" and shapes his presentations of unbelief accordingly, constituting a clear performance of an "investigative" unbelief - one which, in this case, demonstrated outright antagonism towards religion.

Perhaps it was in his $W 5$ interviews of the late 1960s that Templeton presented his most overt oppositions toward the church. Again, while these examples did not constitute a reaction against faith in and of themselves, together they contributed to the larger overall impression of Templeton's antagonism towards Christianity on a variety of

\footnotetext{
${ }^{45}$ Templeton interview with MacLeod, 01:11.
} 
fronts. An interview with Charles Davis, a Roman Catholic theologian who had left the Catholic Church, is a good example of this opposition towards the Catholic church, in particular. Davis' very appearance on the show is significant, especially given that Templeton, the executive producer of the program, had undergone a very similar experience. Templeton structured his questions in a way that highlighted Davis' negative feelings toward the Catholic religion. "Is it fair to say," Templeton suggested, "that you have accused the Pope of being dishonest and being a liar?"46 Davis conceded that this was a fair statement. Templeton then moved the focus to the Catholic system in general. "Do you believe that the Pope is the prisoner of the system," he asked, "that he is unable, for instance, to do what he might feel is right, or what he might feel under the guidance of God is right, because of the system of which he is an integral part, if not the primary part?" ${ }^{, 47}$ It is important to note here that these were not open-ended questions Templeton was asking; rather, they were suggestions. The fact that Davis subsequently disagreed with Templeton's assertion (arguing that the Pope was not a prisoner of the system, he was power-hungry in his own right) reinforces the notion that Templeton had offered a real narrative - of Catholicism as an oppressive religious system - to be either accepted or rejected.

Templeton continued his implicitly hostile treatment of Catholicism throughout the interview, and one gets the impression that he saw much in common between himself and Davis. At one point he asked Davis why he was not opposing the religion. "If the church is as evil as you present it," he stated, "are you not duty-bound, in terms of

\footnotetext{
${ }^{46}$ Charles Templeton, television interview with Charles Davis on $W 5$ (Toronto: CTV, January 22, 1967), 00:09.

${ }^{47}$ Ibid.
} 
conviction, to fight something which does so much harm, in your judgment, to people?" Davis responded that rather than negatively oppose Catholicism, he preferred to address the problem by living his faith in a positive way, to show how much better faith could be apart from the structures of Catholicism. Templeton, however, was unconvinced. "But if it's actually the enemy of the people," he stated, "which is what you clearly say, isn't that an evasion of responsibility?" ${ }^{48}$ Davis repeated that no, he believed that positive action was a much more powerful force than negative action. Three things seem apparent here. First, Templeton was expressing an overt antagonism towards Catholic religion by clearly arguing that if Davis thought something was evil he should fight it, and that Catholicism was the evil Davis should be fighting. Second, he was framing this argument purely through a leading and persistent questioning style, implicitly emphasizing the individual responsibility to work for the public good, and once again tailoring his presentations of unbelief to suit the cultural requirements of the medium through which he was presenting. Third, Templeton seemed to be indirectly alluding to his own experiences with religion. He had been a Christian leader, he eventually found it unconvincing and hypocritical, and having abandoned the religion he was beginning to fight it and reveal its inconsistencies. $^{49}$

Templeton's most antagonistic treatment of Christianity, however, occurred two weeks later. The February 5, 1967 episode of $W 5$ began with Templeton standing with two other men in front of three black, closed coffins. The men were introduced as Rev.

\footnotetext{
${ }^{48}$ Ibid.

${ }^{49}$ Templeton's role as the opponent of religious evil was most greatly realized in his final work, Farewell to God: My Reasons for Rejecting the Christian Faith. In the "Author's Note" he revealed that his rationale for the book was to oppose the Christian Church for presuming "to speak in the name of God and to propound and advocate beliefs that are outdated, demonstrably untrue, and often, in their various manifestations, deleterious to individuals and to society," Charles Templeton, Farewell to God: My Reasons for Rejecting the Christian Faith (Toronto: McClelland \& Stewart Inc., 1996), vii.
} 
Ernest Harrison, an Anglican clergyman who had just been suspended due to his liberal views, and Rev. Paul Smith, a fundamentalist clergyman from the Pentecostal Assembly of Canada. "Mr. Harrison," Templeton began, "these three caskets we have here to symbolize what it seems, in some ways, you suggest: the death of God; the death of Jesus Christ, the founder of the Christian church; and the death of the Christian church. Are you saying that God is, in fact, dead?" ${ }^{50}$ The interview unfolded in a curious manner. Rev. Smith, the fundamentalist Christian, seemed to represent the Christianity that the liberal, Rev. Harrison, was proclaiming dead. Templeton moved through the topics of "God," "Jesus," and "Church," provoking discussion on how each of these pillars of Christianity were either dead or not. Significantly, Templeton presented two parallel narratives through the interview. The first was obvious - an investigation of the question of whether Christianity was or was not dead, as presented through the debate between the conservative and the liberal clergymen. They argued about various issues of Christianity, such as the problem of evil in the world, the difficulty in understanding God, and the divinity (or lack thereof) of Jesus. ${ }^{51}$

The second narrative Templeton established, however, was much more subtle. It consisted of a strong, implicit argument that Rev. Harrison was right - Christianity was dead. This was accomplished in several ways. First, Templeton's featuring of the three coffins of God, Jesus and Church was certainly not a neutral gesture; he constructed the stage as though God had already been declared dead. Second, Templeton asked generally open-ended questions to Harrison, inviting him to share his views, whereas his questions

\footnotetext{
${ }^{50}$ Television interview between Charles Templeton, Rev. Ernest Harrison and Rev. Paul Smith on $W 5$ (Toronto: CTV, February 5, 1967), 01:04.

${ }^{51}$ Ibid.
} 
to Smith were consistently posed as challenges. For instance, he focused on the notion of God destroying entire villages, including children. "[Rev. Harrison] talked about a God who hurts children," Templeton began, "and does other things of this nature. What about that God in your view, because you take the God of the Bible to be God?" Smith responded that he held to the Biblical account of God's rewarding of righteousness and punishment of sin. "Including children," Templeton stated. Smith responded that yes, he took those Biblical passages at face value. "You don't find this in any way repugnant or reprehensible?" Templeton asked. Smith replied that he didn't understand it, but he understood the principles of reward and punishment, to which Harrison commented incredulously that if that was God, he was worse than a human being. ${ }^{52}$

Later in the interview, Templeton brought up what seemed to him a problem in the system of grace and salvation.

Templeton: If Adolph Eichmann had repented on his deathbed, he would go to heaven. But the eight million Jews that Eichmann killed, who didn't accept Jesus, would go to hell. In other words, Eichmann on his deathbed, confessing his sins goes to heaven forever, eight million Jews, who perhaps never heard the preaching of the gospel (through the failure of Christians or whatever), and who did not make that acceptance, they go to an everlasting eternal hell much worse than any Gestapo arrangement.

Smith: $\quad$ Worse than the Bible describes I think.

Templeton laughed softly, and said, "Well." He paused for a moment before continuing.

Templeton: You find no difficulty with this.

Smith: I find this is the obvious teaching of the New Testament, and I accept the New Testament -

${ }^{52}$ Ibid. 
Templeton: - but it gives you no personal difficulty.

Smith: No, I don't have any difficulty with that. I think there has got to be judgment, there has got to be salvation, and where God judges somebody, although I may not be able to explain it and Charles Templeton may not be able to explain it, I believe God knows why he did what he did and there is a reason for it in the big view that I just don't see.

At this point Harrison expressed amazement that Smith was able to admit this, and stated that if this was Christianity then he truly believed it was dead. ${ }^{53}$

Clearly Templeton's incredulity in these interactions represented a challenging and marginalizing of Smith's views. However, his challenges and incredulity extended beyond Smith as an individual; his construction of the interview posed Smith as the representative of Biblical Christianity in general, and Harrison as the representative of thinking and caring people who were declaring this religion to be dead. Templeton, through his skeptical treatment of Smith, implicitly joined Harrison as a representative of the common people who would find ideas of harming children and good people in hell abhorrent. Ironically, although Smith was the better debater of the two clergymen, and although he proceeded to explain his case in very clear terms, this actually worked against him as Templeton - through his leading and incredulous questions - made him into an unwitting example of the kind of religion society now rejected. This, then, represents the culmination of Templeton's progressive antagonism towards Christianity, as well as the clearest possible example of how Templeton effectively shaped his presentations of unbelief through the context of the cultural values and requirements inherent to television - such as the role of the journalist as the public hero of truth and the inherent need to direct interviews through leading and provocative questions.

\footnotetext{
${ }^{53}$ Ibid.
} 
The final way in which Templeton performed an "investigative" unbelief through television was through his demonstration (implicitly, through questions) of an intellectual adherence to the same conservative binary approach to Christianity that had once informed his rejection of Christianity, and which now characterized and continued to define his unbelief. Specifically, this binary approach led Templeton to continue presenting Christianity in very narrow terms (often more narrow than the proponents of liberal Christianity defined it) - terms which ultimately preserved the central foundations of Templeton's ongoing rejection of unbelief, namely his difficulty with the divinity of Jesus.

These binaries were demonstrated throughout his interviews, as he constantly insisted on certain fundamental beliefs. For example, in attempting to determine whether Charles Davis, the theologian who had left Catholicism, was still a Christian, Templeton asked cavalierly if he still held to "the fundamental concepts of the Christian Church: that Jesus Christ is deity, let's say, the operation of the Holy Spirit in the world, and so on." More notably, Templeton's interview with Presbyterian George MacLeod could be called titled "Clash of the Mindsets," so obvious was the conflict between Templeton's blackand-white approach and MacLeod's broader and more liberal expressions of the "grey shades" of Christianity. Time and time again Templeton attempted to narrow MacLeod's statements to "yes or no" scenarios. For example, Templeton's upholding of faith in the divinity of Jesus as the litmus test of Christianity conflicted with MacLeod's broader approach. In a discussion on the universality of God, MacLeod sparked a debate by suggesting that God moved in Hinduism as he did in Christianity.

\footnotetext{
${ }^{54}$ Templeton interview with Davis, 00:09.
} 
MacLeod: $\quad$ There is one God who is the Lord of all... God is God in India as well... The point is, what are you going to do with that into which you have been born? It is quite true that the spirit of God moves in Hinduism, and it was the spirit of Christ that was in Gandhi, under the name of Hinduism.

Templeton: And yet he denies that.

MacLeod: Well he said that he wouldn't have minded being baptized a Christian if it weren't for all the parsons who were hanging about on their motorcarts on the edge of the Ashram waiting to be the people who said 'I baptized Gandhi.' This was more -

Templeton: Wasn't his objection, though, more serious than that, Dr. MacLeod? His objection really was that, as he said, "I made a study of the Christian faith," in response to Dr. E. Stanley Jones, who was a Methodist missionary evangelist, I suppose, who asked him to become a Christian, and he said, "I made the profoundest study of which I am capable," and he said, "I came to the point where I could not accept the deity of Christ, that Christ was in fact God. I took him to be one of the great men of all time, but I couldn't grant him more than that, therefore I couldn't become a Christian."

MacLeod asserted that Gandhi was nevertheless very interested in the teachings of Jesus, and pointed out that he often quoted the classic hymn, "When I Survey the Wondrous Cross."

Templeton: Are you saying that Gandhi was a Christian, then?"

MacLeod: I'm saying that Gandhi was tremendously inspired by the teaching of Christ. $^{55}$

The tension here between Templeton's binary "Christian or non-Christian" approach and MacLeod's broader definition of Christianity is clear. Templeton tried to pin down Gandhi's spirituality into one of two categories, while MacLeod resisted their categorical

${ }^{55}$ Templeton interview with MacLeod, 01:11. 
approach, emphasizing the importance of Gandhi's influences rather than his specific opinion on the divinity of Jesus.

Later, in a discussion on the specific nature of Jesus' divinity, Templeton expressed his binary mindset by equating acceptance of the truthfulness of the Bible with adherence to a literal interpretation of the Bible. Again, this approach conflicted with MacLeod's more liberal attitude:

Templeton: Let me put it as simply as I can. Did [Jesus] not have two human parents? In other words, do you accept the miracle of the virgin birth?

MacLeod: I am not held up or denying... I' $m$ not held up by the doctrine of the virgin birth... But certainly if some kind of proof came that there was not the virgin birth of Christ and that Joseph was the father of Jesus, it wouldn't make the slightest difference to my faith.

Templeton: I take it from what you say that you wouldn't take the Bible as necessarily true as it relates to the facts of Jesus. Do I misinterpret you?

MacLeod: Well you know, I come of salty blood, and whenever people begin talking about facts I find it a very difficult [thing to do]... I believe the truth of the Genesis story. I personally don't believe that there was once a garden in which there was the first man and the first woman. I personally don't believe that the Jews of our Lord's day ever thought in terms of a factual garden in which there was a man and a woman. I believe it's a superb story of truth and it doesn't matter to me whether it happened or whether it didn't happen. ${ }^{56}$

Once more, the differing approaches to religion clashed. For Templeton, to take the Bible as anything less than the literal word of God was to reject its veracity, whereas MacLeod stressed the distinction between "facts" and "truth." Interestingly, the tone of Templeton's conversation with MacLeod is reminiscent of the debate between the conservative and liberal clergymen, Rev Smith and Rev. Harrison. For an unbeliever,

\footnotetext{
${ }^{56}$ Ibid.
} 
Templeton often sounded very much like a conservative Christian. Furthermore, the doggedness with which Templeton attempted to ply these "yes-or-no" statements from MacLeod suggests again an adherence to the notion of the journalist as the public investigator of truth, relentlessly searching for answers understandable to the "common man."

Ultimately, these conservative, binary conditions preserved the terms of Templeton's unbelief. Convinced that the basis of Christianity was an acceptance of the divinity of Jesus, as read through a literal interpretation of the gospels, Templeton rejected Christianity on the basis that he believed Jesus was a mere man, like Gandhi. "Is there any essential difference between Christ and Gandhi?" he asked MacLeod during their conversation. "By that I mean this: both men - if I may presume to call them men, and I would call them men - both men made a contribution which is enormous, immeasurable. Why not... or what's the difference between the two in any essential way?"57 Here, Templeton did two significant things. First, he denied the divinity of Jesus, thus implicitly denying the truth of Christianity in general. Second, he likened Jesus to Gandhi; through his denial of Jesus' divinity, he effectively placed the two on the same level. Here, then, was the beginning of another trend for Templeton - his tendency to turn Jesus into Gandhi, presenting Jesus as a humanist revolutionary, worthy of being followed for his moral and ethical systems alone, as will be explored in the final chapter.

${ }^{57}$ Ibid. 
In conclusion, Templeton's performance of unbelief through the television medium embodied three distinct areas in which he presented his ongoing rejection of Christianity and his attempts to formulate a replacement interpretive system. First, he continually explored the nature of life and various sites of meaning outside the context of Christianity, demonstrating a continuing rejection of the Christian system of interpreting reality and an attempt to locate meaning and purpose elsewhere. Second, he demonstrated an increasing antagonism towards Christianity as the years progressed, eventually proclaiming its death in 1967. Third, he demonstrated an adherence to a very conservative, binary mindset, which steadily informed his continual rejection of a very narrow set of Christian beliefs. Furthermore, it was demonstrated that all of these various expressions of unbelief were framed in accordance with the specific cultural expectations, ideals and requirements of the television medium. Specifically, in Templeton's adoption of the prevalent notion of the "trustworthy journalist" of the public hero of truth and his conforming to the requirements of the interview process, he effectively performed an "investigative unbelief" - an unbelief rooted in an honest and questioning search for truth, on behalf of the general public and the "common man." While this chapter reflected, in the later years, an increasingly confident, confrontational form of unbelief, chapter three will demonstrate how Templeton, in his novels, took his unbelief to a whole new level of expression and articulation as he performed a distinctly "dramatic unbelief." 


\section{Chapter 3: Inside Novels}

"Jimmy Coulter - the thinking man's Billy Graham - has it all. Marriage to a former Miss America. A mansion in Malibu. Love offerings from adoring millions. And a heart that hides a dark secret and darker doubts.

Now as Jimmy launches a great new campaign for Christ, a ruthless newspaper magnate digs into the evangelist's past... and suddenly the charismatic Man of God finds his career - and his faith - facing a tragic, final Amen."

“A BLOCKBUSTER. THE MOST CONTROVERSIAL NOVEL OF THE YEAR."”

The previous chapter examined Charles Templeton's presentations of unbelief with regard to how he expressed a developing unbelief within the specific cultural framework of the "trustworthy journalist" and the expectations of the television medium in general, effectively demonstrating a questioning, "investigative" performance of unbelief. While this performance exhibited a clear and continuing rejection of Christianity, the manner in which he attempted to locate meaning beyond this religious system was very tenuous as he presented a "search" for meaning in rather ambiguous ideas of "happiness" and "success." In this chapter, both his ongoing rejection of Christianity and his attempts to locate meaning elsewhere take on a more definitive, almost sensational tone, as he performed a distinctly "dramatic" unbelief through his novels.

Between 1974 and 1988, Templeton wrote five novels, several of them pertaining directly to religious themes (such as Act of God, The Third Temptation, and World of One (1988)), with the other two (The Kidnapping of the President and The Queen's Secret

\footnotetext{
${ }^{1}$ Quote taken from the back cover of Charles Templeton, The Third Temptation (Toronto: McClelland \& Stewart Limited, 1980).

${ }^{2}$ Quote taken from the front cover of Charles Templeton, Act of God (Toronto: McClelland and Stewart Limited, 1977).
} 
(1986)) touching only indirectly on these issues through discussions on morality and meaning in life. Since the combined material in these novels could fuel the research of an entire thesis in themselves, certain limitations have been imposed in order to provide this chapter with a reasonable length and scope. As such, only the three earliest books will be examined here. ${ }^{3}$

The main argument of this chapter is that, as mentioned, through his novels he performs a distinctly "dramatized" unbelief. This performance is again a function of the interaction between the particular cultural assumptions, expectations and requirements of the medium and the specific nature of Templeton's unbelief. There are four ways in which Templeton expresses unbelief in his novels: through his presentation of meaning apart from God - especially in his treatment of morality, through his presentation of reason as the master and destroyer of faith, through his antagonistic depiction of religion and Christianity, and through his explicit portrayal of the unbelief experience itself, including various forms of doubt which contribute to this process. Templeton's interaction with the cultural assumptions and requirements of the novel form drastically affected the way in which unbelief is expressed. Moralities become personified in the form of characters; intellectual struggles become the driving force behind exciting plots;

\footnotetext{
${ }^{3}$ It seems reasonable to focus on the three earlier novels - as opposed to all of the books dealing directly with religion - for two main reasons. First, together they constitute a coherent chronological group of works written after Templeton's television work, but before he wrote his memoir in 1983. They were each written within three years of each other, with a gap of six years separating them from the final two books. Second, for whatever reason stemming from Templeton's personal life, all three of his early novels are propelled primarily by fierce moral, intellectual or religious struggles, as opposed to the final two novels, which seem to be based more on unlikely or exciting plot twists than on psychological or philosophical tensions. Even World of One, which seems to be obviously based on religious controversy (the World of One is a cult-like church run by an evil genius), only superficially concerns religion, as it rarely pays attention to the actual beliefs and nature of the religious group and centers instead on the interplay between the protagonist newspaper reporter and the evil mastermind who employs him. As such, two distinct groupings emerge within his novels, with the early novels seeming more relevant to a discussion on unbelief.
} 
implicit attitudes against religion become biting satire; ultimately, unbelief is turned into an exciting story, complete with protagonists, antagonists, plots, climaxes, and resolutions.

When Templeton resigned from CTV in 1969, he lost no time in finding other pursuits with which to occupy himself. Within the year, through his vast network of professional contacts, he had secured the position of Editor-in-Chief of Maclean's magazine, which had been struggling for some time to gain a clear sense of identity and purpose. ${ }^{4}$ Templeton led the magazine until the following year, at which time he resigned due to what he described as an "impasse" with the supervising vice president, R. A. MacEachern, who, Templeton complained, persistently interfered with his management of the magazine. ${ }^{5}$ Following this, Templeton instigated a radical career shift by dedicating two years of his life to the practice of full-time inventing. Beginning in 1970, he proceeded to design a variety of items, including a healthier filter for cigarettes, an improved child-proof lid for medication containers, and an overarching plan for transporting oil from northern Canada ${ }^{6}$ None of this proved lucrative, however, as after two years, having created the designs for twenty-seven inventions and spending sixteen thousand dollars from his own finances to develop them, he failed to sell any of them to companies in the broader market. ${ }^{7}$ While this poor financial return eventually discouraged him from devoting himself exclusively to the practice, he continued to tinker at various projects throughout the 1980 s, earning praise as late as 1987 for a teddy bear

\footnotetext{
${ }^{4}$ Charles Templeton, Charles Templeton: An Anecdotal Memoir (Toronto: McClelland and Stewart Limited, 1983), 255-256.

${ }^{5}$ Ibid., 260.

${ }^{6}$ Ibid., 282; Roy MacGregor, “Templeton's Progress” in The Canadian (July 16, 1977): 6.

${ }^{7}$ Templeton, Charles Templeton, 282.
} 
he had designed ("TeddyWarm") which could be heated to provide extra comfort to children in bed. ${ }^{8}$

Since 1966, Templeton had also been involved with his friend Pierre Berton in conducting a radio program entitled Dialogue. The premise of the program was simple: five days a week, Templeton and Berton would meet and "discuss the news in an opinionated way." This they did, both of them being "blessed," according to Templeton's wife, "with an imperturbable egotism."10 The public reaction was quite positive; the program endured until 1983, winning in 1978 the ACTRA award for Best Radio Program. ${ }^{11}$ Templeton and Berton addressed any and every sort of news item, from the censorship treatment of The Exorcist to the problems facing Christianity in Canada in the 1970s and 1980s. Templeton, in particular, seemed to use Dialogue as an opportunity to speak out and test his developing views on Christianity and religion in general, mentioning often that no subject intrigued him as much as religion, and arguing (sometimes intensely) with popular religious figures who appeared on the program, especially between the years 1973 and 1974. Seen in this light, Dialogue likely prepared the way for Templeton to explore matters of belief and unbelief in a more open manner, which he did through his early works of fiction, published subsequently in 1974 (The Kidnapping of the President), ${ }^{12} 1977$ (Act of God), and 1980 (The Third Temptation).

Before delving deeply into a discussion of how Templeton performed this "dramatic" unbelief in his novels, it may be useful to provide a description of each of the

\footnotetext{
${ }^{8}$ Beverley Slopen, "Templeton Bears It" in Quill \& Quire (March, 1987): 64.

${ }^{9}$ Templeton, Charles Templeton, 288.

${ }^{10}$ Madeleine Helen Leger, quoted in Templeton, Charles Templeton, 290.

${ }^{11}$ Templeton, Charles Templeton, 289.

${ }^{12}$ Charles Templeton, The Kidnapping of the President (New York: Avon Books, 1974).
} 
respective books. The Kidnapping of the President was originally intended to be a screenplay entitled The Hostage, but upon the advice of Pierre Berton's agent Templeton decided to write the story as a full-length novel. Aspiring to create "no more than a carefully crafted thriller," Templeton worked seven days a week for eighteen months, finally producing a novel based as heavily on moral difficulties and ethical struggles as on its inherently exciting plot. ${ }^{13}$ As might be assumed, The Kidnapping of the President was about an elaborate scheme of a Latin-American terrorist group to kidnap the president of the United States, Adam Scott, and to ransom him for millions of dollars. Meanwhile, Vice-President Ethan Roberts must lead the cabinet in deciding how to handle the situation - whether to give in to terrorist demands and save the president, or to stand for justice at the cost of Adam's life. Complicating the plot is Ethan's own, private moral struggle, in which he knew that saving Adam's life would effectively end his own political career due to a hidden political scandal the President had uncovered.

Act of God, Templeton's next novel, was based on an idea vocalized by Pierre Berton's mother: the notion of a young Jesuit priest becoming acquainted with an archeologist who, he finds, has discovered the bones of Jesus, leading him to kill the archeologist before the discovery could be made known. ${ }^{14}$ Templeton was enthralled by the idea and inflated the parameters of the book, turning the Jesuit priest into a cardinal favoured to become the next pope, and adding a love story and several political and intellectual layers to the plot. ${ }^{15}$ In the final version, the cardinal, Michael Maloney, is best friends with the archeologist, Harris Gordon. When Harris informs Michael of his

\footnotetext{
${ }^{13}$ Templeton, Charles Templeton, 322.

${ }^{14}$ Ibid., 328

${ }^{15}$ Ibid., 328.
} 
groundbreaking discovery, Michael is thrown into an intense moral struggle over whether to allow Harris' discovery to be published, or whether to protect his parishioners by effectively ending Harris' life. Again, the story had a twist. Michael's sweet and vulnerable niece, Jennifer, adored Harris, whom she considered an adoptive "uncle." Moreover, Jennifer is engaged to a detective, Copeland, whose relentless search for the truth regarding Harris' murder ultimately tears the family apart.

These two books became instant blockbusters, making the top ten lists in Canada and the United States, and garnering international attention. ${ }^{16}$ However, while the masses supported the books with heavy and consistent sales, the reviewers were less enthusiastic. "The end is too obvious to be particularly interesting," wrote one reviewer of The Kidnapping of the President. "17 "Act of God," wrote another, "is neither interesting nor original." ${ }^{, 18}$ Stung by the particularly biting reviews of the Canadian journals, Templeton set out to write a novel that would demonstrate his true strength as an author, "not merely to tell a story and in the doing to cast light on human experience, but to enable me to say, 'So there!"”19 As the subject for his work Templeton chose a topic with which he had much experience - mass evangelism. The book, he contended, "needed to be written but hadn't been." The best effort, he suggested, was Sinclair Lewis' Elmer Gantry, a satirical work about a man who, realizing the potential for easy power, wealth and status to be found in evangelism, conducts a fraudulent ministry, reaping the pleasures of the world at the expense of those around him. Templeton found this to be an inadequate presentation

\footnotetext{
${ }^{16}$ Act of God was translated into several languages and the rights for Kidnapping the President to be internationally translated were sold as well (Templeton, Charles Templeton, 322-329).

${ }^{17}$ Untitled review in Library Journal 100, 9 (May 1, 1975): 886.

${ }^{18}$ Untitled review in Library Journal 103, 7 (April 1, 1978): 780.

${ }^{19}$ Templeton, Charles Templeton, 338.
} 
of the experience of mass evangelism. "For all of Lewis' extraordinarily detailed research and despite his undoubted skills," he wrote, "Elmer Gantry is essentially about a scoundrel who happens to be an evangelist. He could as easily have been a politician or a salesman. The smell and feel of the fundamentalist faith Lewis describes is convincing only to the uninitiated."20

Templeton's answer to this problem was The Third Temptation, a largely autobiographical novel that featured an earnest evangelist gradually losing his faith, presented with the knowledge and finesse of an insider. Jimmy Coulter represented a version of Templeton - a sort of autobiographical "what if" - seemingly representing the person Templeton could have been had he not opted to leave the ministry when he felt his faith slipping away from him. Indeed, the similarities between the two are remarkable: they shared much the same physical appearance, the same childhood experiences, the same mother and father figures, the same conversion experiences, and eventually, the same struggles with doubt. Coulter even preached the same sermons - word for word - as Templeton himself had preached twenty years earlier, and both of their churches had burned down in the middle of their ministries. ${ }^{21}$ Like Templeton, Jimmy's modest beginnings in fundamentalist evangelism quickly vaulted him to international stardom as an icon of Christianity similar to Billy Graham. However, while Templeton left Christianity when he lost his faith, Jimmy opted to continue in the ministry, opting for the "kingdoms and the glory" of the celebrity life rather than the pursuit of honesty that characterized Templeton's experiences. As a result, Jimmy increasingly became a hypocrite and a fraud, and was eventually publically condemned as the truth was revealed

\footnotetext{
${ }^{20}$ Ibid., 338.

${ }^{21}$ See Templeton, The Third Temptation, 12, 55, 57-58, 163, 165.
} 
about his lack of faith and an ongoing affair. Ironically, this book pleased the reviewers, but failed to gain momentum among the broader public. ${ }^{22}$

The cultural assumptions and requirements of - and the general role played by the medium of the novel is also quite important for understanding the cultural context in which he situated his presentations of unbelief in this venue. First, it should be noted that, as Robert Fulford has asserted, "storytelling is an attempt to deal with and at least partly contain the terrifyingly haphazard quality of life." ${ }^{, 23}$ Indeed, it seems significant that more than fifteen years after Templeton had officially left the faith, his novels (especially $A c t$ of God and The Third Temptation) persistently addressed issues of faith and doubt, of the complex relationship between God and man. In this way, the very existence and subject matter of Templeton's early novels represented a demonstration of an unbelief in progress, an attempt to "work out" his continuing rejection of Christianity and his efforts to locate meaning elsewhere - in effect, an attempt to "contain" his ongoing unbelief in various contexts. ${ }^{24}$ These "containing" efforts, in turn, heavily influenced the assumed

\footnotetext{
${ }^{22}$ Templeton, Charles Templeton, 338-339.

${ }^{23}$ Robert Fulford, The Triumph of Narrative: Storytelling in the Age of Mass Culture (Toronto: House of Anansi Press, 1999), 14.

${ }^{24}$ This impression of the novels as an effort to "contain" and explore his own unbelief is further reinforced by Templeton's personal connections to the characters and events of the books. Often, Templeton inserted seemingly biographical elements into his descriptions of the characters and their experiences. For example, the interplay between Michael Maloney, the protagonist of Act of God and Dr. Harris Gordon, his archaeologist friend and sometimes antagonist, is highly suggestive of a dramatization of Templeton's own struggles with faith and doubt. Michael shared an identical experience with Templeton in having been enthralled by the person of Jesus after reading a copy of Goodspeed's translation of the New Testament as a child (see Templeton, Act of God, 27). Similar to Templeton, his largely binary faith was dependent upon assurance of Jesus' divinity, and the challenges posed by Harris and his scientific arguments echoed in many ways the doubts that plagued Templeton through the 1940s and 50s. So personal was the association between Templeton and the story of The Third Temptation that he suffered from a breakdown after a long struggle to complete the story. "I was dealing with subject matter close to me," he recalled in his memoir, "and thrashed about in the material for eighteen months, taking a dozen wrong directions. Three days after completing the final draft, I came apart, collapsing one morning on the living-room floor. There followed time in bed under sedation, and it was not until the end of the summer that I was entirely myself again," (see Templeton, Charles Templeton, 338).
} 
nature and character of his novels, leading the stories to be driven as much by their moral and religious struggles as by their exciting plot twists.

Another foundational element of the cultural context of the novel is the inherent power struggle it entails between the author and the reader. According to literary theorist Robert Detweiler, a central aspect of fictional writing is the continual attempts of the author to "deceive" the reader by keeping secret important elements of the plot until the time of the author's choosing. "The author," writes Detweiler, "delays the reader's enlightenment, plays with and manipulates the reader and in that manner 'plots' against him in order to keep him in his narrating power." 25 This power struggle plays a central role in the negotiations between the cultural medium and Templeton's unbelief as it represents the particular conditions or "rules" in which the various presentations of unbelief must operate. The nature of the medium (the novel) requires that the expression of unbelief - and, indeed, any other expression - participate in this "manipulation" and "deception" of the reader in order to keep the reader under the author's "narrating power." In the case of Templeton's novels, this process of deception and manipulation meant the creation of tension and excitement, the development of convincing and relatable characters, the use of embellishment and exaggeration, the addressing of potent and sensitive topics, frequent references to popular culture and sentiment, a healthy dose of scandal and controversy, and climactic endings that ensured the reader's continued attention and exhilaration. Templeton's framing of unbelief in adherence to these values constituted a performance of a distinctly "dramatic" unbelief.

\footnotetext{
${ }^{25}$ Robert Detweiler, Breaking the Fall: Religious Readings of Contemporary Fiction (Louisville, Kentucky: Westminster John Knox Press, 1996), 9.
} 
Templeton's novels certainly reflect an effort to tailor his writings to the form of this narrative power struggle. Presumably the result of an effort to keep the reader "hooked," the books exhibit several trends that contribute to Templeton's narrative power over the reader. The first of these is the intriguing and dramatic nature of the plots. Conspiracies and capers abound in Templeton's novels. From the exciting scheme to kidnap the president to the tension-filled plot of a Catholic cardinal to murder his best friend, it is difficult to imagine how Templeton could have made his stories any more exciting. Furthermore, each of these plotlines is fuelled by overarching moral, intellectual or religious tensions which have dire consequences. The profound faith struggle of Jimmy Coulter in The Third Temptation is an example of this - the results of his spiritual and moral difficulties ultimately drive the scandal that eventually destroys him. The inherently powerful nature of each of his protagonists - the president and vice-president of the United States, a cardinal (and prospective pope) of the Roman Catholic Church, and a religious cultural icon-also contributes to the epic nature of these plotlines, and as such, to Templeton's narrative power.

Second, Templeton's efforts to make his novels relatable to his audience represent another act of accommodating the inherent narrative power struggle of the novel. He does this mainly through his creation of compelling characters that serve to personalize the conflict. For example, by describing the childhood and youth struggles of Michael, Templeton brings a powerful Catholic cardinal down to earth, allowing the audience to sympathize with him. Likewise, in detailing the perilous development of Jimmy Coulter, describing his innocent efforts to please both God and man, Templeton establishes a bond between the reader and the character, making the characters' subsequent moral and 
religious struggles that much more compelling. In this way, these conflicts become personal matters, leading the reader to become emotionally invested in their outcomes. This personalizing of the conflict also occurs through Templeton's invoking of several prevalent concerns and controversies of the 1960s and 70s, thereby framing the events of the novels in terms that would resonate with the readers. For example, he taps into the ongoing sexual revolution of the $60 \mathrm{~s}$ and $70 \mathrm{~s}$ with the frequent, and often explicit, sexual encounters he presents through his works. He demonstrates sensitivity to several other widespread cultural concerns of the time as well, such as the growing outcry against religious structures of authority (especially the institutional Catholic church and the morality assumptions of evangelical Christianity), the ongoing threats posed by modern sciences (especially psychology and archeology) to traditional faith, and the rise of feminism. In each of these ways, Templeton's writings reveal a sensitivity to the cultural atmosphere of the time, which further bridges the gap between the author and his reader and enables the author to "keep him in his narrating power."

As mentioned previously, it is Templeton's shaping of his unbelief expressions in accordance with these cultural concerns and the inherent narrative struggle of the novel that constitutes his performance of a "dramatic" unbelief. Here, it is worth noting again that this positing of sites of meaning as presentations of unbelief rests on the assertion that unbelief is a relative phenomenon. That is to say, the establishing of morality as meaningful and purposeful could not be considered a presentation of unbelief to an individual who had not undergone such a significant transition from one interpretive system to another. As was demonstrated in chapter two, Templeton's television presentations of happiness and success embodied the beginnings of a search to locate a 
replacement system through which to interpret value and significance. Templeton's treatment of morality in his novels, then, demonstrates a subtle continuation of these efforts to locate an alternate framework through which to ground these ideals.

Furthermore, as he had begun to consciously describe himself as an "agnostic," it seems likely that this was the replacement system reflected in his writings, although he never used the term in his novels. ${ }^{26}$

Templeton's implicit establishment of morality as a site of meaning outside of Christianity is found throughout his novels. For example, moral integrity is continually celebrated, especially through his main protagonists. A quick examination of each of these characters reveals that they are all extraordinarily decent people, prone to sacrifice their own well-being for the sake of honesty and the benefit of others. For example, Ethan effectively ruins himself by acting according to his conscience and saving the president. ${ }^{27}$ Michael refuses a ten million dollar donation because to accept would mean building a statue of the donor, thus compromising his Catholic principles. ${ }^{28}$ Jimmy Coulter works hard to provide for his family, consistently delivering his pay envelope to his mother unopened - missing, as a result, several chances to go out with his friends and co-workers. ${ }^{29}$ While some of these situations - such as Michael's moral temptations take place within the technical context of a religious story with overarching religious values, the overall importance with which Templeton imbues the notion of moral integrity through these characters is not rooted in any religious or faith foundation. Rather, its importance (and the reader's subsequent respect for the protagonist) seems

\footnotetext{
${ }^{26}$ Templeton, Charles Templeton, 337.

${ }^{27}$ Templeton, The Kidnapping of the President, 235,

${ }^{28}$ Templeton, Act of God, 46.

${ }^{29}$ Templeton, The Third Temptation, 113.
} 
assumed. Each of the characters' determination to stick to his moral beliefs (religious or not) is presented as being inherently noble and good.

Templeton also presents morality as a site of meaning in the various moral struggles he establishes between his characters. This is especially found in The Kidnapping of the President and Act of God. As much as these books are stories about kidnapping and conspiracy, they are also - perhaps more so - stories of conflicting moralities. For instance, upon the abduction of the president, the Cabinet undergoes a series of debates over what the proper moral response is to the predicament. The central thrust of the plot becomes less centered on how to heroically rescue the president and more on which morality will eventually prevail, with the Cabinet deadlocked between those adamant on refusing to negotiate with terrorists and those adamant on saving the president's life at all cost. Similarly, while Act of God is largely a story of faith and science as Harris prepares to dismantle Christianity with his discovery of the bones of Jesus, it is also grounded in an intense moral debate over the respective merits of protecting loved ones versus the pursuit of truth. Each of these moral conflicts provides the central tension and thrust of their respective novels, with their outcomes dramatically influencing the resolution (or lack thereof) of the stories.

Templeton's presentation of these moralities largely adheres to the form of a narrative power struggle with the audience (and in this way, reflects his performance of a "dramatic" unbelief). This is especially found in his personification of various moral ideals in the forms of his chacters. In this way, President Adam Scott, along with several members of the Cabinet, comes to embody the notion of rigid and unforgiving justice. When it becomes known that Vice-President Ethan has been implicated in illegal 
activities, Adam demands his resignation, despite his knowledge that Ethan had been only unwittingly involved.$^{30}$ Likewise, the Attorney General views Adam's kidnapping as a legal matter ("extortion"), comparable to the global problem of injustice and extortion caused by Hitler. "The civilized world," he asserts, "found itself faced with the unpleasant necessity of saying, 'Thus far and no further,' even though to do so meant war and the suffering of the innocent." As a result, he and several other members of the Cabinet vote to refuse the kidnappers' ransom, demonstrating the notion that justice is the highest form of good. Vice-President Ethan, on the other hand (again with several Cabinet ministers), seems to represent the extension of mercy. Henrietta Cown, the Postmaster General, states this position well. "The only thing that matters here is Adam's safety," she declared. "Not because he's the President but because he's a human being. There is no principle, no amount of money, no anything important enough to justify putting him in danger." Ethan, despite his enduring principles regarding the importance of standing up to injustice, eventually ratifies this position by choosing to pay the ransom, implicitly defining goodness according to the treatment of the individual life rather than the upholding of legal principles. ${ }^{31}$

Alternately, in Act of God, Cardinal Michael clearly embodies the ideal of the protection or sheltering of the weak. He is consistently presented as a "shepherd," his flock being all those who fit under his umbrella of influence, from the millions of devout Catholic believers in America to his fragile niece residing in his home. ${ }^{32}$ When he realizes that his archeologist friend Harris has uncovered a secret (the supposed bones of

\footnotetext{
${ }^{30}$ Templeton, The Kidnapping of the President, 191-192.

${ }^{31}$ Ibid., 166, 236.

${ }^{32}$ Templeton, Act of God, 125.
} 
Jesus) that could devastate the faith of the poor widows and orphans he had been comforting and cause irreparable harm to the Church he represented, Michael resolves to take action to shield them from this discovery. "It suddenly came clear," Templeton narrates, "Harris' 'truth' must never be uttered. Jesus' words echoed in his brain: 'He who is... not a shepherd, whose own the sheep are not, sees the wolf coming and leaves the sheep and flees; and the wolf snatches them and scatters them. ${ }^{33}$ His subsequent murder of Harris thus signifies his belief of the protection of the innocent and weak as being more intrinsically valuable than truth, honesty or the individual life. Copeland, on the other hand, represents the pursuit of truth at all costs, even when the pursuit is painful to all involved. The doggedness with which he investigated the truth regarding Michael's deception and Harris' death leads Jennifer to compare him to Inspector Javert, claiming “your job is becoming you. You've stopped being a man who works as a detective and you've become a detective. ${ }^{~} 34$ Eventually, the value he assigns to the pursuit of truth inevitably alienates him from his loved ones, driving Jennifer into a deep depression. ${ }^{35}$ Templeton's framing of these moral struggles in the form of his characters' actions and personalities effectively reinforces the narrative power of the author by presenting abstract morality in relatable terms. Thus, as the reader follows the story of one of the characters like Michael, he or she sees the struggle and circumstances of Michael's efforts to determine the best course of action and realizes that his decision to kill Harris is motivated by genuine love for others. The result, if it is not a sympathy for the actions of

\footnotetext{
${ }^{33}$ Ibid., 125.

${ }^{34}$ Ibid., 304-305. The reference is to Inspector Javert from Les Misérables, whose relentless pursuit of Jean Valjean ultimately leads to his own destruction.

${ }^{35}$ Ibid., 316.
} 
the characters, is at least an understanding of them, and of why they were important to the characters at the time.

Templeton further frames his presentations of morality according to the inherent narrative power struggle of the novel by turning these moral struggles into something exciting and epic, using them as the very force that drove his novels towards their inevitable climaxes. As previously mentioned, while The Kidnapping of the President is superficially a story of an elaborate crime, as the story progresses the overarching question becomes less "how will they rescue the president," and more "will, or will not, the Cabinet decide to pay the ransom?" Templeton intensifies the moral tension between the proponents of justice and mercy by creating a deadlock situation in the Cabinet, with an equal amount of ministers voting for and against the notion of paying the ransom. This forces the choice upon Ethan, who, in a moment of cumulative tension, forsakes his previous moral and political stance against negotiating with terrorists - not to mention his own dreams for the presidency - by voting to pay the ransom. "Suddenly," writes Templeton, "overarching every other consideration - even those affecting his own future - was the realization that if he voted against the motion and the President died, he would move into the White House past the mangled and bloody body of Adam Scott. And that he could not do. ${ }^{, 36}$ Here, the climax of the book - the culmination of its excitement and tension - lay not in a dramatic rescue of the President, but in the decision of a character to opt for one moral system instead of another.

Similarly, while Michael's murdering of Harris was indeed a point of high excitement in Act of God, the real thrust of the book lies in the gradual increase of tension

\footnotetext{
${ }^{36}$ Templeton, The Kidnapping of the President, 236.
} 
as the story moves towards some sort of unavoidable final confrontation between Michael and Copeland - fueled by the fundamental incompatibility between their respective moral systems. Surprisingly, this expected encounter never takes place. Instead, the climax of the story occurs when Jennifer stumbles across a forceful letter written from Copeland to Michael which reveals both the deceptions and crimes of Michael and the depth of the obsession and single-mindedness with which Copeland had pursued him. While Templeton does not explain the significance of the letter, it seems to essentially represent the cumulative tension that had grown between the two men as a result of their conflicting moralities. Whatever its meaning, its effect on Jennifer was clear. Crushed by truths revealed about both of her loved ones, she drowns herself in a nearby river. Templeton finishes the story with a subdued encounter between Copeland and Michael, in which Copeland reveals the letter that had driven Jennifer to suicide. "'I killed her, he said softly, and then turned to look at Michael for the first time since entering the car.

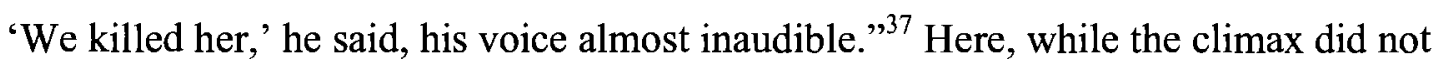
consisted of the victory of one moral system over another, it was nevertheless propelled by the tension and antagonism caused by conflicting moral ideologies - the lack of resolution between the two extremes ultimately resulting in the destruction of the innocent party, Jennifer.

It is difficult to identify any overriding "moral" or message in these novels. Even in the case of The Kidnapping of the President, there was no real judgment over which moral system was inherently better. Rather, like the more dramatic case in Act of God, Templeton leaves the tension between the moralities largely unresolved, with both Adam

\footnotetext{
${ }^{37}$ Templeton, Act of God, 363.
} 
and Ethan unsure of whether Ethan's choosing of mercy over justice was "an act of weakness or of strength. ${ }^{38}$ While it is difficult to understand what Templeton meant in his framing of these moral conflicts, it seems likely that the tension and lack of resolution within his various presentations of morality reflect a continuing effort to search for meaning and purpose apart from God. Which system of morality is best? How should one live? What is goodness? These are the implicit questions posed by Templeton's perpetually unresolved conflicts, and within the context of his life, they represent a continuing rejection of the Christian interpretive system, and an ongoing effort to locate answers elsewhere. Furthermore, it should be noted that the tension between these moral systems was fuelled precisely by their functions as sites of inherent meaning for each of the protagonists, ultimately driving them to selfless choices, extreme actions, or obsessive pursuits. To these characters, then, these moralities were literally life-or-death matters. In other words, these conflicting moralities represented several ways in which Templeton's characters found inherent meaning and purpose in simply doing what they believed to be good - usually outside the context of religion or faith (with the exception of Michael, whose morality was linked to his faith but was nevertheless inherently meaningful in and of itself). Whether presented in the lives of his characters or in the implicit questions posed by the utter lack of resolution, Templeton's treatment of morality reflected his ongoing locating of meaning outside of God, framed within the context of a narrative power struggle.

Another way in which Templeton expressed unbelief throughout his novels is in his consistent (if implicit) presentation and treatment of a rationalist epistemology - a

\footnotetext{
${ }^{38}$ Templeton, The Kidnapping of the President, 276.
} 
system of thought premised on the positioning of reason, and rational understanding, as the highest form of knowledge and the most valid approach to interpreting truth. ${ }^{39}$ This is another trend that was seen in Templeton's television performances, albeit in a much less aggressive form. While this philosophy might not in itself represent an expression of unbelief, Templeton's particular appropriation of the device in his novels enabled him simultaneously to create a dichotomy between faith and reason, and to render faith subservient to reason, establishing it as the lower form of knowledge.

This trend pervades every aspect of these books. For example, the personalities and actions of Templeton's characters often emphasize the power of reason and rational science: many of Templeton's protagonists are "much given to introspection," often evaluating their circumstances through the lens of psychology, and Cardinal Michael, in counseling Jennifer regarding her ongoing fears, delivers a two-page lecture on the psychological phenomenon of guilt repression. ${ }^{40}$ This near-worship of reason is presented perhaps most clearly in the dialogue Templeton creates between characters. One chapter in Act of God finds Michael, Copeland and Jennifer listening in rapt attention to Harris the archaeologist as he expounds on Jewish history, Roman culture, and the science of archeology. Templeton portrays the listeners as being enthralled with Harris' knowledge through several snippets of conversation. "There was wonder in Jennifer's voice," Templeton writes. "Tell us the rest. There is more?"” Encouraged, Harris explains the

\footnotetext{
${ }^{39}$ In Templeton's novels, this rationalism is largely equated or associated with an elevation of science, such as psychology or archeology, or modern philosophies - anything which had a largely logical basis, as opposed to, for example, the trust basis that characterized conservative Christianity and its reliance on the Bible.

${ }^{40}$ Templeton, The Kidnapping of the President, 124; Templeton Act of God, 36, 270-271.
} 
rational process by which the identity of a skeleton was deduced. "'Fascinating,' breathed Jennifer."41

Several moments of reflection by Templeton's protagonists serve to reaffirm this positive presentation of reason and place it within relationship to faith and belief. "How willful the mind," pondered Michael one evening as he struggled with his faith upon viewing the bones purported to be Jesus'. "How futile to command it. You can't say, 'Go to now; I will not permit myself, even for a moment, to believe that these are the bones of my Lord.' No, the mind is unruly as a globule of mercury: elusive, running where it will, contrary. $" 42$ Here, the mind is presented as an autonomous force, untamable, in this instance, by the forces or causes of belief. A tenuous link is drawn between the mind and faith, and faith cannot bend the mind to its will. Later in the novel, Michael reflects, "Perhaps striving to understand was itself sin. Perhaps he should simply trust. But surely not, for the commandment is in part: 'You must love the Lord your God with all your mind...' If one is commanded to love with the mind then the failure to think must surely be $\sin .{ }^{, 43}$ Here again the mind is placed in relationship with faith, this time pitted against the notion of a "trust" in an either-or fashion. Templeton presents no middle ground between the two, and ultimately establishes the mind as the better foundation for faith.

As with Templeton's treatment of morality, his presentation of reason also works within the context of the novel form. Again, Templeton uses personification in order to make certain ideas or characteristics more compelling - in this case, reason, science and the love of knowledge are represented and expressed in the characters of Harris and Mr.

\footnotetext{
${ }^{41}$ Templeton, Act of God, 105-106, 112.

${ }^{42}$ Ibid., 172.

${ }^{43}$ Ibid., 365 .
} 
Rimmington, from Act of God and The Third Temptation, respectively. Harris seems to represent the voice of science. A brilliant and celebrated archeologist, Harris is the definition of a rationalist, claiming the scientific process as the most valid way to obtain knowledge. A particularly intense argument with Michael reveals his worldview:

We're in different disciplines, and we approach things differently. Religion's based on a set of fixed beliefs, many of them centuries old. The church's duty is to keep them from being sullied and to hand them intact from generation to generation. New ideas are heresies and they're rejected and opposed. Well, we don't see things that way. Science is based on the thesis that beliefs are theory and that our task is systematically to try to eliminate the false theories. We believe that every theory should be challenged, every idea subjected to critical examination. Not to do so is to perpetuate ignorance. ${ }^{44}$

Here again is the established dichotomy between science and religion, between the critical examination of ideas and the perpetuation of ignorance.

The Third Temptation's Mr. Rimmington is slightly different, not representing any science or philosophy in particular, but rather embodying the very love of knowledge itself. Jimmy's meeting of Mr. Rimmington is presented as a symbolic affair, the entering into a new, exciting realm, of which Jimmy had never imagined. ““Enter, lad,' [Mr.

Rimmington] said with a deep bow, indicating the dark interior with a grand sweep of his hand. 'The world awaits within." ${ }^{45} \mathrm{He}$ continued extravagantly: "We'll talk about life and death, love and hate, sex and lust, copulation and mitosis, the earth and the stars, the exquisite beauty and utter indifference of nature; about the engineering in a snail's shell, the aerodynamics of a gull's wing, the superlative design of a shark, the artistry of a wood duck's plumage..." ${ }^{, 46}$ Mr. Rimmington continued to teach Jimmy a great many

\footnotetext{
${ }^{44}$ Ibid., 153.

45 Templeton, The Third Temptation, 63.

${ }^{46}$ Ibid., 64.
} 
things, such as the importance of critically testing all knowledge, and refusing to believe everything "just because it's in print." ${ }^{47}$ The dichotomy between rationality and faith is not so explicit here, but Templeton still establishes it by simultaneously presenting Mr. Rimmington as an anti-religious figure, even as he represents a love of learning and knowledge. ${ }^{48}$ Furthermore, as with Templeton's personalizing of his various moral systems through the persons of Adam, Ethan, Michael and Copeland, Templeton's embodying of the rationalist sentiment within the developing stories of these characters complete with their respective struggles and moments of happiness - brings the intellectual philosophy to the readers' level, grounding a potentially abstract principle in personal story that increases its application and effectiveness, thereby contributing again to his "narrative power" over his audience.

Templeton's treatment of reason further conforms to his trend of expressing unbelief within the context of a narrative power struggle through his use of conflict and tension to establish the dominance of reason over faith. In two distinct locations of conflict within these novels - one ongoing and the other, a single episode - he simultaneously creates a gulf between faith and reason and proceeds to dismantle faith with reason. The first of these encounters is found in the long history of conflict and debate between Michael and Harris, the figures of faith and science respectively. Through several debates in the first half of Act of God, Michael and Harris argue constantly over the validity of each of their claims to truth - each, significantly, operating within the rationalist framework, basing each of their arguments upon appeals to reason. Michael,

\footnotetext{
${ }^{47}$ Ibid., 86.

${ }^{48}$ As will be explored later in this chapter, Mr. Rimmington often railed against the notion of God on the basis of the prevalent suffering in the world. Templeton, The Third Temptation, 75.
} 
for example, found Harris' scientific analysis of the bones he had found to be threatening precisely because it spoke to the weakness Michael had identified in his own rationalist faith. "There was a disturbing credibility to the entire account," he reflected. "The stories of the resurrection in the Gospels and in the Acts of the Apostles had long troubled scholars. There were contradictions in the texts, apparent interpolations, sections that seemed not to jibe, others that yielded evidence of having been added by other authors. ${ }^{, 50}$ Templeton proceeds to list a variety of intellectual weaknesses of the Christian faith, which subsequently launches Michael into an intense struggle with his faith, which will be discussed in more detail later in the chapter. The point here, however, is that Michael found Harris' rational arguments threatening because they challenged the intellectual foundations of Michael's own faith. Conversely, during the times when Michael enjoyed periods of strong faith, it was not because he was able to place his trust in the Biblical account of the resurrection, but because he found the truth of Harris' intellectual arguments to be "highly unlikely." 51

Working within this rationalist mindset, Michael sets out to intellectually combat Harris, to disprove Harris' claims that the bones were Jesus'. "Perhaps he could dissuade him by argument," Michael reflected, "disarm him by challenge, force him back to his data until the error of his conclusions was revealed." ${ }^{52}$ At this point, Templeton launched the two men into a sort of recurring intellectual duel, with each man trying to lay claim to

\footnotetext{
${ }^{49}$ Christians - especially conservatives - have long held that the proof of Christianity lies in the physical resurrection of Jesus. The words of the apostle Paul have been especially influential in this trend: "And if Christ has not been raised, your faith is futile; you are still in your sins. Then those also who have fallen asleep in Christ are lost. If only for this life we have hope in Christ, we are to be pitied more than all men" (1 Corinthians 15:17-19, NIV). In this way, the discovery of the bones of Jesus would represent, to many Christians, proof that their faith was in vain.

${ }^{50}$ Templeton, Act of God, 65.

${ }^{51}$ Ibid., 163.

${ }^{52}$ Ibid., 78.
} 
reason in order to disprove the other, and with Michael, significantly, being forced to try much harder to prove his claim than Harris, whose claim to reason seems largely assumed. During one debate, Harris offered to show Michael the bones, which Michael quickly declined.

Harris was silent for a moment. "You really don't believe they're Jesus bones, do you?"

"To be blunt - no."

Harris' voice was quiet, reasonable. "But Mike, they are."

There was some impatience in Michael's response. "Harris, you'll forgive me, but you don't know that for sure. The bones you found depend for their authentication on the manuscript you found, and I know enough about antiquities of that sort to know how often they are forged... Why have you taken no steps to authenticate the dating?"

"Michael," Harris said patiently, "you must realize what would happen if word got out of what I've discovered. We'd be besieged."

"I realize that. But you wouldn't have to specify precisely what it is you're seeking to authenticate. Why, for instance, haven't you submitted the material to the carbon-14 dating process?"

"Because it's impractical and because it's unnecessary."

Harris proceeds to effortlessly disarm Michael's arguments, explaining (patiently) that the carbon dating process would destroy a large portion of the document, and that there already existed overwhelming evidence of the authenticity of the manuscript anyway, based on the composition of the materials and the unique circumstances that associated it with the obvious authenticity of the skeleton. In the end, Michael admits, "I can't argue it with you, Harris. I get out of my depth," eventually changing the subject. ${ }^{54}$

In another, more intense, debate, the men continue their intellectual sparring, each again trying to claim reason for their own ends.

\footnotetext{
53 Ibid., 120-121.

${ }^{54}$ Ibid., 122.
} 
"Harris, old friend," Michael said evenly, "you really are given to leaps of presumption. A veritable rhetorical mountain goat. One hopes that the evidence on which you base your conclusions as an archeologist is less tenuous than that from which you've just proceeded."

"Mike, let's not get into a discussion on basing one's conclusions on evidence. The church bases its claims mostly on the teachings of an obscure young Jew with messianic pretentions who, let's face it, didn't make much of an impression in his lifetime. There isn't a single word about him in secular history. Not a word. No mention of him by the Romans. Not so much as a reference by Josephus, who damned well mentioned everything else!"

"But why do you specify secular history? What about the gospels and the rest of the New Testament? Surely as an archeologist you know that their validity as historical documents is beyond question. We know more about Jesus than we do about Plato." 55

This particular conversation carried on for some time, with both men growing so angry that their shouting wakes up Mrs. Pritchard, the housekeeper, who expresses her irritation at the commotion. In both of these discussions - regarding the authentication of knowledge and the validity of historical sources, Templeton presents both men as clearly grappling for the intellectual high ground, using reason simultaneously to establish their own positions and to dismantle the arguments of the other.

These conversations clearly demonstrate the prevalent rationalist philosophy that characterizes these characters, as well as an effort to make intellectual struggles exciting, in accordance with the demands of the cultural medium. However, Templeton takes this dramatic presentation of rationalism even further, turning it into an expression of unbelief by ultimately creating a gulf between faith and reason - implicitly positioning science as the true bearer of reason. This trend is found in the way in which Michael struggles to reconcile faith and reason while Harris is presented as cool, collected, and simply more

${ }^{55}$ Ibid., 152. 
successful at rallying reason to his cause. Harris' "quiet, reasonable" assertion, "But Mike, they are [the bones of Jesus]" seems to represent Templeton's own implicit judgment of the veracity of science over faith - science simply is more rational than faith. Later, when Michael was struggling with his faith, the very thought of Harris filled Michael with angst:

Always, no sooner did he shore up his convictions and reinforce his faith, than he was confronted by Harris. Damn Harris! Harris with his quiet confidence, Harris with his imperturbable certainty: not the excessive assertiveness of the man who compensates for his insecurity with adamancy, but the uncontentious assurance that is the more unnerving for its absence of stridency. ${ }^{56}$

The science figure is presented as more naturally rational than the faith figure, who must struggle to reconcile his religion with his intellectual philosophy.

This attitude is carried into several victories Templeton arranges of science, or a science figure, over faith and its representative, in which he consistently aligns science with rationality instead of faith. In the climactic moment of the first half of the novel, Michael decides to go to Harris' workshop while he is away, in order to gauge the threat of Harris' discovery. The subsequent encounter seems largely symbolic of a battle between faith and science as two systems of knowledge, in which the science is presented as winning a decisive victory. "Trembling," Michael entered the room. Templeton's description is significant:

To his right he saw a table on which there were a three-turret microscope, a Polaroid camera, an assortment of bottles, some flat pans, a Bunsen burner, a variety of sculptor's tools, some camel's hair brushes and a pad of notepaper covered with neat jottings. Beyond, in the near darkness, he could just make out two longer tables, three dish-shaped floodlights on

\footnotetext{
${ }^{56}$ Ibid., 166.
} 
stands, and a chair. An acrid smell flared his nostrils... The only sound was the sustained whirr of the dehumidifier. ${ }^{57}$

Templeton's descriptive language here seems quite deliberate - he is presenting, through the various tools, the tangible expression of science. Moreover, he presents it in a stale, almost antiseptic fashion, as though to portray the tools of science as instruments of pure, unadulterated truth, the physical forms of rationality. Then Michael approaches the bones - the ultimate expression of scientific and rational evidence:

He had been trembling and now began to shake. His skull constricted and his brain dissolved behind his eyes. He was smothering and couldn't draw a breath and was certain he was dying. He grasped the table with both hands, striving to stay erect. The muscles of his legs went slack and he pitched forward and slumped to the floor...",58

Templeton's presentation of the collapse and "dying" of the faith figure in the presence of the bones - the tangible evidence of science - strongly suggests a symbolic victory of science over faith. This is especially true in the context of Michael, who, on the basis of his intellectual faith system had previously been convinced of the bones' illegitimacy, but who upon experiencing the rational instruments and evidence of science - the tools and the physical bones - was, temporarily but devastatingly, convinced. These passages thus serve as a presentation of the final alignment of rationality with science instead of faith, and the subsequent domination of science over faith.

The second encounter in which Templeton uses a dramatic presentation of rationalism to express unbelief is found in a largely autobiographical passage in The Third Temptation. Although this book was written three years before his autobiography, Templeton's description of Jimmy's experience in the library of an elderly parson (as do

\footnotetext{
${ }^{57}$ Ibid., 167.

${ }^{58}$ Ibid., 168.
} 
many of the situations and events of the book) mirror his own experiences as portrayed in his 1983 memoir. ${ }^{59}$ The situation posits Jimmy staying in the parsonage with the "short, slat-thin," "bald and cavern-eyed" minister while conducting an evangelistic campaign in Cherry Valley, Michigan. ${ }^{60}$ Poor weather kept Jimmy indoors for the entire week, and to pass time he read from the minister's extensive library, particularly books such as Paine's The Age of Reason, Voltaire's The Bible Explained at Last, Russell's Why I Am Not a Christian, and Ingersoll's The Mistakes of Moses. The effects of these books on Jimmy were identical to those on Templeton as he expressed later on: "He was shattered. Nothing had prepared him for the thrust of their logic or the persuasiveness of their arguments." ${ }^{61}$ Templeton continues to discuss several of Jimmy’s previous doubts, revealing that his faith, similar to that of Michael, had been at least superficially predicated on a foundation of rationalism:

Jesus' cursing of the barren fig tree couldn't be fact - the vindictiveness was out of character. Gideon couldn't have caused the sun to stand still even Jimmy's rudimentary knowledge of cosmology recognized that as patently impossible. The feeding of the 5,000 undoubtedly had some less miraculous explanation. ${ }^{62}$

From this passage it is clear that Jimmy's faith - like Michael's - had previously relied on rational coherence for validation. In other words, if a Biblical event or situation did not seem rationally plausible, it must have been a falsehood, or at least an exaggeration "by overzealous followers." ${ }^{63}$ Thus, when the books of philosophers such as Paine, Voltaire, Russell and Ingersoll posed focused, rational challenges to Jimmy's

\footnotetext{
${ }^{59}$ See Templeton, Charles Templeton, 41. Several of the phrases in Templeton's memoir regarding Templeton's doubts in the library are identical to those describing Jimmy Coulter's experiences in The Third Temptation.

${ }^{60}$ Templeton, The Third Temptation, 168.

${ }^{61}$ Ibid.

${ }^{62}$ Ibid.

${ }^{63}$ Ibid.
} 
religious belief system, his faith was largely dismantled then and there: "The words of Thomas Paine!" Templeton exclaims. "Jimmy was defenseless before that precise mind. Bertrand Russell's unornamented arguments left him disarmed. They struck to the heart of the matter." ${ }^{\prime 64}$ Jimmy, having based his faith on reason, now found that this very foundation to be the agent of his faith's destruction. He continued to struggle desperately with his faith for a week, before he found temporary relief in a "proof" of God, the changed life of Jesus' disciples after the resurrection ${ }^{65}$ Once again, this encounter represents the rationalism that is prevalent throughout Templeton's works, and, in this case, the explicit expression of unbelief as Templeton subdues faith with reason. Even during the peaks of Jimmy's convictions, Templeton portrays reason as the master over faith; in the valleys, the master becomes the destroyer. Moreover, this encounter represents yet another way in which Templeton expresses unbelief within the cultural context of the novel. The sheer tension, conflict and excitement with which he establishes the "death" of faith at the hands of reason is largely indicative of the ongoing power struggle between the Templeton and the reader as the he continually attempts to keep his audience within his narrative influence. Furthermore, the doubt that arises due to this triumph of reason over faith becomes one of the biggest sources of tension in the novel (as will be discussed later) as Jimmy becomes less and less a believer and more and more a hypocrite waiting to be exposed.

A further means by which Templeton performed a dramatized unbelief in his novels is through his treatment of religion and Christianity, once again framed within the cultural assumptions and expectations of the novel. Hugh Hoffman, the powerful news

\footnotetext{
${ }^{64}$ Ibid.

${ }^{65}$ Ibid., 169.
} 
magnate of The Third Temptation, seems to personify the anti-religious sentiment. Simply put, Hoffman represents hatred of all things religious, especially Christian evangelists. Reflecting on his own oppressive childhood in a small Amish community, he is angered at the thought of the evangelists who passed through. "Those black-haired, black-browed bullies," he recalled, "thundering their denunciations, venting their own frustrations in the name of God." ${ }^{\prime 66}$ Templeton seemed to use Hoffman in The Third Temptation to establish a proper counterbalance to the sincere love for God expressed by Jimmy before he lost his faith. Hoffman's own attitude is so consumed by hatred for God and religion that it becomes the defining characteristic in his relationship with Jimmy. "Was it a sin to hate the Bible?" Hoffman reflected, "filled as it was with foreign experiences that had to be committed to memory... A sin to hate God? - to be so enraged by him at times that you were prepared to risk the lightning bolt, standing in an open field railing against the heavens?"67 As the story progresses, Hoffman becomes Jimmy's chief human adversary - arguably playing slightly less an antagonistic role than the doubt that plagues Jimmy throughout the story - investigating Jimmy's every secret and eventually exposing him as a fraud, effectively destroying his life.

Aside from Templeton's use of personification, he demonstrates antagonism against religion and God through the satirical narrative style he adopts. While he portrays a sort of naive nobility in the faith of Michael and Jimmy (in his early years), they are framed as the exceptions within a largely materialistic, power-hungry, opportunistic, socially damaging and - to put it simply - ridiculous religious culture. For instance, Templeton continually emphasizes the artificial and opportunistic of Christianity. This is

\footnotetext{
${ }^{66}$ Ibid., 20.

${ }^{67}$ Ibid., 21.
} 
found throughout his novels, and the general effect is the portrayal of religion as something that is ultimately contrived and fake. The most notable example is likely found in Templeton's portrayal of Rev. Leo McGeer, the very epitome of artificial religion. Functioning as Jimmy's unofficial mentor, McGeer instructed Jimmy in how to speak and read scripture in such a way as to evoke an emotional reaction from the audience.

"Sit there," he said to Jimmy, pointing to the front pew. McGeer placed his hands on the pulpit and for a moment stood motionless except for the blinking of his eyes. Then his voice rang out, strong, passionate, controlled, the sound of it resonating:

"For God so loved the world, that he gave his only begotten son his only begotten son - that whosoever believeth in him should not perish, but..." his voice fell away to a whisper filled with awe, "but have everlasting life! ",68

Later, Templeton describes how McGeer used his manipulative skills to try to lure Jimmy's sister Kathleen to the faith. After one particularly moving song ("Tell Mother I'll Be There"), McGeer, "sensing her vulnerability as a jungle cat might a wounded animal, came from the platform to her pew... put his handsome, perspiring face next to hers, and whispered, 'Do this for your mother's sake, dear one. And for your father's... your Father in heaven." ${ }^{, 69}$ These encounters, and several others like them, effectively contribute to the impression that religion is largely fake, opportunistic and hypocritical; as Jimmy reflects at the end of the book, his religious work had turned him into a "clever, clear-eyed, unselfish, ingratiating mannequin."70

Templeton also makes much of the blunders, insensitivities and eccentricities of Christian leaders and laypeople. The examples range from serious topics to comical incidences, but the general impression created is that Christians are at best untactful, and

\footnotetext{
${ }^{68}$ Ibid., 137.

${ }^{69}$ Ibid., 119.

${ }^{70}$ Ibid., 271.
} 
at worst, simply crazy. During one morose passage in Act of God in which Templeton reveals the circumstances of the deaths of Jennifer's parents, he lightens the moment with a darkly comedic description of the minister officiating the funeral. The man repeatedly confused the name of Jennifer's mother, Templeton wrote, and "maundered on oleaginously and interminably." Thankfully, the rain at the cemetery "did have the advantage of abbreviating the reverend doctor's remarks." "71 Perhaps Templeton's most overt mocking of the eccentricities of religion is found in The Third Temptation in his portrayal of an evangelical service during the sharing of personal faith stories:

With the randomness of jets leaping in a geyser pool, men and women got to their feet to give halting or set-piece witness to what God was doing in their lives... A Brother Pike arose. In the voice of a drayman he launched into his testimony. He was a converted drunk. With the freshness of the great actor in a long-run play, he told his story, ending with a leap into the air and the words, "Once I was pickled but now, thank God, I'm preserved!"72

While Templeton's commentary on the amusing elements of Christianity is rarely meanspirited, it does present the religion as something difficult to take seriously. Moreover, it remains consistent with the other branches of his presented antagonism against religion in its reliance on the cultural mechanisms of the novel - most notably his use of personification and satire, both of which served to make the issues more palatable to the reader and thus, keep him or her within Templeton's narrating power.

The final way in which Templeton expressed unbelief through his novels is in his explicit presentation of the unbelief experience itself. For the first time, rather than merely presenting unbelief in indirect ways, in his novels he actually addresses unbelief directly and deeply, describing, especially in the case of The Third Temptation, specific

${ }^{71}$ Templeton, Act of God, 143.

${ }^{72}$ Templeton, The Third Temptation, 134. 
encounters of individuals struggling with and losing their faith due to a variety of social and intellectual doubts. In this way, he drew upon a traditional cultural fixation that had been prevalent since the beginning of the century, the traditional "loss of faith" narrative. This narrative represented a whole genre of literature between the years of 1880 and 1920, and effectively embodied the exact framework through which Templeton expressed Jimmy's (and his own) unbelief experience. According to the Literary History of Canada, these works were characterized by "the dissolution of traditional beliefs, the intellectual problems that result from the impact on traditional religion of science and "Higher Criticism" and the growth of skepticism and agnosticism... The chief problems are the inspiration of the Bible, the presence of pain and evil in the universe, and the divinity of Christ." ${ }^{, 73}$

Once again, Templeton uses personification to make this process relatable and compelling. In particular, Jimmy Coulter's entire character is based on the slow transition between innocence and cynicism, between faith and unbelief. This is evident as early as the first page of The Third Temptation, when Templeton symbolically introduces Jimmy, who, while walking on spring day, "felt the sun on his shoulders, knew its promise to be a lie, and recalled those years when he too had permitted hope to discount experience, convincing himself that winter had been routed." ${ }^{, 74}$ In the following pages it becomes clear that Jimmy is reflecting on more than just the weather.

Furthermore, as previously mentioned, Jimmy's character development seems to be fuelled by Templeton's own life experiences. Aside from sharing the same

\footnotetext{
${ }^{73}$ Carl F. Klinck (ed.), Literary History of Canada: Canadian Literature in English (Toronto: University of Toronto Press, 1973), 305-306.

${ }^{74}$ Templeton, The Third Temptation, 11.
} 
background and general life circumstances, Jimmy's transition from a steadfast, genuine faith to a haunting, hidden unbelief mirrored Templeton's own experiences (as expressed in his memoir) before he officially left the faith in 1957. The two shared the same dramatic conversion experience, accepting forgiveness for sins after a night at a sleazy strip club. ${ }^{75}$ Both of their faith journeys were generally positive and confident until devastating encounters in the libraries of reclusive ministers, during which doubt is introduced through the works of rationalist secular philosophers. ${ }^{76}$ For both of them, these doubts ultimately brought about such a schism between their public persona and their actual faith that the stress of their inner tensions caused them to feel physical pains in their arms and chest. ${ }^{77}$ In many of these incidences the wording is identical in the novel and the memoir, which was published three years later. The fundamental difference between Jimmy and Templeton was that while the former persisted in the ministry, participating in a sort of perpetual hypocrisy as Templeton portrayed it, Templeton himself ultimately escaped this hypocrisy by abandoning Christianity.

In light of Templeton's own experiences, Jimmy Coulter is presented as a sort of autobiographical "what if" for Templeton, representing what might have become of himself had he succumbed to the temptations of fame and wealth at the expense of honesty and integrity. As revealed in his memoir, he seems to draw from a combination of his own experiences and Sinclair Lewis' Elmer Gantry to fashion a convincing story about an evangelist who slowly becomes a fraud. ${ }^{78}$ In this way, Templeton not only expresses unbelief through the context of the personification and excitement inherent to

\footnotetext{
${ }^{75}$ Ibid., 128; Templeton, Charles Templeton, 34.

${ }^{76}$ Templeton, The Third Temptation, 168; Templeton, Memoir, 41-42.

${ }_{78}^{77}$ Templeton, The Third Temptation, 34; Templeton, Memoir, 87.

${ }^{78}$ Templeton, Charles Templeton, 338.
} 
the novel form, he actually transforms his own unbelief experiences into an exciting and palatable story, with the faith struggles effectively providing the plot's tension - much as the moral and intellectual tensions propelled The Kidnapping of the President and Act of God, respectively - as well as the climax and resolution (or lack thereof).

The consistent antagonist of The Third Temptation is not ultimately Hugh Hoffman so much as doubt itself. Moreover, Templeton continued to frame these battles with doubt in accordance with the narrative power struggle that so defined the medium. The first of these dramatic doubt experiences is perhaps the most obvious - doubt of an intellectual nature persistently ravaged Jimmy's faith, much as it had challenged Michael in Act of God. This was mostly clearly demonstrated in Jimmy's aforementioned experience in the library, where his largely rationalist faith was "shattered" by the works of various secular philosophers. ${ }^{79}$ While Templeton does not elaborate regarding the specific nature of the intellectual problem that plagued Jimmy, it is clear that the difficulty posed to him was some sort of rationalistic undercutting of his faith, an effectual subjugation of his faith by the forces of reason. "Nothing," Templeton wrote (to recycle a quote), "had prepared him for the thrust of their logic or the persuasiveness of their arguments." ${ }^{, 80}$ After a week of deep depression, an intellectual "proof" of the truth of the Bible lifted him out of his stupor and he was able, once again, to pray. ${ }^{81}$ Nevertheless, from this moment on, Jimmy's faith was characterized more by struggle than peaceful

\footnotetext{
${ }^{79}$ Templeton, The Third Temptation, 168.

${ }^{80}$ Ibid.

81 Ibid., 170. Templeton describes this "proof" in terms of the changed lives of the disciples after Jesus' resurrection. In his memoir he describes this recovery process as less a moment of illumination and more a conscious act of commitment. Templeton, Charles Templeton, 42.
} 
relationship, and his feelings of hypocrisy increased from this moment on due to his projection of a strong faith despite his ongoing doubts.

The second doubt experience Templeton presents resembles more of a sociallyoriented doubt, rooted in a strong anxiety of the prevalence of suffering and death in the world. This form of doubt had roots in Jimmy's life back to his childhood, when his tutor, Mr. Rimmington, had railed against the idea of God due to the suffering that seemed to define life on earth. "To be the omniscient God!" Mr. Rimmington had once exclaimed, in what continued to be a long rant.

To be aware of all suffering - every horror, every brutality. To see the sparrow fall, yes, but also to see the antelope eaten alive by jackals, the caribou smothering in mosquitoes. To see the baby encephalitic, the tenyear-old being gang-raped, a thousand bodies putrefying in a plague, an entire town destroyed by an earthquake, twenty million dead from the flu! ...How could it be borne? ...If the universe unfolds at such a price, can it be worth it? ...And don't tell me, as Jesus said, that suffering is so that God may be glorified. What monstrous evil is the divine ego if it so needs to be glorified? ${ }^{82}$

Later on, after Jimmy had become a Christian, this same sense of the injustice of the world haunted him, standing as evidence against the idea of a loving God. This doubt reached its culmination in an event shared by both Jimmy and Templeton himself. During one campaign in Minden, Louisiana, while preaching on "God's Perfect Love," a tornado touched down, razing the African Methodist church across the street and killing, in the process, eight attendees and the pastor (who had been in the midst of a sermon), and injuring fifty more. This incident troubled Jimmy for weeks, causing him to wake often in the middle of the night, heart pounding. "Why them?" Templeton reflected in Jimmy's voice. "Why especially them - the poor and discriminated against. And why during

${ }^{82}$ Templeton, The Third Temptation, 75-76. 
worship?" ${ }^{83}$ This particular faith struggle continued to plague Jimmy through his life, resurfacing again during a relief visit to the survivors of a flash flood in Italy. Seeing the hundreds of dead, "heaped in a tangle of bodies, twisted and pinioned by each other and by uprooted trees and boulders," Jimmy felt like a hypocrite again as he realized that while the other religious figures were able to provide hope in the form of their faith convictions, he himself had nothing to offer. ${ }^{84}$

Templeton's last presentation of the doubt Jimmy encountered was foreign to Templeton's own experience, because it constituted the main difference between Jimmy's life and Templeton's own. The most enigmatic example, Templeton presents a doubt that is based on disobedience - the succumbing to what he calls the "third temptation." This, Jimmy explains at the end of the book to his secret lover, Arla Todd, is the last temptation Jesus faced in the desert, in which Satan promised to give Jesus all the kingdoms and the glory if he would but bow down to him. ${ }^{85}$ Here Templeton establishes a puzzling doubt dynamic - whether to accept the world and lose one's faith, or to be willing to give up the world and retain faith. He establishes this in two distinct passages. The first hints at the faith troubles Jimmy would later experience as the result of settling for "the kingdoms and glory." As the media had initially begun to support Jimmy and launched him into international fame, he found himself spending more and more time fostering his image and empire and less time with God. "Tense and near exhaustion,"

\footnotetext{
${ }^{83}$ Ibid., 193.

${ }^{84}$ Ibid., 221.

${ }^{85}$ Ibid., 258.
} 
Templeton explained, "he pushed his devotions to the end of the day, often performing them while preoccupied; and he began to fear that he was losing touch with God."86

This doubt dynamic is later developed in Jimmy's retreat to Caithness, on the Isle of Wight, to which he escaped after his traumatic experience with the flood survivors in Italy. Here, Jimmy later told Arla, he struggled with idea of whether or not to leave the ministry, and, as he suggested in a remarkable passage, his decision to keep the prestige and power that accompanied his persona resulted in his further loss of faith.

"That's what the struggle was about on the Isle of Wight - was I willing to give up everything?" His voice had fallen so low it was almost inaudible. "I'm afraid I settled for the kingdoms and the glory... From that time on... gradually, imperceptibly, my faith slipped away. I found it harder to believe. Now, I don't even pray."

[Arla] studied him, her face troubled. "Are you telling me that you don't believe in God anymore?"

'I'm sorry. But what could I do? I couldn't quit.' His voice was infinitely weary. 'I'm afraid I don't have it in me to be a saint, to turn my back on the world..., 87

The primary theme in this final portrayal of doubt is disobedience. Templeton positions Jimmy's doubt and unbelief in his failure to give up "the kingdoms and the glory." The reasoning behind this assertion seems bizarre - it effectively suggests that if Jimmy had obeyed God, he might still be able to believe in him - and the terms of this particular spiritual struggle regarding obedience to God are subtly interwoven with the terms of his moral struggle regarding hypocrisy and honesty. However, regardless of the logic behind this presentation of doubt - which seems likely to have contributed to the breakdown Templeton experienced as he attempted to finish the novel - it is clear that here

\footnotetext{
${ }^{86}$ Ibid., 210

${ }^{87}$ Ibid., 258.
} 
Templeton has presented a form of doubt that was based on one's relationship with, and obedience to, God.

Templeton closes this dramatized presentation of the unbelief experience on a low note. Jimmy's climatic decision on the Isle of Wight to gain the world at the cost of his soul ultimately turns him into a hypocrite who enjoys the benefits that accompany his religious station, but who does not believe the message he preaches. Templeton resolves the situation by exposing Jimmy for the fraud he has become: the press eventually gains access to a letter Jimmy has written to his estranged son, in which he reveals that he no longer accepts the Bible as the true Word of God or Jesus Christ as the Son of God, and furthermore, that the suffering in the universe makes it "impossible to conceive of God either as a Father or as a God of love." ${ }^{, 88}$ The letter is subsequently published in the city newspaper where Jimmy is about to begin his biggest campaign. The reaction is tremendous and violent: Jimmy is effectively destroyed as the entire religious crowd, along with his family, turns on him, reducing everything he has worked for over the years to ruins. ${ }^{89}$ Significantly, Templeton does not present unbelief itself as the reason for Jimmy's downfall; rather, in congruence with his own life, he presents unbelief as merely forcing Jimmy to a watershed decision. It is Jimmy's decision to stay in the ministry despite his unbelief (in effect, his hypocrisy, a favorite target of Templeton's) that leads to his destruction - and, as will be discussed in the next chapter, justifies Templeton's own life choices.

In conclusion, it is clear that Templeton, in his interplay between the cultural expectations and assumptions of the medium of the novel and his various expressions of

\footnotetext{
${ }^{88}$ Ibid., 261, 131.

${ }^{89}$ Ibid., 285.
} 
unbelief, gave rise to a distinctly "dramatic" performance of unbelief, made compelling and palatable to the masses as Templeton endeavored to keep them within his "narrative power." This is the presentation of the various competing moralities - personified in the forms of four of his main protagonists, which suggests the possibility of finding ultimate meaning apart from God. Secondly, the rationalism Templeton presented throughout his novels formed another central tension that helped make his stories exciting, and was once again personified in Templeton's characters. Within this context, Templeton effectively subdued faith with reason, positioning reason as the master and destroyer of faith. In addition, Templeton presented a heavy-handed antagonism against Christianity in the form of satirical commentary, thus mocking religion and brutally emphasizing its problems. Finally, Templeton explicitly presented the entire unbelief experience in the form of a story - associating himself with the main character - and presenting several forms of doubt which battered the weathered believer. The reciprocal influence between the novel form and Templeton's expressions of unbelief are clear; unbelief became dramatized, even while it formed the foundation and the momentum which enable to stories to function. In this next chapter, an examination of Templeton's autobiography will demonstrate a very different performance of his increasingly mature unbelief, expressed through the prevalent narrative of "nobility" in which he frames his presentation of self. 


\section{Chapter 4: Inside Autobiography}

I was discovering that I could no longer accept many of the fundamental tenets of the Christian faith. I had been converted as an incredibly green youth of nineteen. I had only a grade-nine education and hadn't the intellectual equipment to challenge the concepts advanced by my friends and mentors... In the beginning, I accepted the beliefs of the people around me, but I read widely in every spare minute: on planes and trains and in bed. Slowly - against my will-for I could perceive the jeopardy-my mind began to challenge and rebut the things I believed. ${ }^{\prime}$

"I understand you're an atheist," she said.

I explained that, no, I wasn't an atheist but an agnostic, a very different thing. I really didn't want to get into it; we had only seven minutes and I wanted to promote the book. I'd come five hundred miles to do that.

"But you don't believe in God," she said, her face mirroring distaste.

"Nor do I disbelieve," I said. "I just don't know."

"But you were a preacher."

"Yes I was."

"Well then, let me ask you this: are you happy? How can you be?"

She was doing her twenty-four-karat-earnest bit, looking deeply into my eyes. I looked back into hers for a moment, irritated, tempted to say, "You silly girl - what in God's name has believing in God got to do with being happy?" I restrained myself and said the same thing in a more judicious way. ${ }^{2}$

In 1983, as a sort of intermission in the midst of writing his novels, Charles Templeton presented his life story in the form of his book, Charles Templeton: An Anecdotal Memoir. This effort constituted the last performance of unbelief to be discussed in this thesis - a final enacting of a mature unbelief along the cultural confines of a specific medium, autobiography. Within this performance, Templeton continued his multifaceted

\footnotetext{
${ }^{1}$ Charles Templeton, Charles Templeton: An Anecdotal Memoir (Toronto: McClelland and Stewart Limited, 1983), 67.

${ }^{2}$ Templeton's description of an interview with Jane Pauley on the Today show, regarding his new book, Act of God. Templeton, Charles Templeton, 337.
} 
presentation of unbelief, expressing both continuing rejections of Christianity along narrow, binary terms, and new, positive forms of unbelief that reflected of an attempt to ground sites of meaning and purpose within an alternate interpretive framework identified, for the first time, as "agnosticism." Moreover, as in his other performances, he continued to express these tenets of unbelief in accordance with the specific qualities of the cultural medium. In this case, the medium was dominated by a particular autobiographical narrative structure which, for various reasons to be discussed later on, emphasized Templeton's life as being characterized by nobility - by the honesty he pursued in his own life and with others, by the responsible way in which he conducted himself at all times, and by his almost heroic efforts to pursue what he believed to be good, even at great disadvantage to himself. As he framed his various expressions of unbelief within the context of this narrative, a distinctly "noble" form of unbelief emerged, in which both his conservative rejection of Christianity and his situating of meaning in agnosticism were presented as being ultimately rooted in an honest pursuit of truth, in an effort to be responsible and decent, and in an effort to contribute to the world in a positive way.

Likely due to this interaction between Templeton's presentations of unbelief and the cultural form through which he was expressing them, his performance of unbelief in this chapter is conspicuously devoid of any sort of negative presentation of Christianity, unlike his television and novel performances in which he belittled, if not mocked, Christianity. Rather, in his efforts to seem imminently respectable he treats Christianity accordingly, presenting much sympathy and attachment to his Christian years, even while asserting that his sense of honesty and truthfulness compelled him to ultimately depart 
from the religion. Instead of that negative treatment of Christianity, however, Templeton seems to compensate through his portrayal of a staunch rationalist subjugation of faith by reason that effectively dominates the entire unbelief performance, overshadowing even the alternate forms of morality that so informed his previous presentations of unbelief. It seems fitting that rationalism would play so great a part in Templeton's presentation of self, for he presented it as the most honest possible means of perceiving truth and reality. However, this is not to say that morality, and other sites of meaning apart from religion, had no part to play. On the contrary, in his autobiography Templeton finally brings his presentation of morality home, implicitly establishing himself as the ultimate example of integrity, honesty and goodness. Through autobiography, he defines himself foremost as a communicator, in accordance with a narrative of nobility and concern for the greater good of society, outside of any purpose or meaning associated with God.

Charles Templeton: An Anecdotal Memoir is a unique autobiography. Indeed, in his introduction Templeton attempted to distance the work from the autobiographical genre, stating, "this is an anecdotal memoir rather than an autobiography. Judging them to be of limited interest, I have not written about my psychic struggles or intimate relationships.", Elsewhere, he stated that "this book is less about me than about what happened to me." ${ }^{4}$ Despite these assertions, however, it is clear that while Templeton may have attempted to avoid discussing his various "psychic struggles," he was not wholly able to avoid them, and although he certainly wrote much about what happened to him, he revealed much about himself in the process. Regardless of his intentions,

\footnotetext{
${ }^{3}$ Templeton, Charles Templeton, foreword.

${ }^{4}$ Ibid., 15.
} 
Templeton's memoir was very much a deliberate representation of his self, a structuring of his life according to specific narratives and within a specific organizational structure.

However, his efforts at shaping the format of the book are still quite evident in the character and tone of the autobiography. First of all, his is a distinctly anecdotal autobiography - the grand arch of Templeton's life story is composed of hundreds of shorter stories, many of which are quite exciting or amusing. Second, the story is told largely through dialogue, which lends a warm, conversational quality to the work. Finally, as Templeton admits in the foreword, the work is not rigidly accurate - it was mostly reconstructed from experiences from which Templeton was several years, if not decades, removed. He could not remember the exact words spoken in each of the conversations, he confesses, although he remembered the general sense of the conversations. "If my recollection is at any point inaccurate," he reassures the audience, "it is a result of the tenuousness of memory and not for want of a desire to present things as they happened."

These three qualities - the anecdotal quality, the use of dialogue, and the fact that Templeton was reproducing most of this from memory - contribute to the notion that this autobiography, like the rest of his various media and communicative presentations, was itself a performance. It was as much an enactment of cultural narratives and a particular presentation of self as it was an objective history of an individual. These observations, in turn, point to the need for an examination of the nature of the autobiographical genre, in order to understand the specific cultural framework that was so influential in shaping Templeton's presentations of unbelief in this medium.

\footnotetext{
${ }^{5}$ Ibid., foreword.
} 
First of all, what is autobiography? Anthropologists L.L. Langness and Geyla Frank treat autobiography as an agent of self-definition. "Autobiographies are reports by individuals about their own lives," they state, proceeding to argue that the authors of autobiographies "typically narrate those events that went into making them unique persons." In this light, autobiography is presented as a means of defining oneself - of establishing the unique and essential "personhood" that constitutes one's self to the exclusion of all others and creating a story, or narrative, that provides a structure within which one's various life experiences conspire to bring about the realization of this presented self. Literary theorist Paul John Eakin contributes to this characterization of autobiography by asserting that the "unique personhood" presented by the author is fundamentally constructed. He suggests that the very usage of the first person - "the 'I,' autobiography's dominant key" - implies a constructed coherence among the many competing and often contradictory selves that constitute a person at any given moment. "[The 'I'] not only conveniently bridges the gaps between who we once were and who we are today," he writes, "but it tends as well to make our sense of self in any present moment seem more unified and organized than it could possibly be." Autobiography, then, is not merely a process of defining one's personality through story and narrative, it is the use of story and narrative to invent a unified self, fashioned by repressing or ignoring some of the selves that comprise the complex individual personality, and emphasizing and celebrating of others.

\footnotetext{
${ }^{6}$ L. L. Langness and Gelya Frank, Lives: An Anthropological Approach to Biography (Novato, California: Chandler \& Sharp Publishers, Inc., 1991), 89.

${ }^{7}$ Paul John Eakin, How Our Lives Become Stories: Making Selves (London: Cornell University Press, 1999): ix.
} 
The constructed nature of the autobiography genre has been the source of controversy since the 1980s as scholars have struggled with its implications upon the veracity of the text. Was autobiography a valid historical source, given the degree to which the author inevitably fabricated the cohesive structure of his or her life? Was autobiography essentially fiction? In the 1970s, the autobiographical form was generally accepted as the objective account of the development of what Philippe Lejeune called the "real person" or "personality." In the 1980s, however, this notion was rejected by theorists such as Michael Sprinker, who contested that the "I-figure" was utterly contrived, thus casting autobiography into disrepute as a historical source, given that its premise - "I" - was essentially untrustworthy. The genre was eventually redeemed in part by philosophers such as John Searle, who argued that though autobiography was indeed largely constructed, the universal recognition of the unified self and the structured life effectively validated the medium, ${ }^{8}$ however the medium is still an enigma as academics grapple with how to approach a source that seems so obviously construed and yet resonates so profoundly with the experiences of readers.

This theoretical struggle carries naturally into an investigation of Charles Templeton's performances of unbelief: how should one approach Templeton's autobiography, the principle source of any investigation of his life and faith? Eakin offers one suggestion, stating that even if we cannot accept the autobiographical story as the objective account of the true experiences of a "real," unified self, we can "approach autobiography in the spirit of a cultural anthropologist, asking what such texts can teach us about the ways in which individuals in a particular culture experience their sense of

\footnotetext{
${ }^{8}$ Eakin, 4. For a more comprehensive account of the theoretical debate surrounding the validity of the autobiography genre, see Eakin, 4-8.
} 
being ' $I$ '." Eakin's proposal that autobiography be used as a tool for investigating the manner in which individuals understood and perceived their lives is much more manageable than previous attempts to use autobiography to probe the objective development of an impossibly coherent "real personality." Furthermore, it suggests the plausibility of applying a similar approach to Templeton's autobiographical writings, with a slight twist. Rather than treating autobiography as a way of examining the ways in which he perceived his experience of "being 'I,", this chapter will take one step back and treat the medium as a way of exploring how he chose to present and construct this experience.

A close examination of Templeton's Anecdotal Memoir reveals the presence of at least three distinct narratives, each of which seems to accomplish a slightly different function. Each of these narratives, moreover, represents a different way in which Templeton structured his life experiences so as to contribute to a particular presentation of self. These narratives are relevant to a discussion on Templeton's performance of unbelief because they shape the cultural framework in which the performance was rooted. The first of these might be called the "explicit" narrative, or the one which Templeton directly introduced in his forword as the central story of book. "My purposes," he writes, "are to recreate various incidences and encounters in what has been an eventful life and, having had the unique opportunity to work at the heart of most of the communications media, to tell what it is like on the inside." ${ }^{10}$ In other words, the explicit narrative of his work is the story of his exciting life experiences in his work as a communicator. Indeed, Templeton's entire work is structured around his careers in various media, with the

\footnotetext{
${ }^{9}$ Eakin, 4. The emphasis is Eakin's.

${ }^{10}$ Templeton, Charles Templeton, foreword.
} 
chapters arranged not so much chronologically but thematically, with titles such as "Inside Television," "Inside Radio," "Inside the Toronto Star," and "Inside Books."11 As will be discussed later in this chapter, this narrative contributes overwhelmingly to Templeton's construction of his self as a "communicator" above all else.

The second narrative presented in Templeton's autobiography is more implicit, but still quite obvious when examining the whole of the work: it is a story of overwhelming success against all odds. Templeton contrasts the impoverished early years of his life with the wealth and stature of his later careers. He makes much of the sheer poverty his family experienced when they were young, five children being raised by a single mother. "It seemed the relief cheque was always late," he wrote at one point. "There was one twenty-four-hour period when there was nothing, not a thing, in the house to eat. How often the six of us waited hushed and motionless - like animals freezing when a predator is near - until the bill collector had gone from the door."12 From this starting point of helplessness and despair, however, Templeton slowly transitions into a surge of increasing victories over poverty and powerlessness, fuelled by the various successes he experienced in each of his careers. All of these were detailed in vivid clarity throughout his memoir: before the age of twenty, he states, he had achieved "minor celebrity status" as a sports cartoonist for the Globe; following his conversion soon after he explains how he quickly became an internationally recognized preacher and Christian leader, became an award winning television and radio personality, ran several of the most largest media efforts in Canada (such as CTV's News and Public Affairs Division, the

\footnotetext{
${ }^{11}$ Although this framework does not follow a rigidly chronological order, Templeton still manages to maintain a loose sense of chronology by discussing the various media careers in the order in which he worked at them.

${ }^{12}$ Templeton, Charles Templeton, 20.
} 
Toronto Star, and Maclean's magazine), was offered the premiership of Ontario "on a silver platter,"13 and had presently become a bestselling author who regularly rubbed shoulders with some of the most powerful people in Canada. The clear effect of Templeton's various success stories is the presentation of a self that is itself inherently successful; Templeton was presenting himself as a winner - one who had been dealt a difficult hand, but who had come out on top nevertheless. ${ }^{14}$

More significant than either of these narratives, however, is what might be called Templeton's "narrative of nobility." This narrative is the most subtle of all, being neither introduced explicitly like his narrative of communication nor expressed extravagantly like his narrative of success, yet it seems to be the primary way in which he strives to present his life. Even in his presentation of his early life, before he described himself as a seasoned communicator, and in the times when he experienced outright failure instead of success, Templeton establishes himself as a fundamentally good, honourable, and honest person - the epitome of culturally-recognizable ideals of responsibility, respectability and honesty. In each decision he made and each life direction he pursued, he presents himself doing these things for "noble" reasons or purposes. For example, his entire narrative and self-definition of himself as a communicator is based on the premise that communication is an essentially useful and important for society. As will be discussed later in this chapter, Templeton saw his communicative work as an act of service for his country, a way of making ideas more true and accessible. Even situations in his life he saw as marginally embarrassing, such as his previous work as a mass evangelist, he expressed

\footnotetext{
${ }^{13}$ Ibid., 236.

${ }^{14}$ The notion of Templeton's efforts to present a successful self is further reinforced by his subsequent publishing of his book, Succeeding, six years later.
} 
through the lens of nobility - although he might have been wrong in his beliefs, he suggests, what he was doing was still socially useful and respectable. Moreover, he asserts that throughout his years of Christianity he consistently pursued truth and intellectual honesty, to the degree that he gave up his faith - and, in essence, his entire life to that point - when he had come to doubt the veracity of Christianity's claims.

It should be noted that in framing his life in these noble terms, Templeton was effectively tapping into prevalent cultural concerns regarding an increasingly threatened gender hierarchy, and establishing himself as the epitome of what Chris Dummitt calls the "manly modern" - the man who effectively masters and manages the pervading risks inherent to postwar society. ${ }^{15}$ Rationality was certainly one celebrated feature of this modern form of masculinity, for it embodied a clean and logical way of ordering reality (as opposed to the more inconsistent, emotional quality assumed of women). However, Templeton's presented moral fortitude and consistent sense of purpose also seem to correspond with these admirable notions of masculinity, for they effectively presented him as inherently stable - an anchor during a tumultuous time. Furthermore, Templeton's consistent emphasis on morality contributes to the impression of himself as a gentlemen in a modern setting, a sort of stalwart defender of masculine virtue and poise. In each of these ways, Templeton's narrative of nobility was influenced by the prevalent gender ideals of postwar Canadian society.

It is probable that Templeton's determination to present himself in such noble terms also stemmed from his complex, and sometimes tumultuous, relationships with his

\footnotetext{
${ }^{15}$ Dummitt describes the relationship between notions of masculinity and modernity as a series of complex and contested portrayals of the role of man as a "risk-manager" and the varied ways in which he attempted to subdue modernity. Chris Dummitt, The Manly Modern: Masculinity in Postwar Canada (Vancouver \& Toronto: UBC Press, 2007), 5, 17.
} 
various audiences. If he was well known to Canadians during the mid-to-late twentieth century, he was not well understood. He had hurt and angered many Christians in his abandonment of the faith in $1957 .{ }^{16} \mathrm{He}$ had offended many journalists and media workers with his habit of rising to the top of their career fields (often becoming their boss in the progress) only to abandon their dream jobs on a whim a short while later. Between the years 1958 and 1968, several articles were written about Templeton, many of which highlighted and criticized his career-hopping tendencies. The titles of several articles demonstrate the trend: "Nothing Succeeds Like Charles Templeton," "Charles Templeton: Another Career," and "The Sweet Smell of Charles Templeton." ${ }^{17}$ The latter began with the words, "And Charles Templeton, in a lifelong-on-again-off-again love affair with fame and fortune, has met a lot in the course of his 52 years. An awesome amount: a seemingly intolerable amount...,18

Indeed, it seems that while his memoir was designed to be readable by a general Canadian public - his frequent references to recognizable events and situations, such as "Trudeaumania," the FLQ crisis, the death of Martin Luther King, Jr., and the landing of Apollo 11 on the moon, assured this - each chapter of his book was also directed towards the specific audience inherent to the medium he was discussing. For example, in his chapter on evangelism, he features none of his usual scorn and mockery of religion. Rather, he addresses the Christian public, exhibiting sympathy and nostalgia regarding his years in the faith, and effectively attempting to explain and justify his abandonment of

\footnotetext{
${ }^{16}$ Richard Gilbert, personal email to David Vance, March 3, 2006.

${ }^{17}$ John Clare, "Nothing Succeeds like Charles Templeton," in Maclean's (November 8, 1958); Kenneth G. Wares, "Charles Templeton: Another Career," in Christianity Today 8 (September 25, 1964); and Alan Edmonds, "The Sweet Smell of Charles Templeton," in Maclean's (August, 1968).

${ }^{18}$ Edmonds, 27.
} 
the religion. Similarly, in his chapters on the television, radio, and newspaper media, he likewise speaks to members of these respective media, attempting to explain and defend his apparently inconsistent participation in their fields by grounding all of these apparently disparate activities within the framework of a continuing effort to communicate. In this context, he argued, his various activities showed continuity, not inconsistency; "after all," he argued, "I was in the ministry almost twenty years, appeared on Dialogue five days a week for almost eighteen years and have worked as a performer or producer in television for thirty years - longer, I think, than any other Canadian." ${ }^{, 19}$ All of these justifications suggest that Templeton's narrative was driven by an apparent need to win the approval of others for his actions. At the end of his Anecdotal Memoir he wrote, "I have sometimes wondered why I work with such singlemindedness... If there has been one dominant drive it has been a deep need for approval. For a while I considered calling this book Hey Dad, look at me!"20

By far, the most significant and explicit way in which Templeton presents unbelief through the framework of his noble presentation of self is found in his expression of a rationalism grounded in social respectability and in an honest pursuit of truth. In many ways, this rationalist unbelief reflects continuity between his manifestations of unbelief in his television performances and his novels; in all three media, rationalism denotes Templeton's preference to approach truth and reality through the context of reason and understanding rather than through a framework of faith in the Bible or divine revelation. In all three cases, it effectively compartmentalizes faith and reason, pitting them against each other in some context and inevitably positing reason as

\footnotetext{
${ }^{19}$ Templeton, Charles Templeton, 347.

${ }^{20}$ Ibid., 349.
} 
the victor over faith. However, the difference between Templeton's autobiographical rationalism and his previous presentations of the epistemology is that while rationalism merely played a peripheral part in his television expressions of unbelief and a supportive role in those of his novels, it undoubtedly constitutes the principle thrust of his autobiographical performance of unbelief. Moreover, while his television rationalism was defined in terms of its tenuous, investigative nature and his novel rationalism was characterized by its intensely dramatic character, Templeton's autobiographical rationalism is framed within his narrative of nobility, and so reason and faith are placed in opposition largely in terms of the dynamics of honesty, integrity, responsibility and respectability.

Like the rationalism presented in his novels, the epistemology Templeton presents in his autobiography clearly posits reason as the most valid form of truth. This is demonstrated in several key encounters, perhaps most notably in a remarkable conversation he recalls between himself and Billy Graham in 1948, just before he left fundamentalism to pursue a more intellectually-respectable faith. In this encounter, he establishes himself as the voice of reason, which seems irreconcilable with the voice of the faith, embodied by a resolute Graham.

I had said, "But Billy, it's not possible any longer to believe the Biblical account of creation. The world wasn't created; it has evolved over millions of years. It's not a matter of speculation, it's demonstrable fact." who don't."

"I don't accept that," he said. "And there are reputable scholars

"Who are they?" I said. "Men in conservative Christian colleges?"

"Most of them, yes. But that's not the point. I believe in the Genesis account of creation simply because it's in the Bible. I've discovered something in my ministry: when I take the Bible literally, when I proclaim it as God's Word, I have power. When I stand before the people and say, 'God says,' or 'The Bible says,' the Holy Spirit uses me. There 
are results. People respond. Wiser men than you or I have been arguing questions like this for centuries. I don't have the time or the intellect to examine all side of each theological dispute, so I've decided, once and for all, to stop questioning and to accept the Bible as God's Word."

"But Billy," I protested, "you can't do that. You don't dare stop thinking. Do it and you begin to die. It's intellectual suicide."

"I don't know about anybody else," he said, "but I've decided that that's the path for me." 21

Templeton's presentation of this conversation clearly places himself as choosing reason over Biblical faith as the authority for apprehending knowledge and truth. The notable thing about this conversation, however, is Templeton's attitude towards Graham's decision; he is almost offended, and likens it to a kind of death - "intellectual suicide." In other words, Templeton presents a Christianity that places faith over reason as intellectually irresponsible, asserting that this is somehow akin to putting a part of one's self to death. The implicit suggestion here is that while faith was not necessarily irresponsible in itself - after all, Templeton too was operating within the context of faith - what was irresponsible was the placing of faith over reason instead of the reverse.

Templeton carried on this condemnation of the faith-based epistemology by comparing and contrasting the tangible manifestations of the two philosophical positions - the evangelism produced by each. He had few kind words for the evangelists engendered by a faith-driven epistemology. They were "simple men; strong on passion and deficient in education," and "relatively ignorant men with narrow minds and narrow interests." 22 According to Templeton, this sort of primarily faith-driven approach to Christianity rendered evangelism much less respectable than his own reason-driven approach because it was characterized by emotionalism, fear and superficiality rather

\footnotetext{
${ }^{21}$ Ibid., 71.

${ }^{22}$ Ibid., $91,94$.
} 
than the intellectual honesty and genuine usefulness that marked his own efforts. Once again, he presents this dynamic largely through comparison between Graham and himself:

There were many fundamental differences in Billy's and my campaigns. Billy is an 'old-fashioned' evangelist with a heavy emphasis on the judgement aspects of the gospel. He speaks much about heaven and hell, rewards and punishments, and ends each sermon with an appeal for converts to come forwards. I seldom spoke about heaven, never preached on hell, and eschewed the traditional 'altar call.' At the end of the sermon, deliberately avoiding any emotional pressure, I would announce that an afterservice would be held for any who wanted to make a commitment, and would dismiss the meeting. Those who wanted to remain had to move against the flow of the thousands leaving. ${ }^{23}$

The consistent theme of Templeton's comparisons is that unlike his own, modest evangelism, the persuasiveness of this faith-driven evangelism was dependent on extravagant displays of "show business," designed to manipulate the crowd into an artificial spiritual fervour. ${ }^{24}$ And it worked, he asserted, discussing the Youth for Christ rallies held at the Maple Leafs Gardens in Toronto. "For Christian young people," he wrote, "the Gardens rallies were pop extravaganzas; they were participating in something larger than life. Surrounded by thousands of their fellows, all holding a common faith, they found a tangible justification of their religious commitment.,"25

Whereas Templeton presents fundamentalism's theological evangelism as superficial, "old-fashioned," caught up in emotionalism and premised on concepts of fear and judgement, his own reason-driven evangelism incorporated the latest ideas and philosophies from such well-known thinkers as Albert Einstein, Aldous Huxley, Carl Jung, Leslie D. Weatherhead, and C. S. Lewis, and is thus presented as eminently

\footnotetext{
${ }^{23}$ Ibid., 80.

${ }^{24}$ Ibid., 65.

${ }^{25}$ Ibid.
} 
respectable and universally helpful. "I would speak for thirty-five minutes on practical problems of ethics and human relationships," he explained. "Business people at every level came down from their offices, eating their lunches as they listened. ${ }^{26}$ His television show, Look Up and Live, geared towards young people and "addressed to the mind and the will of the listener rather than the emotions," was similarly presented as inherently honest, responsible and socially useful. As he points out, the show was lauded by critics; to demonstrate his point he quotes a review by the New York Daily News, "A Protestant pastor has gone behind the cameras to battle juvenile delinquency in a quiet but effective way. He's Charles Templeton, a former football player and syndicated sports cartoonist, whose approach is far removed from the hellfire-and-brimstone school of preaching.,"27 Ultimately, through his comparisons of the two evangelistic approaches, reason is presented as inherently more useful, honest and responsible than faith, and Templeton, in pursuing such a responsible, reason-based evangelism, is imbued with these characteristics as well.

This rationalist subjugation of faith by reason is made even more explicit in Templeton's reinterpretation of his religious experiences through the lens of science, and again it is presented in a way that corresponds to his autobiographical presentation of self. This time, however, the way in which rationalism is structured within the narrative of nobility functions less to augment Templeton's image as responsible or honest and more as a way of tempering what might otherwise be regarded as melodramatic or emotionalist portrayals of religious experience, the trend from which he tried so consistently to distance himself. In his chapter on evangelism, he recounts what might be

\footnotetext{
${ }^{26}$ Ibid., 83.

${ }^{27}$ Quoted in Templeton, Charles Templeton, 98.
} 
considered three extraordinary supernatural encounters, and in each case he provides some sort of scientific explanation or disclaimer for why these might be natural, ordinary events, thereby humanizing them and emphasizing their respectable, rather than sensational, nature.

The first of these encounters is his conversion experience. He prefaces his account of the incident with a sort of intellectual apology, seemingly striving to emphasize his recognition that religious experiences were indeed irrational, and demonstrating his knowledge that whatever he experienced was surely rooted in natural, rather than supernatural causes. "From my present vantage point," he begins, "I am at a loss to understand my blind acceptance of the fundamentalists' Christian beliefs." $\mathrm{He}$ continues: "A number of facile explanations present themselves: that I yearned for a satisfactory father figure; that I wanted very much to repay my mother for her years of loneliness and struggle by accepting her new-found faith; that my adolescent experiences of sex - innocent enough in retrospect - had burdened me with guilt., ${ }^{, 28}$ In establishing this context for the story of his conversion, Templeton uses reason to reinterpret and humanize a religious experience. This has the effect of moderating what might otherwise be considered an emotionalist account of a conversion experience by ensuring the reader that the experience was a natural, human event, properly interpreted through the lens of psychological notions of guilt complexes and attempts at validation. He frames his descriptions of the actual conversion experience in similar psychological terms,

${ }^{28}$ Templeton, Charles Templeton, 32. 
emphasizing the culmination and release of guilt inherent to the narrative of the traditional conversion experience. ${ }^{29}$

The second religious experience Templeton presents consists of two cases of what he calls "instantaneous healing." Once again, he prefaces his accounts of the incidences with a sort of disclaimer, distancing himself from the event. "I had, when requested, prayed for the sick many times," he began, "never effectually. I never preached on faith healing, seldom referred to it, and was publically critical of evangelists who majored in it. I regarded it as peripheral and, in the hands of charlatans, dangerous. ${ }^{, 30}$ Nevertheless, he found himself calling on a woman one day, "feeling like a mountebank." 31 He then provides an extraordinary account of how after laying his hands on the woman's baby, whose head was bound to the left due to a muscular deformity in its neck, and praying for its healing, the baby began moving its head around as it peered at Templeton and its mother. He explains the story in great detail, mentioning how the child had been examined several times in the hospital and that its condition was declared to be inoperable, and how her healing was later documented in a Christian journal entitled New World. $^{32}$ Templeton then provides another healing account, this time in the case of his Aunt Ada, who was suffering from what had been diagnosed as terminal cancer of the stomach. ${ }^{33}$ He is quick to point out that she was a graduate nurse, and had been medically examined several times. Once again, the woman seemed to be miraculously healed;

\footnotetext{
${ }^{29}$ Ibid., 33. See David Bebbington's works on evangelicalism, especially Evangelicalism in Modern Britain, for several descriptions of intense, emotional conversion experiences which often involved the building and releasing of guilt. D. W. Bebbington, Evangelicalism in Modern Britain: A History from the 1730s to the 1980s (London: Unwin Hyman Ltd., 1989).

${ }^{30}$ Templeton, Charles Templeton, 44.

${ }^{31}$ Ibid.

${ }^{32}$ Ibid., 45.

${ }^{33}$ Ibid.
} 
"there was no return of the malignancy," Templeton reported. "The adhesions ended. She outlived the rest of her brothers and sisters and died forty-two years later at the age of eighty-seven." 34

Aside from their extraordinary nature, the significance of these accounts is that after taking such great care to portray the credible nature of these bizarre incidences notably, by referring repeatedly to medical science - he immediately dismisses the notion that they might be genuine supernatural events.

How do I account for these two instances of apparently instantaneous healing? I cannot. They certainly didn't happen because of my faith. Nor do I believe that they resulted from divine intervention. Having investigated faith healing over many years I have no doubt that, occasionally, men and women are healed of actual illness. I am not speaking of those illnesses that are hysteric in nature, symptoms of an underlying psychological problem. Nor of those healings that are undoubtedly remissions; the temporary subsidence of symptoms or pain. ${ }^{35}$

In this passage, Templeton makes the telling assertion that while something mysterious and unexplainable certainly occurred in both incidents, whatever happened was emphatically not supernatural. Rather, he insists on interpreting them in the context of reason, arguing that they must be somehow natural phenomena. "I am convinced," he asserts resolutely, "that what may loosely be called faith healing is an area of medicine with unrealized potential. ${ }^{, 36}$ Here again, his resolve to interpret the phenomena through the context of science reflects a subjugation of faith by reason. The example is especially notable because the scientific interpretation to which he turns is so tenuous; unable to point to any particular theory or explanation to explain the events, he vaguely asserts that

\footnotetext{
${ }^{34}$ Ibid., 46.

${ }^{35}$ Ibid.

${ }^{36} \mathrm{Ibid}$.
} 
the phenomena belonged to an "unrealized" scientific field, demonstrating a persistent inclination to interpret reality through a secular framework instead of a supernatural one.

The final religious experience Templeton presents is an incident he experienced as he was walking alone through the golf course at Princeton Theological Seminary one night. These walks had been his regular practice during his years at Princeton, he asserts, as he explored and struggled with his faith. During them he did not exactly pray, but rather, he walked "in the solitary darkness, head up, eyes open, sometimes silent, sometimes trying to articulate the almost intolerable yearning I was feeling. ${ }^{37}$ On this particular night, Templeton was walking through the golf course when he was suddenly overcome with emotion. He writes:

Standing with my face to the heavens, tears streaming, I heard a dog bark off in the distance and, from somewhere, faintly, eerily, a baby crying. Suddenly I was caught up in a transport. It seemed that the whole of creation - trees, flowers, clouds, the skies, the very heavens, all of time and space and God Himself - was weeping. I knew somehow that they were weeping for mankind: for our obduracy, our hatreds, our ten thousand cruelties, our love of war and violence. And at the heart of this eternal sorrow I saw the shadow of a cross, with the silhouetted figure on it... weeping.

When I became conscious of my surroundings again, I was lying on the wet grass, convulsed by sobs. I have been outside myself and didn't know for how long. Later, I couldn't sleep and trembled as though with a fever at the thought that I had caught a glimpse through the veil. ${ }^{38}$

Of the three experiences Templeton recounts, this one is likely the most dramatic and emotional. Indeed, as he was struggling at the time with questions concerning the reality of God and the nature of Jesus, this experience must have seemed quite meaningful and personal to him, which is suggested in his frequent efforts to repeat the

\footnotetext{
${ }^{37}$ Ibid., 78 .

${ }^{38}$ Ibid.
} 
experience. However, as astonishing as this encounter seems to the reader, equally astonishing is Templeton's curt dismissal of it in the following paragraph.

For the next few weeks I sought to repeat the experience. It never recurred. I recognized it to be a mystical experience, and in the library pored through books on the subject. The literature is not extensive but I learned that what had happened to me was not unusual: it had been commonplace at various times in the history of the church. More important, I learned that it was of no special significance. Mystical experience has added no insight to our knowledge of God or to Christian doctrine. Indeed, the experience is not uniquely religious: the poet Henry Wadsworth Longfellow could go into a transport at will merely by repeating his name aloud. ${ }^{39}$

Templeton then switches to his next subject, neatly ending his discussion on this extraordinary experience. There are many things to note here. First, it is significant that Templeton reports turning to books and the library to understand and contextualize a faith experience. This is not an isolated incident; in fact, it is the fourth of five occasions in the same chapter in which Templeton brings up the subject of the "library" in relationship to his faith. ${ }^{40}$ Templeton's invocation of the library is revealing, as it effectively affirms the epistemological order he presents in his discussion with Billy Graham - faith is defined by, and interpreted through, reason. Moreover, the manner in which Templeton dismissed this profound experience - especially likening it to a transport akin to those experienced by Longfellow when he spoke his name out loud - suggests that he is again transforming a potential faith experience into a psychological phenomenon through the use of reason (in this case, rational insight gain through library research).

\footnotetext{
${ }^{39}$ Ibid.

${ }^{40}$ The first occasion involved Templeton's faith being shattered by the secular arguments to which he is exposed in the small library of a minister in Michigan (Templeton, Charles Templeton, 41-42), and the second, third and fifth involved the library at Princeton, and its role in helping Templeton understand his faith and the world $(76,77,79)$.
} 
It is important to note that in all three of these encounters, Templeton's use of reason to effectively humanize faith also serves to mediate the potentially sensationalist nature of the events. From his use of psychological language in his conversion narrative, to the assertion that there must be some scientific explanation for the healings, to his abrupt dismissal of his transport on intellectual grounds, each rationalist interpretation also effectively allowed him to portray a potent religious experience in respectable terms. It is not that religion, or religious experiences, is essentially scandalous. The problem, for Templeton, lay in the fact that these experiences fell into a larger story in which he was attempting to portray himself as respectable, upright and honest, and he likely felt that religious experiences which left him sobbing on the ground or healing people with his bare hands would not fit well into that narrative - especially given his consistent efforts to distance his modest evangelism from the emotionalism of fundamentalism.

The final way in which Templeton's rationalism contributes to his presentation of a noble unbelief is through his explicit portrayal of his own loss of faith, presented directly in terms of a faith struggling with, and slowly succumbing to, the dominating force of reason. This account is quite similar to the experiences of Jimmy Coulter, in The Third Temptation; indeed, it seems that the events of the novel were heavily borrowed from Templeton's own experiences, as suggested by several passages that are similar, or even identical, to those included in his autobiography. ${ }^{41}$ However, while the circumstances of the events are quite similar, the differing manner in which the same essential event is presented is quite remarkable. While the novel's portrayal was characterized by its dramatic and exciting nature (eventually leading to Jimmy's own

${ }^{41}$ See Charles Templeton, The Third Temptation (Toronto: McClelland \& Stewart Limited, 1980), 12, 55, $57-58,163,165$. 
destruction), Templeton's autobiographical account presents a much more conservative experience, marked by a distinct emphasis that unbelief was not something he chose, it was something that was forced on him - against his will - as his mind rejected his faith. In this way, Templeton's very expression of unbelief - his shaping of his loss-of-faith narrative in terms of reason destroying faith - is presented in the ironic form of a noble battle against unbelief: the story of Templeton's efforts to be true to his faith and friends, and his eventually undoing caused by his own honest pursuit of truth.

Templeton was quite aware that he had hurt and offended many people in his rejection of Christianity in 1957 . As he wrote of the time, "I was abandoning people who looked to me, including thirty-six men and women who were in the ministry or on the mission fields because of my work. I felt like a betrayer." ${ }^{" 42}$ In his later chapters, he includes many encounters of people voicing confusion, anger and disappointment over his decision, even decades later. This knowledge, combined with his awareness of the negative sentiment many felt towards him as a result of his career-hopping tendencies, likely fuelled his largely defensive portrayal of his abandonment of the Christian faith, in which he portrayed himself as effectively fighting against his own sense of reason in order to stay true to his faith, family and friends. It is a noble, if tragic, narrative Templeton weaves, and it is all premised on that notion of intellectual honesty he portrays in the aforementioned conversation with Billy Graham, in which he presented a staunch pursuit of reason as the only true method through which to approach reality. The alternative, he insisted, was "intellectual suicide." ${ }^{43}$ Ironically, this intellectual decision which he vocalized in 1948 but was implicit in his attitudes long before that - laid the

\footnotetext{
${ }^{42}$ Templeton, Charles Templeton, 90.

${ }^{43}$ Ibid., 71
} 
groundwork for the growth of his presented unbelief; because of his dedication to treating reason and rational arguments as the highest form of truth, he continually fuelled the very force that was undermining his faith. Thus, Templeton's account presents perhaps the most "noble" narrative possible: despite a valiant effort to be faithful and true, he was ultimately foiled by his own honest pursuit of truth.

Fittingly, Templeton begins this narrated battle against unbelief in a "dreary Michigan town," in the library of a "neurotically shy, shrivel-souled" pastor. ${ }^{44}$ Here, Templeton borrows from the classic loss-of-faith narrative, in which the earnest believer has his faith shattered in the library, by stumbling innocently across the works of secular philosophers and their rationalist arguments against the existence of God. ${ }^{45}$ "I picked up Thomas Paine's The Age of Reason," he writes. "In a few hours, nearly everything I knew or believed about the Christian religion was challenged and in large part demolished. My unsophisticated mind had no defences against the thrust of his logic or his devastating arguments. ${ }^{, 46}$ Significantly, Templeton portrays the effectiveness of rationalist arguments in dismantling his faith as an attack against himself, in which he is a passive agent. Though he is clearly operating within a rationalist mindset (which naturally provides greater power to rational arguments over faith-based claims), he presents no recognition of the role his ideology assumes; unbelief is something that happens to him, as his reason independently assaults his faith. This is clearly presented in a brief explanation Templeton provides for what was happening to him. "Slowly," he wrote, "against my will

\footnotetext{
${ }^{44}$ Ibid., 41. This entire incident, like many others in Templeton's autobiography, was first expressed in his novels. In this case, the encounter was presented in The Third Temptation.

${ }^{45}$ Carl F. Klinck (ed.), Literary History of Canada: Canadian Literature in English (Toronto: University of Toronto Press, 1973), 305-306.

${ }^{46}$ Templeton, Charles Templeton, 41.
} 
- for I could perceive the jeopardy - my mind began to challenge and rebut the things I believed. ${ }^{47}$

As Templeton continues to tell the story, unbelief - in the form of reason subjugating faith - persistently devastates him:

I read through the days and into the morning hours. Each night, I stumbled lamely through my sermon, drenched in perspiration, desolate of spirit. By the end of the two weeks my course seemed obvious: my faith was disintegrating, I couldn't remain in the ministry, couldn't possibly continue to preach. I couldn't even pray. I cancelled the few meetings I had scheduled and returned to Toronto, utterly at a loss. There, I wandered in the wilderness of my mind for six weeks, fending off the questions of my family and friends, trying to get some bearings... I was like a boxer who has been stunned and is out on his feet. Then, slowly, I began to emerge from the grey befuddlement. In hope, I turned again to the New Testament... The way back was tortuous and slow. ${ }^{48}$

In this passage and the many proceeding accounts of unbelief's attack against his faith, an ongoing pattern is identifiable: reason dominates his faith - sometimes slowly, sometimes in destructive bursts - but Templeton nevertheless struggles his way back, "not through enlightenment," he writes at one point, "but through a conscious act of commitment." "I wanted to believe," he insists; "there was in me then as there remains now an intense, inchoate longing for a relationship with God." ${ }^{, 50}$ Indeed, he presents himself as going to extreme measures to hold on to his faith. Aside from nightly walks spent trying to "open [his] spirit to whatever is," he tried to reconcile his faith and reason by fostering an extremely intellectual faith. ${ }^{51}$ This, as much as a desire for intellectual respectability, was the reason for his move to Princeton Theological Seminary. ${ }^{52}$ Furthermore, when this

\footnotetext{
${ }^{47}$ Ibid., 67.

${ }^{48}$ Ibid., 42.

${ }^{49}$ Ibid., 79.

${ }^{50}$ Ibid., 67.

${ }^{51}$ Ibid., 78 .

${ }^{52}$ Ibid., 69.
} 
failed to halt the destruction of his faith by reason he tried again to reconcile the two by accepting a job as Director of Evangelism for the Presbyterian Church USA, a job that allowed Templeton to work in a more intellectual leadership position as he fostered a program of "responsible evangelism" for the next generation of spiritual leaders. ${ }^{53}$ It was all in vain, however; "for almost three years," he wrote, "I trained ministers and laymen, lectured in theological seminaries and universities, wrote two books and did a weekly television show on the CBS network... And I struggled with my faith." ${ }^{54}$

It is worth noting that the primary area in which Templeton's faith was attacked was his belief in the divinity of Jesus. This reflects a continued trend among the potential unbelief he presented in his religious literature and the investigative unbelief he presented through television. Whereas in his religious literature he established a very narrow - and largely conservative - set of binary parameters in which he defined Christianity, here, as in his television interviews, he continues to present his intellectual objection to faith along the same lines. For Templeton, Christian faith is dependent upon belief in the divine nature of Jesus Christ. "The foundation of Christianity is the person of Jesus," he declared. "If he was a man, however gifted, he could be no more than a superlative teacher and a soaring example. If I was going to continue in the ministry, I would need to know that Jesus Christ was God." ${ }^{, 55}$ Indeed, this very issue was what plagued Cardinal Michael Maloney in Templeton's novel, Act of God, as well. It seems that Templeton's insistence on a relatively conservative definition of Christianity had carried through the decades and continued to serve as the terms by which he rejected Christianity; ultimately,

\footnotetext{
${ }^{53}$ Ibid., 87.

${ }^{54}$ Ibid., 88 .

${ }^{55}$ Ibid., 79.
} 
he could rationally accept Jesus as a great moral teacher but not as a deity, and as such, he could not accept Christianity. ${ }^{56}$

Templeton concluded his noble narrative of unbelief by establishing a situation in which he had no choice but to accept defeat and embrace unbelief. In the late 1950s after nearly fifteen years of struggling to maintain his faith - he states that he began to experience assorted health problems: pains in his arms and chest, and frequent episodes of anxiety in the middle of the night. ${ }^{57}$ In response, he explains, he visited several doctors - surely a deliberate reference given the weight Templeton consistently attributes to medical knowledge and science. Here is Templeton's account of one doctor's comments:

There is nothing wrong with your heart. Nothing. The pains you get - let me put it in layman's language - are the result of what I'll call heart spasm. But the trouble isn't in your heart, it's in your head. There is something in your life that is bothering you. Some conflict. Some unresolved problem. Whatever it is, deal with it. Otherwise you will probably continue to suffer the symptoms you have described to me and will likely see other manifestations. ${ }^{58}$

Here, Templeton effectively established a scenario in which the only responsible choice in fact, the only feasible choice - was to end the tension between his faith and his reason. Indeed, this was the unresolved issue to which Templeton was pointing - as he states, "I knew what the problem was but couldn't discuss it with him. It was my old nemesis doubt. ${ }^{, 59}$ Moreover, as Templeton portrays it, there was no real option. He was dedicated to the honest pursuit of reason over a whole-hearted acceptance of faith; this was the very way in which he defined himself in opposition to Billy Graham. Although he does not explicitly address his decision to abandon his efforts to hold to his faith, not long

\footnotetext{
${ }^{56}$ Ibid., 348.

${ }^{57}$ Ibid., 87.

${ }^{58}$ Ibid.

${ }^{59}$ Ibid.
} 
afterward he gave up the Christian ministry - a decision he effectively presents as synonymous with the death of his faith and the beginnings of his agnosticism. ${ }^{60}$ In this way, Templeton has set in place all the essential elements of a rationalist portrayal of noble struggle against unbelief. He tried with all his might to stay true to his faith, and to an extent he succeeded for nearly fifteen years. However, in the end, his rational doubts regarding the nature of Jesus overwhelmed his faith, forcing him to a watershed decision - and his dedication to reason emerged victorious over an embattled faith.

While Templeton's various manifestations of rationalism certainly composed the bulk of his noble portrayal of unbelief, two other significant presentations of unbelief are also identifiable. Both of these less subtler expressions are concerned with the ways in which Templeton presents meaning and purpose in his life. As with his television and novel performances, the element of unbelief within these presentations of meaning is not constituted in the isolated fact that Templeton is establishing sources of meaning; rather it lies in the context in which he establishes these sites. Due to Templeton's explicit rejection of Christianity in 1957 , the various sources of meaning he presents are established as being inherently meaningful in and of themselves, outside of any religious framework in which to situate them. Furthermore, while the expressions of meaning in Templeton's television shows and novels reflected relatively undeveloped forms of unbelief in their tenuous suggestions of an undefined replacement framework, here he presents a much more defined replacement framework, which he describes repeatedly as "agnosticism." his confident situating of various sites of meaning and purpose within it, demonstrates an

\footnotetext{
${ }^{60}$ Ibid., 72.

${ }^{61}$ Ibid., 337.
} 
expression of a much more mature form of unbelief, second only in articulation to Templeton's final work, Farewell to God: My Reason's For Rejecting the Christian Faith.

Templeton expresses this mature replacement framework in his establishment of a firm, and clearly defined, sense of morality - in his implicit suggestion that some things in life were inherently right or wrong, and that some attitudes, ideals and decisions were ultimately more valuable, or good, than others. Once again, this presentation of unbelief is fundamentally shaped by Templeton's autobiographical presentation of self. Whereas his television treatments of morality took place in almost interrogative format, and his portrayals of morality in his novels took place in epic moral battles between various ideals embodied by his different protagonists, in his autobiography he likewise shapes his treatment of the subject in accordance with the specific nature of the cultural medium, by deliberately portraying himself as an exceptionally good, honest, just, and - to put it simply - noble person.

The specific nature of Templeton's enacted morality seems to be rooted in a humanistic ethical system based on an amalgamation of several moral teachers and philosophies. "There have been two principle wellsprings from which my convictions have flowed," he asserts at the end of his autobiography, "a religious philosophy informed by, among others, Jesus of Nazareth, Albert Schweitzer, and Mohandas Gandhi, and a political disposition toward traditional liberalism, a philosophy that sees society as in need of reform and seeks to effect the necessary changes through law - as few laws as possible but as many as necessary." ${ }^{162}$ His references to "Jesus of Nazareth" and Gandhi

${ }^{62}$ Ibid., 348. 
are particularly telling, as they essentially constitute a textual divorcing of this site of meaning from any exclusive Christian context. As noted in chapter two, since Templeton had left Christianity he had begun to look at Jesus differently. In one particular television interview, he had asserted that there was no fundamental difference between Jesus and Gandhi, and that rather than missing the valuable ethical teachings of Jesus by emphasizing his deity, society should treat him as a moral teacher like Gandhi, focusing on how his teachings might improve life here and now. ${ }^{63}$ Templeton re-emphasized on this trend in his autobiographical writings. His consistent references to "Jesus of Nazareth" - a conspicuous name for Jesus which he never used during his years of Christianity - seem to reflect a deliberately-chosen alternative to the more popular name, “Jesus Christ," which implies divinity. In essence, Templeton's references to this location-defined Jesus, and his emphasis on Jesus' moral influence (discussed alongside Gandhi), all point to a human Jesus - one stripped of his divinity and made into to a moral teacher like Gandhi instead of a divine agent of redemption. In this way, Templeton's presentation of morality is further established apart from the Christian context, for it is ultimately based on a human system of ethics (suggestive of an agnostic moral system) rather than any sort of divine ordering of reality.

As previously mentioned, Templeton framed his presentation of morality around his noble presentation of self by effectively portraying himself as the prototypical example of goodness, honesty and justice within his particular life context. The intentionality with which he casts himself in this role is quite remarkable; at times, he appears as almost heroic in his efforts to do the right thing in any given situation. While

\footnotetext{
${ }^{63}$ Charles Templeton, television interview with Sir George F. MacLeod on Close-Up (Toronto: CBC, December 2, 1962), 01:11.
} 
there is insufficient space in this chapter to discuss every occasion in which he establishes an image of himself as an upstanding and noble individual, a few notable examples may suffice. Templeton presents himself as an exceptionally honest person, and full of integrity. This is seen most clearly in his account of the moral struggle he experienced during his battle with unbelief. At heart, this was the overarching moral issue he presented in The Third Temptation, in which Jimmy Coulter grappled with the decision of whether to keep the "kingdoms and the glory" associated with being a renowned evangelist even though he no longer believed what he was preaching, or to be honest with himself and the public by leaving the ministry. Unlike his tragic protagonist, however, Templeton portrays himself as making the right choice: shunning hypocrisy and false religion in favour of an honest life. He heightens the nobility of the decision by framing it in terms of an ongoing struggle that he eventually overcame. For a long time, he asserts, he continued to preach and evangelize even though he was unconvinced of the truth of what he was saying. ${ }^{64}$ After winning a debate with an earnest student from Yale University, however, he decided that he needed to change his life. "The student had seemed half-convinced," he explains. "He was searching for meaning in life and it was entirely possible that he might go from our meeting to pray, perhaps even to commit himself... What right did I have to meddle in his life? What right did I have to stand before the entire student body or the thousands of people I had been preaching to nightly for years, using all my persuasive skills to win them to something I was no longer convinced of myself? It was a reprehensible thing to do and I must stop it." ${ }^{, 65}$ This he

\footnotetext{
64 Templeton, Charles Templeton, 85-87.

65 Ibid., 89.
} 
promptly did, resigning from the ministry in 1957 and moving back to his home city of Toronto. ${ }^{66}$

Templeton's portrayal of his own honesty and integrity in leaving Christianity was only the beginning of his establishment of himself as an exceptionally "good" person. Over and over, he continually constructs situations in which he is presented with some sort of moral choice, and he inevitably demonstrates his attempts to do the right thing, even at the cost of embarrassment or inconvenience to himself. He tells two anecdotes of how he was offered questionable financial and political deals, and how he unfailingly declined these deals (and in the case of the former cases, notified the authorities) ${ }^{67} \mathrm{He}$ constantly emphasizes his efforts to eschew the easy successes of "yellow journalism" and contribute to the establishment of "responsible journalism" - a journalism that blended interesting content with an ethical investigative approach. ${ }^{68} \mathrm{He}$ portrays himself as refusing to play a part in any dishonest exhibition, no matter how well-intentioned. For example, after Templeton had revealed himself an agnostic, he attended one of Billy Graham's first solo crusades. When Graham surprised him by asking him to open the massive meeting in prayer, Templeton was thrown into a moral dilemma. "I rose and walked to the pulpit, my mind in tumult," he writes. "What should I do? I could not embarrass Billy and everybody present with a stuffy explanation as to why I couldn't lead them in prayer, but neither could I involve myself in a charade." ${ }^{\prime 99}$ Ultimately, he states, he ended up giving a "brief homily on the need to come to terms with one's self and on the importance of trying to understand the motives, attitudes and

\footnotetext{
${ }^{66}$ Ibid., 90.

${ }^{67}$ Ibid., 57, 233.

${ }^{68}$ Ibid., 167.

${ }^{69}$ Ibid., 72.
} 
actions of others," much to the confusion and somewhat negative reaction of the audience. $^{70}$

Perhaps the most striking of Templeton's various efforts to portray himself as a fundamentally good, decent person lies in an anecdote he presents in which he woke up one day and remembered a large sum of money he had received from a previous job, which he had subsequently forgotten to declare in his taxes. The situation was made more serious by the fact that he, along with Pierre Berton, had just blasted the National Revenue Agency over security leaks on their popular radio show, Dialogue. Templeton's accountant stressed on no uncertain terms that he should not declare the money, principally because a sudden declaration of such a large sum of money would most likely cause him to be audited - all the more strenuously because of his recent treatment of the NRA. Again, Templeton presents himself as being in moral turmoil:

I tried to dismiss it from my mind but I couldn't. I owed the money. I believe people should pay their taxes... Beyond that, I'd built a reputation for veracity over a lifetime; was I prepared to destroy that?

I called my accountant. "Declare it.",71

This passage is illuminating because it highlights both Templeton's portrayal of himself as morally upright, and the significance he afforded this morality. It was a defining characteristic of his life, a means of constructing his identity and imbuing his actions with meaning and purpose. In his continual presentations of his own morality, he was doing more than merely describing himself as a good person; he was establishing morality as a potent site of meaning - in his case, as a part of an increasingly mature framework of

\footnotetext{
${ }^{70}$ Ibid., 73.

${ }^{71}$ Ibid., 305.
} 
"agnosticism" that had effectively replaced the Christian system of meaning he had rejected two decades earlier.

The final way in which Templeton reflected unbelief through his expressions of meaning through this replacement interpretive framework is in his portrayal of his specific role in life. As stated at the beginning of this chapter, one characteristic of the autobiographical genre is its ability to serve as an agent of self-definition - of establishing one's role in life, the place from which one perceives, experiences and contributes to reality. In his autobiography, Templeton, despite his seemingly disparate career history, presents himself as having one particular role - a sort of "life calling" which he establishes as a site of meaning in that it imbued his life with a sense of direction and purpose, aside from simply being a good and honest person, and apart from any religious context. This "life calling" was found, as he stated at the beginning and end of his autobiography, in his role as a communicator.

It is almost mandatory that I speak briefly to what is perceived to be in me a lack of constancy, a tendency to be a vocational butterfly... My various "careers" are not like beads on a table, each separate and solitary; rather, they are like beads on a string, the common thread being that I am essentially a communicator. Whether at the drawing board or on a platform, whether in the electronic or print media, whether before the cameras or behind them, I have continually sought to communicate ideas that have seemed important to me. If I have a compulsion, it is the need, being caught up in an idea, to communicate it to others by such means as are available. ${ }^{72}$

As previously mentioned, this depiction of himself as a communicator is one of Templeton's primary autobiographical narratives - so much so that he actually organizes his chapters according to the various communicative outlets in which he was involved. However, it is important to note that he did not feel attachment to any of these media in

${ }^{72}$ Ibid., 347. 
and of themselves, they were merely the vehicles through which he pursued his communicative calling. ${ }^{73}$ Moreover, with his heavy emphasis on personal truthfulness and honesty, and the length of time he devoted to journalism, it is tempting to describe him as essentially a "trustworthy journalist" figure, a sort of arbiter of truth. However, while he occasionally played that role (especially as a television interviewer), this was not how he chose to define himself. Indeed, most of the time his efforts do not portray attempts to provide unadulterated truth, but rather a "good show" (which seemed to involve truthfulness, but was more about the relative entertainment and production value of any given piece of work). ${ }^{74}$ Ultimately, it is communication in general, rather than any particular media or journalistic impulse, in which he reveals himself as finding meaning and purpose. As he stated several years before in an interview with Sylvia Fraser, "It's a passion to share. Go back to the Biblical story about the man who found the pearl of great price. He wanted to tell about it! When I was converted, I couldn't wait to get down to the Globe, where I was working as a sports cartoonist, to tell a bunch of hard-bitten sportswriters... I thought it was marvellous! It's about the sharing of what you feel, and a hell of a lot more than the egoism of believing the world needs to know what you know. ${ }^{75}$

While in that earlier interview Templeton described the meaningfulness of communication as simply a matter of being able to "share" one's experiences and feelings, in his autobiography he remained consistent with his narrative of nobility and presented communication as an essentially good and useful calling. In this way he again framed his expression of unbelief - located in his presentation of alternate sites of

\footnotetext{
${ }^{73}$ Ibid., 153.

${ }^{74}$ Ibid., 120.

${ }^{75}$ Sylvia Fraser, "The Real Charles Templeton," in Chatelaine (Feb. 1975): 73.
} 
meaning and purpose - in accordance with the autobiographical form. In particular, he asserted, communication provided an essential service to people by making ideas and issues more accessible to them, making it easier for common people to apprehend realities that they would not easily be able to experience. For example, he describes his efforts in creating a televised debate between new prime minister Pierre Trudeau and opposition leader Robert Stanfield as a matter of helping Canada better understand the two men who were expected to dominate the coming election. "It was my view that a face-to-face debate between Trudeau and Stanfield would not only be great television," he writes, "it would provide an invaluable public service, enabling the Canadian public to take stock of the two men, both of whom were new to the national political scene." sort of sentiment is repeated throughout Templeton's memoir, as each of his communicative efforts is portrayed as not only entertaining, but as an act of public service. Providing a reason for his editing of Jesus, an readable synthesis of the four gospels, he explains that by helping people understand who Jesus was, he was effectively using media to make knowledge of their identity and heritage more accessible.

I thought the project worthwhile, not because I was a Christian (for I wasn't; I had become an agnostic) but because I believe that it is not possible for people to understand what their civilization is (and therefore who they are) without an understanding of their roots... The standards and attitudes of society have been profoundly influenced by the person and life of Jesus. Regardless of one's attitude toward religion, a knowledge of what Jesus of Nazareth said and did is enormously enriching. ${ }^{77}$

By presenting Jesus' life in the form of a small, readable book, rather than an enormous, intimidating Bible, Templeton allowed the public easier access to this man who, he asserted, defined them in several ways.

\footnotetext{
${ }^{76}$ Templeton, Charles Templeton, 149.

${ }^{77}$ Ibid., 319.
} 
Templeton also suggested that his communication skills allowed him to enhance the value of "ideas," effectively contributing to their success if worthwhile and noble. Although he never explicitly addresses this notion, it is remarkable how much emphasis he places on production value: speeches and presentations must be exciting, camera angles and television production must be dramatic, evangelism - even modest, respectable evangelism - must ultimately engage and enrapture the audience. ${ }^{78}$ His very autobiography itself is written in a way so as to garner the interest and attention of his audience - it is not just an autobiography, it is an anecdotal autobiography, written in the form of hundreds of short stories that capture the excitement of any given moment. For instance, he begins one anecdote with a one-sentence paragraph. "Don MacPherson's voice rasped in my ear: 'Charles! Charles! Martin Luther King has just been shot!",79 In essence, his constant emphasis on proper production suggested that ideas may be powerful and profound - even readily available and accessible through the media - but they must be communicated in a way that is essentially interesting in order to make an impact. Likewise, he suggested, a poor expression of a worthy idea diminished its power and effectiveness. Again, this is found all throughout his autobiography. Some of Templeton's harshest criticisms in his autobiography were reserved for those who, despite having solid and profound content to communicate, squandered their

\footnotetext{
${ }^{78}$ This emphasis on presentation techniques is truly prevalent in his autobiography - in every section of every chapter. In evangelism, he fashioned his campaigns in such a way as to charm and captivate the audience - even in his respectable, business-like presentations. In television he presents himself as constantly ensuring that his (CTV's) programming be superior in presentation than the better-funded CBC's, and continually exhausted himself with using various technologies and journalistic techniques to ensure lively and timely footage. In politics he explains how he stuffed white confetti into the ventilation system during a leadership campaign in which he was supporting candidate Bob Winters - "As Bob finished a lacklustre speech, suddenly it was winter time. The air was full of confetti snow and hundreds of snowballs flew through the air" (Templeton, Charles Templeton, 145). Even in his inventing work, he presents himself as staging elaborate demonstrations of his inventions, in an effort to emphasize the importance and effectiveness of his ideas.

${ }^{79}$ Templeton, Charles Templeton, 144.
} 
opportunities through poor presentation. His treatment of Lester Pearson is a good example of this. He lauded Pearson for his excellent credentials, experiences and personality, "and yet..." Templeton wrote,

when he rose to speak at a public function, one's soaring expectations were suddenly earthbound. His self-depreciating wit fell flat. His lisp, barely noticeable in private conversation, was accentuated by tension. Speaking in public, he had a way of closing his eyes, and of lolling his head back to one side that appeared almost spastic. Ringing phrases became prosaic on his lips. Often, when he summoned indignation or reached for outrage, his sentences collapsed in boneless ineffectuality... Loyal liberals covered their dismay, and tried to reassure themselves... ${ }^{80}$

The clear assertion is that although Pearson should have been great, his inability to present himself compellingly greatly diminished his power and effectiveness as a politician. Templeton's communicative calling, therefore, is twofold - he portrays himself as making ideas accessible to the public through the various media in which he was involved, and he establishes himself as doing this well, in such a way as to encourage people to take advantage of this accessibility. In both of these ways, he depicts communication as an inherently noble calling, and in doing so, he again frames his expression of an alternative site of meaning in accordance with his dominant autobiographical narrative of nobility; in other words, he again presented unbelief through the cultural context of the medium.

At the end of his autobiography, Templeton commented on his satisfaction with life. "The path I have chosen has yielded a rich, full and happy life," he wrote, "a life that has been eventful and rewarding, and most of the time, exciting. It has kept my eyes on tomorrow and has made retirement, not a goal to be looked forward to, but a time to be

${ }^{80}$ Ibid., 212. 
postponed indefinitely." ${ }^{81}$ Ultimately, this portrayal of his "rich, full, and happy" life was one that was full and meaningful apart from God. In establishing the various pillars, or sites of meaning, that contributed to his overall happiness and satisfaction - and in doing so in such clear, well-articulated terms - Templeton was effectively demonstrating a firm situation of these sites within a developed framework of agnosticism, which in turn constituted a replacement to the interpretive system of Christianity. This mature expression of unbelief also included his continual subjugation of faith with reason, ultimately establishing reason as more respectable and honest than faith. This explicit rationalism also informed Templeton's continuing conservative rejection of Christianity as he persisted in positing certain, conservative elements of a narrowly defined Christianity as "unreasonable" and therefore, untrue. Consistent with his presentations of unbelief in his television interviews and his novels, Templeton's various expressions of unbelief in his autobiography formed one coherent performance of a "noble unbelief," as each of his various manifestations of unbelief were framed and expressed through the lens of the distinctive narrative of nobility that characterized and defined his autobiography and presentation of self. As such, Templeton's unbelief was portrayed as being ultimately rooted in an honest pursuit of truth and an effort to be a good, and socially useful, person.

${ }^{81}$ Ibid., 348. 


\section{Conclusion}

"What will I do next? I am by no means sure. I will certainly continue to broadcast. I will maintain an active interest in politics... It is, I think, the most interesting activity in which people engage, and probably... the most important. I will continue to work as an amateur inventor. It is more than a hobby with me - it is akin to exploring... I will continue to draw, and intend to return to sculpting, something I have neglected for twenty years. The only activity I will not return to is the Christian ministry; I remain a reverent agnostic."

In chapter four, it was demonstrated that Charles Templeton consistently structured his in terms of what he considered to be a sort of "life calling," that of communication. Within this narrative he organized his life into chapters according to the various media in which he participated, with titles such as "Inside Evangelism," "Inside Television," "Inside Books," and so on. These self-inventive attempts are quite significant for understanding what this thesis has attempted to accomplish, for the entire thrust of this work has represented an effort to take seriously Templeton's definition of himself as a communicator. By following the narrative structure he establishes in his Anecdotal Memoir, this dissertation has examined the ways in which he performed unbelief in terms of his work in various media, through chapters such as "Inside Christian Literature," "Inside Television," "Inside Novels," and finally, "Inside Autobiography."

Through this communicative context, many important trends have been identified with regard to Templeton's unbelief. For example, in his Christian books he demonstrated a tendency to discuss Christianity within a very narrow, binary framework, which effectively enabled and preserved the specific terms by which he eventually

\footnotetext{
' Charles Templeton, Charles Templeton: An Anecdotal Memoir (Toronto: McClelland and Stewart Limited, 1983), 349.
} 
rejected the religious system. This rejection continued in each of his successive media performances, becoming increasingly grounded in a staunch rationalism, whereby anything that could not be explained through rational investigation was purported to be untrue - or at least, unbelievable. This was apparent in his television shows and his autobiography, where he explicitly expressed his rejection of Christianity in terms of an intellectual inability to accept what he considered the essential element of faith - the divinity of Jesus. Templeton's novels presented this rationalism as well, albeit in a more aggressive tone in which he presented the symbolic "death" of faith at the hands of rational science.

Another important trend found in Templeton's communicative efforts was his ability to move beyond this rationalist rejection of Christianity and positively present an alternate interpretive system - that of agnosticism. This was suggested in tenuous terms at first. Hints of this transition were found in his religious works with his commodification of Christianity, as he effectively reduced his faith from a system for interpreting reality to a site for achieving meaning and purpose within another framework, one not necessarily rooted in any sort of religious base. His treatment of this alternate framework became more defined in each successive medium; his television performances added the elements of "happiness" and "success" to the framework, positioning these ideals as its end goals - the ultimate sites of significance. In his novels, he built on notions of the centrality of morality, effectively situating "goodness" - in a variety of conflicted forms - as another site of meaning. Finally, in his autobiography, he 
fleshed out the interpretive system, calling it "agnosticism" and firmly rooting his various locations of meaning and purpose within this secular framework. ${ }^{2}$

Perhaps the most important unbelief trend identified in this thesis, however, was found in the very communicative context in which this whole investigation is rooted. Simply put, Templeton was a communicator, and he framed his various expressions of unbelief according to the recognizable cultural expectations and assumptions inherent to the various situations in which he operated. Partially, these cultural frameworks were a function of the inherent natures of the media through which he was communicating. For example, Templeton's television work occurred in the form of interviews, which necessitated the use of questions and "investigations" in any portrayal of unbelief. Likewise, his autobiography required him to define and structure his life in some way, leading him to frame his unbelief within the context of specific life narratives. The cultural frameworks were also rooted in Templeton's recognition of specific assumptions and expectations inherent to the various audiences to which he was communicating. For example, he tapped into prevalent ideals regarding the "trustworthy journalist" in his television interviews, and in his novels he clearly used various controversial concerns of the 1960 s and 70 s to augment the sense of drama and excitement of his books, thereby contributing to his "narrative power" over the reader. In all of these ways, Templeton presented unbelief through a complex system of cultural attitudes, effectively demonstrating several distinct performances of unbelief: inadvertent "echoes" of unbelief

\footnotetext{
${ }^{2}$ See Charles Templeton, Farewell to God: My Reasons for Rejecting the Christian Faith (Toronto: McClelland \& Stewart Inc., 1996) for a description of the advanced form this agnosticism assumed in the final years of Templeton's life.
} 
in his religious literature, an "investigative" unbelief in his television interviews, a "dramatic" unbelief in his novels, and a "noble" unbelief in his autobiography.

What is the significance of all of this? Is there any real use in exploring Templeton's performances of unbelief? Certainly this thesis represents the first in-depth analysis of the latter half of Templeton's life. While Kevin Kee explored Templeton's evangelism admirably, this constituted only the third of eleven exciting chapters in Templeton's autobiography. ${ }^{3}$ This thesis has attempted to explore the remaining eight chapters of his life - chapters that describe a life that touches on such a variety of academic fields - religion, communication, media, gender, politics, psychology, and celebrity, to name a few - that it would seem irresponsible to leave it unexamined. By extending Kee's work in further opening the life of Charles Templeton to academic study, it is hoped that others will do the same and explore Templeton from a different angle.

Secondly, an examination of Templeton's public performances contributes to the efforts of historians like Callum Brown and Tina Block to introduce new language to the often-stagnant discussion of religious decline. Specifically, while Brown described secularization in terms of a great reconfiguration of identity which took place in Britain during the 1960s, and Block discussed it in terms of the creative ways in which “irreligious" Pacific Northwesters subtly resisted a variety of cultural religious assumptions and authority structures, this thesis discusses religious decline in the

\footnotetext{
${ }^{3}$ Kevin Kee, Revivalists: Marketing the Gospel in English-speaking Canada, 1884-1957 (Kingston and Montreal: McGill-Queen's University Press, 2006).
} 
framework of "unbelief." ${ }^{4}$ It combines James Turner's treatment of unbelief as the ability for a group of people to say "I do not believe in God" with insights from both Brown and Block and treats religious decline as a process - a continual rejection of a previous religious system and an ongoing embracing of a replacement. This language enables religious decline to be discussed without falling into the temptation of assuming the loss of certain "essential" elements, which can never be demonstrated in the "scrambled" nature of daily life. ${ }^{5}$ The unbelief framework also allows decline to be examined beyond the timeframe in which secularization has traditionally been discussed. Instead of positioning the actual "loss-of-faith" experience (or the deliberate rejection of the religion) at the end of the narrative, as do so many accounts of secularization, this framework positions this event in the middle, if not at the beginning, of the secularization process. This, in turn, places emphasis on the gradual development of a new interpretive system instead merely the rejection of the previous one, resulting in a more comprehensive view of the decline process.

Finally, while Templeton cannot be positioned as representative of a typical unbelief experience - he was exceptional in so many ways - his life and public performances nevertheless demonstrate ways in which unbelief can take place, and as such, they shed light, to some extent, on the nature of religious decline in general. In particular, his consistent theme of communication is useful for understanding how, just as

\footnotetext{
${ }^{4}$ Callum Brown, The Death of Christian Britain: Understanding Secularisation, 1800-2000 (London and New York: Routledge, 2006); Tina Block, "Everyday Infidels: A Social History of Secularism in the Postwar Pacific Northwest," (Ph.D. dissertation, University of Victoria, 2006).

${ }^{5}$ The term "scrambling," in this case, refers to Colleen McDannell's discussion on the impossibility of distinguishing between the "sacred" and "profane" the tangible expressions of religion. Colleen McDannell, Material Christianity: Religion and Culture in Popular America (New Haven \& London: Yale University Press, 1995), 4.
} 
the public expression of belief was grounded in an understanding of and in accordance with, the specific cultural demands and values of society, so is the presentation of unbelief influenced by the same. In this way, Templeton's life demonstrates that while unbelief might be, at core, a matter of intellectual dissent and assent to various frameworks of meaning, the ways in which it is cloaked, shaped and framed can be dramatically influenced by the attitudes, assumptions and ideals of the culture in which it is situated.

Templeton's unbelief experience was not finished when he wrote his autobiography; indeed, one of the implications of the way unbelief has been defined in this thesis is a distinct lack of any sort of imagined ending of the unbelief experience, save through death itself. After his autobiography he wrote two more novels, both of which continued to present developing opinions on God, morality and religion. In 1996 he wrote his last work, entitled Farewell to God, My Reasons for Rejecting the Christian Faith. In this book Templeton exhibited a nearly religious devotion to agnosticism and rationality, lamenting for his friend Billy Graham, who had "given up the life of unrestricted thought." As he intellectually journeyed through various tenets of the Christian faith, he struck them down with the resounding judgement that each was "unreasonable."7 "Whom should you believe," he demanded in one place, "the theologians or the physicists?"8 "Whom should you believe on the question," he asked later, "the theologians or the geneticists?" Continuing to cycle through various scientific

\footnotetext{
${ }^{6}$ Templeton, Farewell to God, 9.

${ }^{7}$ Ibid., 28.

${ }^{8}$ Ibid., 29.
} 
threats to Christianity, he finally concluded, "Whom should you believe, the Christian church or your own common sense?"9

Clearly, these varied expressions of agnosticism and rationalism marked the continuing experience of unbelief in Templeton's life as he refined his replacement interpretive system. Unfortunately, this is where the analysis must end, as Templeton increasingly suffered from Alzheimer's disease from 1996 until his death in 2001. His entire body of published material, along with his various performances through other media, reflected a process of moving from one interpretive system to another. Therefore, while he was often criticized for his apparent lack of constancy in his careers and life pursuits, he was actually remarkably consistent in two areas: he remained a communicator throughout his lifetime, and in this, he reliably suggested, expressed and performed his ongoing unbelief.

\footnotetext{
${ }^{9}$ Ibid., 31.
} 


\section{Bibliography}

\section{Primary Sources:}

The Voice [The official church newsletter for Avenue Road Presbyterian Church, New York (attended by Templeton during his years as the official evangelist for the National Council of Churches)]:

"Evangelistic Advance and Youth." The Voice (April, 1950).

"Plans for Lenten Evangelistic Mission." The Voice (January, 1951).

"Pastoral Letter." The Voice (February, 1951).

"Special Choral Music for Lenten Meetings." The Voice (February, 1951).

“Easter at Fifth Avenue." The Voice (April, 1951).

“Mr. Templeton Engaged by National Council." The Voice (April, 1951).

"Templeton and Gilbert in Evangelism Posts." The Voice (October, 1954).

"Summer Preachers at Fifth Avenue." The Voice (May, 1955).

"Summer Preachers at Fifth Avenue." The Voice (May, 1956).

“Mr. Nesbitt Goes to Puerto Rico." The Voice (December, 1956).

"Plans for Lenten School of Religion." The Voice (January, 1957).

The Globe and Mail:

McAree, J.V. "Sports Cartoonist Becomes Evangelist." The Globe and Mail. October 21, 1942.

“Toronto Youth Lusty at Rally." The Globe and Mail. March 26, 1945. ,

"Queue Up in Downpour For Templeton Rally." The Globe and Mail. May 6, 1945.

"Rousing Ovation Given Templeton on Return." The Globe and Mail. April 30, 1946 
"Rev. C. Templeton Quits Pastorate." The Globe and Mail. March 1, 1948.

Works by Templeton:

Templeton, Charles. "The Church and Its Evangelistic Task." Religion in Life 21:3 (Summer, 1952).

Templeton, Charles. Life Looks Up. New York: Harper \& Brothers Publishers, 1955.

Templeton, Charles. Evangelism for Tomorrow: A Vigorous Reappraisal of the Mission of the Church to Win the Commitment of Modern Man. New York: Harper \& Brothers Publishers, 1957.

Templeton, Charles. Jesus. Ontario: McClelland \& Stewart Ltd., 1973.

Templeton, Charles. The Kidnapping of the President. New York: Avon Books, 1974.

Templeton, Charles. Act of God. Toronto: McClelland and Stewart Limited, 1977.

Templeton, Charles. The Third Temptation. Toronto: McClelland \& Stewart Limited, 1980.

Templeton, Charles. Charles Templeton: An Anecdotal Memoir. Toronto: McClelland and Stewart Limited, 1983.

Templeton, Charles. The Queen's Secret. Toronto: McClelland \& Stewart Limited, 1986.

Templeton, Charles. World of One. Toronto: McClelland \& Stewart Limited, 1988.

Templeton, Charles. Succeeding. Toronto: Stoddart Publishing Co. Ltd., 1989.

Templeton, Charles. End Back Attacks. Toronto: Key Porter Books Limited, 1991.

Templeton, Charles. Farewell to God: My Reasons for Rejecting the Christian Faith. Toronto: McClelland \& Stewart Inc., 1996.

\section{Manuscript Fonds:}

Charles Templeton Fonds. York University Archives, Toronto, Canada.

United Church Archives, Toronto, Canada. 
Archive of the National Council of Churches, New York City, New York.

Billy Graham Center Archives, Wheaton College, Illinois.

Other Primary Literary Sources:

Graham, Billy. Just As I Am: The Autobiography of Billy Graham. San Francisco: HarperCollins Worldwide, 1997.

Strobel, Lee. The Case for Faith: A Journalist Investigates the Toughest Objections to Christianity. Michigan: Zondervan Publishing House, 2000.

Interviews and Personal Correspondence:

Gilbert, Richard. Personal email to David Vance. March 3, 2006.

Kee, Kevin. Unpublished interview with Charles Templeton, August 27, 1997.

Shuster, Robert. Transcript of Interview with Torrey Johnson. February 13, 1985.

Collection 285. Billy Graham Center Archives, Wheaton College, Wheaton, Illinois.

Shuster, Robert. Transcript of Interview with John Von Casper "Jack" Wyrtzen. October 5, 1991. Collection 446. Billy Graham Center Archives, Wheaton College, Wheaton, Illinois.

\section{Online Sources:}

Templeton, Bradley. “Charles Templeton (1915-2001)” Charles Templeton Home Page. http://www.templetons.com/brad/cbt.html (accessed September 28, 2005).

Templeton, Bradley. "Eulogy for Charles Templeton." Charles Templeton Memorial Page. http://www.templetons.com/brad/eulogy.html (accessed March 24, 2006).

Television Sources (Organized by date):

Templeton, Charles. Television interview with Bernie Braden. Close-Up. Toronto: $\mathrm{CBC}$, June 22, 1957: 00:32.

Templeton, Charles. Television interview with Rev. Alpheus Noseworthy, Dr. E. Crosley Hunter and Dr. John Griffin. Close-Up. Toronto: CBC, October 13, 1957: 01:44. 
Templeton, Charles. Television interview with Dean Charles Fielding and Dr. Herbert C. Modlin. Close-Up. Toronto: CBC, October 27, 1957: 00:55.

Templeton, Charles. Television interview with Dr. Elinor Black. Close-Up. Toronto: CBC, November 3, 1957: 01:21.

Templeton, Charles. Television interview with Edgar and Jean Riley. Close-Up. Toronto: CBC, December 15, 1957: 00:37.

Templeton, Charles. Television interview with Dr. Norman Vincent Peale. Close-Up. Toronto: CBC, December 27, 1957: 01:20.

Templeton, Charles. Television interview with Sir George F. MacLeod. Close-Up. Toronto: CBC, December 2, 1962: 01:11.

Templeton, Charles. Television interview with Charles Davis. W 5. Toronto: CTV, January 22, 1967: 00:09.

Templeton, Charles. Television interview with Rev. Ernest Harrison and Rev. Paul Smith. W 5. Toronto: CTV, February 5, 1967: 01:04.

\section{Secondary Sources:}

Works on, or directly related to, Templeton:

Boyd, Edward. “Religion's Super Salesman.” American Magazine (August, 1953).

Boyer, Peter J. "The Big Tent.” New Yorker 81:24 (August 22, 2005).

Brewis, John. "Life Looks Up." Church Quarterly Review 158 (January - March,1957).

Berton, Pierre. "Lives Lived: Charles Bradley Templeton." The Globe and Mail (September 6, 2001).

Byfield, Ted and Virginia. "As Evangelist or Atheist, Irrationality is Charles Templeton's Besetting Problem." Albert Report 24:9 (February 10, 1997).

Clare, John. "Nothing Succeeds Like Charles Templeton." Maclean's (November 8, 1958).

Clare, John. "Sunday Sensation.” Maclean's (May 15, 1947).

Delaney, Moses N. "Evangelism for Tomorrow." Journal of Religious Thought 16 
(Summer-Autumn, 1959).

Downey, Donn. "Canada's Man of Many Parts." The Globe and Mail (June 8, 2001).

Edmonds, Alan. “The Sweet Smell of Charles Templeton." Maclean's (August, 1968).

Fraser, Sylvia. "The Real Charles Templeton." Chatelaine (February, 1975).

Griffith, A. Leonard. “A Farewell to Templeton.” The Canadian Baptist (March, 1997).

Hansen, Collin. "Billy Graham's Bible Dilemma." Christian History \& Biography 83 (Summer 2004).

Jones, Preston. "Farewell to God: My Reasons for Rejecting the Christian Faith." Gravitas (Spring, 1999).

Kik, J. Marcellus. “Evangelism for Tomorrow.” Christianity Today (February 17, 1958).

Little, Alanna. "Succeeding." Canadian Banker 97:1 (January/February 1990).

MacGregor, Roy. "Templeton's Progress.” The Canadian (July 16, 1977).

Malcolm, Douglas. "The Queen's Secret.” Books in Canada (January/February, 1987).

Parker, Shafer, Jr. "Farewell to God, and to Reason." Alberta Report 24:12 (March 3, 1997).

“Passages.” Maclean's (June 18, 2001).

Perry, John. “Bookshelf Gleanings.” Compass: A Jesuit Journal (May/June, 1997).

Rhodes, Ann. "How Six Women Dressed Charles Templeton." Impetus (February, 1973).

Robertson, Lloyd. "World of One: A Review." The Presbyterian Record (September, 1988).

Slopen, Beverley. “Templeton Bears It." Quill \& Quire (March, 1987).

“The Kidnapping of the President." Library Journal 100:9 (May 1, 1975).

Wares, Kenneth G. "Charles Templeton: Another Career." Christianity Today 8 (September 25, 1964).

General Works: 
Airhart, Phyllis. Serving the Present Age: Revivalism, Progressivism, and the Methodist Tradition in Canada. Montreal \& Kingston: McGill-Queen's University Press, 1992.

Allen, Richard. The Social Passion: Religion and Social Reform in Canada, 1914-1918. Toronto: University of Toronto Press, 1971

Bebbington, D.W. Evangelicalism in Modern Britain: A History from the 1730s to the 1980s. London: Unwin Hyman Ltd., 1989.

Bendroth, Margaret Lamberts. Fundamentalists in the City: Conflict and Division in Boston's Churches, 1885-1950. New York: Oxford University Press, 2005.

Block, Tina. "Everyday Infidels: A Social History of Secularism in the Postwar Pacific Northwest." Ph.D. dissertation, University of Victoria, 2006.

Block, Tina. "Going to Church Just Never Even Occurred to Me": Women and Secularism in the Pacific Northwest." Pacific Northwest Quarterly 96.2 (2005): 61-68.

Brown, Callum. The Death of Christian Britain: Understanding Secularization, 18002000. London: Routledge, 2001.

Bruce, Steve. God is Dead: Secularization in the West. Oxford: Blackwell Publishers, 2002.

Carpenter, Joel A. Revive Us Again: The Awakening of American Fundamentalism. New York: Oxford University Press, 1997.

Cavert, Samuel McCrea. Church Cooperation and Unity in America: A Historical Review: 1900-1970. New York: Association Press, 1970.

Cook, Ramsay. The Regenerators: Social Criticism in Late Victorian English Canada. Toronto: University of Toronto Press, 1985.

DeBerg, Betty. Ungodly Women: Gender and the First Wave of American Fundamentalism. Minneapolis: Fortress Press, 1990.

Dening, Greg. Performances. Chicago: The University of Chicago Press, 1996.

Detweiler, Robert. Breaking the Fall: Religious Readings of Contemporary Fiction. Louisville, Kentucky: Westminster John Knox Press, 1996.

Dillenberger, John, and Claude Welch. Protestant Christianity: Interpreted Through Its Development. New York: Macmillan, 1988. 
Eakin, Paul John. How Our Lives Become Stories: Making Selves. London: Cornell University Press, 1999.

Emery, George. The Methodist Church on the Prairies, 1896-1914. Montreal \& Kingston: McGill-Queen's University Press, 2001.

Fulford, Robert. The Triumph of Narrative: Storytelling in an Age of Mass Culture. Toronto: House of Anansi Press, 1999.

Gauvreau, Michael, and Nancy Christie. A Full Orbed Christianity: The Protestant Churches and Social Welfare in Canada, 1900-1940. Montreal \& Kingston: McGill-Queen's University Press, 1996.

Grant, John Webster. The Church in the Canadian Era. Burlington, Ontario: Welch Publishing Company Inc., 1972.

Hall, David D., ed. Lived Religion in America: Toward a History of Practice. Princeton, New Jersey: Princeton University Press, 1997.

Harsch, George IV. "Puff Graham": American Media, American Culture and the Creation of Billy Graham, 1949-1953. [PhD Thesis] University of Southern Mississippi, 2005.

Hutchison, William R. The Modernist Impulse in American Protestantism. New York: Oxford University Press, 1976.

Kee, Kevin B. Revivalists: Marketing the Gospel in English Canada, 1884-1957. Montreal: McGill-Queen's University Press, 2006.

Langness, L. L., and Gelya Frank. Lives: An Anthropological Approach to Biography. Novato, California: Chandler \& Sharp Publishers, Inc., 1991.

Marsden, George M. Fundamentalism and American Culture: The Shaping of Twentieth - Century Evangelicalism: 1870-1925 Oxford: Oxford University Press, 1980.

Marshall, David. Secularizing the Faith: Canadian Protestant Clergy and the Crisis of Belief, 1850-1940. Toronto: University of Toronto Press, 1992.

McDannell, Colleen. Material Christianity: Religion and Popular Culture in America. New Haven: Yale University Press, 1995.

McKillop, A.B. A Disciplined Intelligence: Critical Inquiry and Canadian Thought in the Victorian Era. Montreal \& Kingston: McGill-Queen's University Press, 1979. 
Moore, Lawrence R. Selling God: American Religion in the Marketplace of Culture. New York: Oxford University Press, 1994.

Opp, James. The Lord for the Body: Religion, Medicine, and Protestant Faith Healing in Canada, 1880-1930. Montreal: McGill-Queen's University Press, 2005.

Orsi, Robert. "Everyday Miracles: The Study of Lived Religion." Lived Religion in America: Toward a History of Practice, David D. Hall, ed. Princeton, New Jersey: Princeton University Press, 1997.

Rutherford, Paul. Prime Time Canada. Toronto: University of Toronto Press, 1990.

Seldon, William K. Princeton Theological Seminary: A Narrative History, 1812-1992. New Jersey: Princeton University Press, 1992.

Smith, Timothy L. Called Unto Holiness: The Story of the Nazarenes: The Formative Years. Missouri: Nazarene Publishing House, 1962.

Stackhouse, John G., Jr. Canadian Evangelicalism in the Twentieth Century: An Introduction to Its Character. Toronto, Buffalo and London: University of Toronto Press Incorporated, 1993.

Szasz, Ferenc Morton. The Divided Mind of Protestant America, 1880-1930. Alabama: The University of Alabama Press, 1982.

Turner, James. Without God, Without Creed: The Origins of Unbelief in America. Baltimore and London: The John Hopkins University Press, 1985.

Van Die, Marguerite. An Evangelical Mind: Nathanael Burwash and the Methodist Tradition in Canada, 1839-1918. Montreal \& Kingston: McGill-Queen's University Press, 1989.

Wacker, Grant. Heaven Below: Early Pentecostals and American Culture. Cambridge: Harvard University Press, 2001.

Westfall, William. Two Worlds: The Protestant Culture of Nineteenth-Century Ontario. Montreal \& Kingston: McGill-Queen's University Press, 1990.

Williams, Bernard. "Rationalism." In The Encyclopedia of Philosophy, edited by Paul Edwards. New York: Macmillan Publishing Co., Inc. \& The Free Press, 1967.

Wuthnow, Robert. The Struggle for America's Soul: Evangelicals, Liberals, and Secularism. Grand Rapids: William B. Eerdmans Publishing Company, 1989. 